
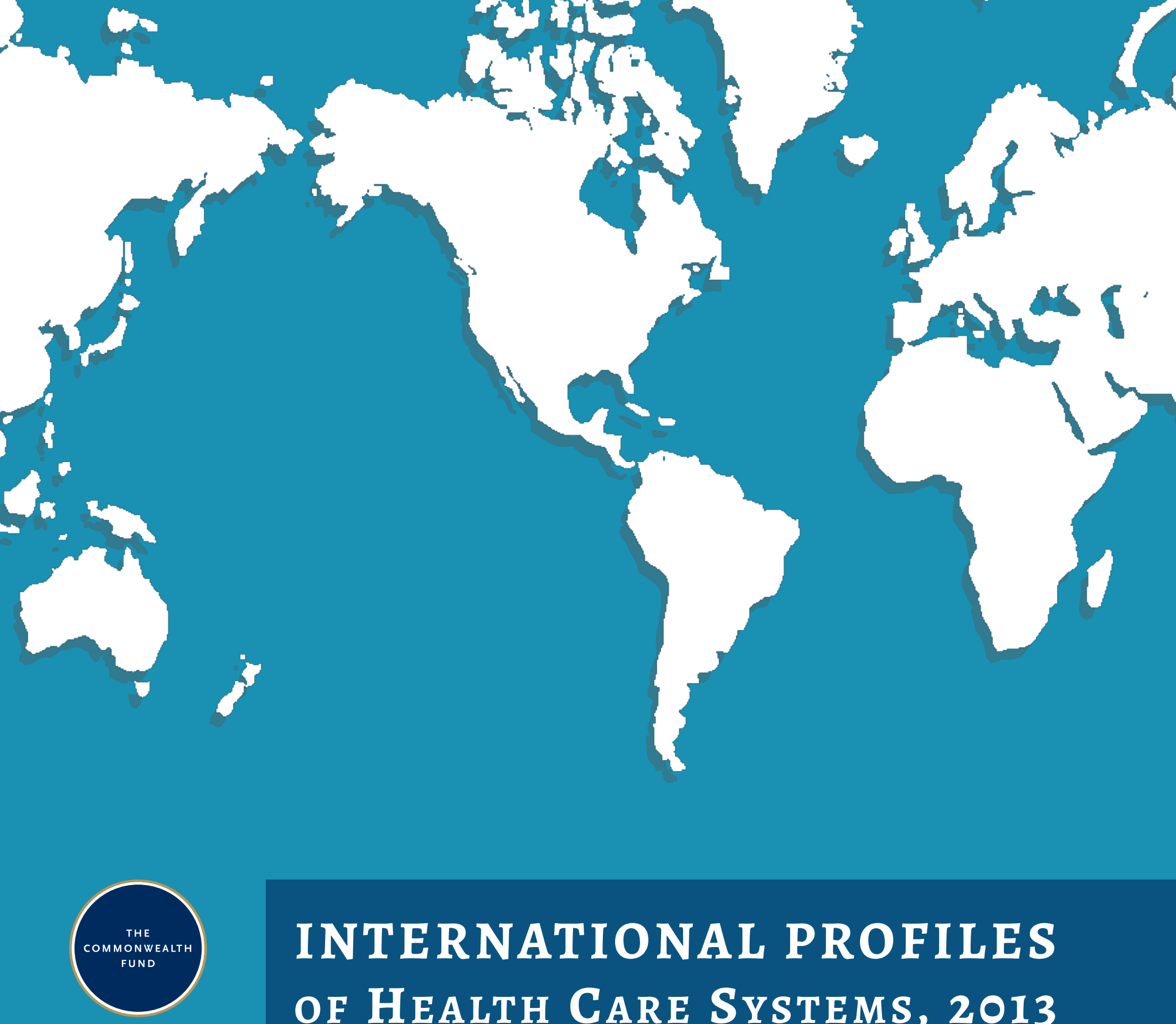

\title{
INTERNATIONAL PROFILES of Health Care Systems, 2013
}

Australia, Canada, Denmark, England, France, Germany, Italy, Japan, the Netherlands, New Zealand, Norway, Sweden, Switzerland, and the United States

Edited by Sarah Thomson, London School of Economics and Political Science, Robin Osborn, The Commonwealth Fund, David Squires, The Commonwealth Fund, and Miraya Jun, London School of Economics and Political Science

NOVEMBER 2013 
The Commonwealth FUnd is a private foundation that promotes a high performance health care system providing better access, improved quality, and greater efficiency. The Fund's work focuses particularly on society's most vulnerable, including lowincome people, the uninsured, minority Americans, young children, and elderly adults.

The Fund carries out this mandate by supporting independent research on health care issues and making grants to improve health care practice and policy. An international program in health policy is designed to stimulate innovative policies and practices in the United States and other industrialized countries. 


\title{
INTERNATIONAL PROFILES of Health Care Systems, 2013
}

Australia, Canada, Denmark, England, France, Germany, Italy, Japan, the Netherlands, New Zealand, Norway, SWeden, Switzerland, and the United States

\author{
Edited by Sarah Thomson, London School of Economics and \\ Political Science, Robin Osborn, The Commonwealth Fund, \\ David Squires, The Commonwealth Fund, and Miraya Jun, \\ London School of Economics and Political Science
}

NOVEMBER 2013

\begin{abstract}
This publication presents overviews of the health care systems of Australia, Canada, Denmark, England, France, Germany, Japan, Italy, the Netherlands, New Zealand, Norway, Sweden, Switzerland, and the United States. Each overview covers health insurance, public and private financing, health system organization and governance, health care quality and coordination, disparities, efficiency and integration, use of information technology and evidence-based practice, cost containment, and recent reforms and innovations. In addition, summary tables provide data on a number of key health system characteristics and performance indicators, including overall health care spending, hospital spending and utilization, health care access, patient safety, care coordination, chronic care management, disease prevention, capacity for quality improvement, and public views.
\end{abstract}

To learn more about new publications when they become available, visit the Fund's website and register to receive email alerts. Commonwealth Fund pub. no. 1717. 



\section{Contents}

Table 1. Health Care System Financing and Coverage in Fourteen Countries 6

Table 2. Selected Health Care System Indicators for Fourteen Countries $\quad 7$

Table 3. Selected Health Care System Performance Indicators for Eleven Countries $\quad 8$

Table 4. Provider Organization and Payment in Twelve Countries 9

$\begin{array}{ll}\text { The Australian Health Care System, } 2013 & 11\end{array}$

$\begin{array}{ll}\text { The Canadian Health Care System, } 2013 & 19\end{array}$

The Danish Health Care System, $2013 \quad 28$

The English Health Care System, 2013

The French Health Care System, 2013

The German Health Care System, 2013

The Italian Health Care System, $2013 \quad 66$

The Japanese Health Care System, 2013

The Dutch Health Care System, 2013

The New Zealand Health Care System, 2013

$\begin{array}{lr}\text { The Norwegian Health Care System, } 2013 & 104\end{array}$

$\begin{array}{ll}\text { The Swedish Health Care System, } 2013 & 113\end{array}$

$\begin{array}{ll}\text { The Swiss Health Care System, } 2013 & 120\end{array}$

The U.S. Health Care System, $2013 \quad 129$ 


\begin{tabular}{|c|c|c|c|c|c|}
\hline & \multicolumn{3}{|c|}{ HEALTH SYSTEM AND PUBLIC/PRIVATE INSURANCE ROLE } & \multicolumn{2}{|c|}{ BENEFIT DESIGN } \\
\hline & Government Role & Public System Financing & $\begin{array}{c}\text { Private Insurance Role } \\
\text { (Core Benefits; Cost-Sharing; Noncovered } \\
\text { Benefits; Private Facilities or Amenities; } \\
\text { Substitute for Public Insurance) }\end{array}$ & Caps on Cost-Sharing & Exemptions and Low-Income Protection \\
\hline Australia & $\begin{array}{l}\text { Regionally administered, joint (national \& } \\
\text { state) public hospital funding; universal pub- } \\
\text { lic medical insurance program (Medicare) }\end{array}$ & General tax revenue; earmarked income tax & $\begin{array}{l}\sim 50 \% \text { buy coverage for private hospital costs } \\
\& \text { noncovered benefits }\end{array}$ & $\begin{array}{l}\text { No. Safety nets include } 80 \% \text { OOP rebate } \\
\text { if physician costs exceed AUS\$1,222 } \\
\text { [US\$1,160] }\end{array}$ & $\begin{array}{l}\text { Low-income and older people: Lower cost- } \\
\text { sharing; lower OOP maximum before } 80 \% \\
\text { subsidy }\end{array}$ \\
\hline Canada & $\begin{array}{l}\text { Regionally administered universal public } \\
\text { insurance program (Medicare) }\end{array}$ & Provincial/federal tax revenue & $\sim 67 \%$ buy coverage for noncovered benefits & No & $\begin{array}{l}\text { No cost-sharing for Medicare services. Some } \\
\text { cost-sharing exemptions for non-Medicare } \\
\text { services, e.g., drugs outside hospital; varies } \\
\text { by province }\end{array}$ \\
\hline Denmark & National health service & Earmarked income tax & $\begin{array}{l}\sim 55 \% \text { buy coverage for cost-sharing, } \\
\text { noncovered benefits, or access to private } \\
\text { facilities }\end{array}$ & $\begin{array}{l}\text { No. Decreasing copayments with higher } \\
\text { drug OOP spending }\end{array}$ & $\begin{array}{l}\text { Drug OOP cap for chronically ill (DKK } 3,410 \\
\text { [US\$617]); financial assistance for low- } \\
\text { income and terminally ill people }\end{array}$ \\
\hline England & National health service & $\begin{array}{l}\text { General tax revenue (includes employment- } \\
\text { related insurance contributions) }\end{array}$ & $\begin{array}{l}\sim 11 \% \text { buy for private facilities mainly for } \\
\text { elective surgery and consultations with } \\
\text { specialists }\end{array}$ & $\begin{array}{l}\text { No general cap for OOP. Prepayment certifi- } \\
\text { cate with } £ 2 \text { [US\$3.20] per week ceiling for } \\
\text { those needing a large number of prescrip- } \\
\text { tion drugs. }\end{array}$ & $\begin{array}{l}\text { Drug cost-sharing exemption for low- } \\
\text { income, older people, children, pregnant } \\
\text { women and new mothers, and some dis- } \\
\text { abled/chronically ill. Financial assistance with } \\
\text { transport costs available to people on low } \\
\text { incomes. }\end{array}$ \\
\hline France & $\begin{array}{l}\text { Statutory health insurance system, with all } \\
\text { SHI insurers incorporated into single national } \\
\text { exchange }\end{array}$ & $\begin{array}{l}\text { Employer/employee earmarked income and } \\
\text { payroll tax; general tax revenue, earmarked } \\
\text { taxes }\end{array}$ & $\begin{array}{l}\sim 90 \% \text { buy or receive government vouchers } \\
\text { for cost-sharing; some noncovered benefits }\end{array}$ & $\begin{array}{l}\text { No. } € 50 \text { [US\$67] cap on deductibles for con- } \\
\text { sultations and services }\end{array}$ & $\begin{array}{l}\text { Exemption for low-income, chronically ill and } \\
\text { disabled, and children }\end{array}$ \\
\hline Germany & $\begin{array}{l}\text { Statutory health insurance system, with } 134 \\
\text { competing SHI insurers ("sickness funds" in a } \\
\text { national exchange); high income can opt out } \\
\text { for private coverage }\end{array}$ & $\begin{array}{l}\text { Employer/employee earmarked payroll tax; } \\
\text { general tax revenue }\end{array}$ & $\begin{array}{l}\text { Cost-sharing }+ \text { amenities ( } 20 \%) \text {; Substitute: } \\
10 \% \text { opt-out of SHI system for private cover- } \\
\text { age only }\end{array}$ & $\begin{array}{l}\text { Yes. } 2 \% \text { income; } 1 \% \text { income for chronically ill } \\
+ \text { low-income people }\end{array}$ & Children exempt \\
\hline Italy & National health service & $\begin{array}{l}\text { National earmarked corporate and value- } \\
\text { added taxes; general tax revenue and } \\
\text { regional tax revenue }\end{array}$ & $\begin{array}{l}\sim 15 \% \text { buy coverage for access to private } \\
\text { facilities and amenities }\end{array}$ & $\begin{array}{l}\text { No. } € 46.15 \text { [ } \$ 59 \text { USD] copayment on outpa- } \\
\text { tient care; limited copayment (regional rates) } \\
\text { on drugs }\end{array}$ & $\begin{array}{l}\text { Exemptions for low-income older people/ } \\
\text { children, pregnant women, chronic condi- } \\
\text { tions/disabilities, rare diseases }\end{array}$ \\
\hline Japan & $\begin{array}{l}\text { Statutory health insurance system, with } \\
\text { approx. 3,500 noncompeting public, quasi- } \\
\text { public, and employer-based insurers }\end{array}$ & General tax revenue; insurance contributions & $\begin{array}{l}\text { Majority buy coverage for cash benefits/ } \\
\text { cost-sharing }\end{array}$ & $\begin{array}{l}\text { No. Coinsurance reduced to } 1 \% \text { after } 80,100 \\
\text { yen [\$999 USD] monthly cap }\end{array}$ & $\begin{array}{l}\text { Low-income monthly OOP ceiling: } 35,400 \\
\text { yen [\$ } \$ 441 \text { USD]; reduced cost-sharing for } \\
\text { young children and older people }\end{array}$ \\
\hline Netherlands & $\begin{array}{l}\text { Statutory health insurance system, with } \\
\text { universally mandated private insurance } \\
\text { (national exchange) }\end{array}$ & $\begin{array}{l}\text { Earmarked payroll tax; community-rated } \\
\text { insurance premiums; general tax revenue }\end{array}$ & $\begin{array}{l}\text { Private plans provide universal core benefits; } \\
90 \% \text { buy for noncovered benefits }\end{array}$ & $\begin{array}{l}\text { No. But annual deductible of } € 350 \text { [US\$ } \$ 72] \\
\text { covers most cost-sharing }\end{array}$ & $\begin{array}{l}\text { Children exempt from cost-sharing; premium } \\
\text { subsidies for low-income }\end{array}$ \\
\hline New Zealand & National health service & General tax revenue & $\begin{array}{l}\sim 33 \% \text { buy for cost-sharing, access to special- } \\
\text { ists, and elective surgery in private hospitals }\end{array}$ & $\begin{array}{l}\text { No. Subsidies after } 12 \text { doctor visits/20 pre- } \\
\text { scriptions in past year }\end{array}$ & $\begin{array}{l}\text { Lower cost-sharing for low-income, some } \\
\text { chronic conditions, Maori and Pacific Island- } \\
\text { ers; young children mostly exempt }\end{array}$ \\
\hline Norway & National health service & General tax revenue & $\begin{array}{l}<10 \% \text { holds VHI, mainly bought by employ- } \\
\text { ers for providing employees quicker access }\end{array}$ & $\begin{array}{l}\text { Yes. Main cost sharing ceiling is NOK 2,040 } \\
\text { [US\$342] }\end{array}$ & $\begin{array}{l}\text { Exemptions for children }<16 \text { years somatic, } \\
<18 \text { years psychiatric, pregnant women, and } \\
\text { for some communicable diseases (STDs) }\end{array}$ \\
\hline Sweden & National health service & General tax revenue & $<5 \%$ buy for private facilities & $\begin{array}{l}\text { Yes. SEK } 1100 \text { [US\$169] for health services \& } \\
\text { SEK } 2200 \text { [US\$337] for drugs }\end{array}$ & Exemption for children and pregnant women \\
\hline Switzerland & $\begin{array}{l}\text { Statutory health insurance system, with } \\
\text { universally mandated private insurance } \\
\text { (regional exchanges) }\end{array}$ & $\begin{array}{l}\text { Community-rated insurance premiums; } \\
\text { general tax revenue }\end{array}$ & $\begin{array}{l}\text { Private plans provide universal core benefits; } \\
\text { majority buy private plans for noncovered } \\
\text { benefits and amenities }\end{array}$ & Yes. 700 CHF [US\$768] max after deductible & $\begin{array}{l}\text { Income-related premium assistance ( } 30 \% \text { re- } \\
\text { ceive); some assistance for low-income; some } \\
\text { exemptions for children, pregnant women }\end{array}$ \\
\hline $\begin{array}{l}\text { United } \\
\text { States* }\end{array}$ & $\begin{array}{l}\text { Medicare: age } 65+\text {, some disabled; Medicaid: } \\
\text { some low-income (most under age } 65 \text { cov- } \\
\text { ered by private insurance; } 16 \% \text { of population } \\
\text { uninsured) }\end{array}$ & $\begin{array}{l}\text { Medicare: payroll tax, premiums, federal tax } \\
\text { revenue; Medicaid: federal, state tax revenue }\end{array}$ & $\begin{array}{l}\text { Primary private insurance covers } 56 \% \text { of } \\
\text { population (employer-based and individual); } \\
\text { supplementary for Medicare }\end{array}$ & No & $\begin{array}{l}\text { Low-income: Medicaid; older people and } \\
\text { some disabled on Medicare }\end{array}$ \\
\hline
\end{tabular}


Table 2. Selected Health Care System Indicators for Fourteen Countries

\begin{tabular}{|c|c|c|c|c|c|c|c|c|c|c|c|c|c|c|c|}
\hline & & Australia & Canada & Denmark & France & Germany & Italy & Japan & Netherlands & $\begin{array}{c}\text { New } \\
\text { Zealand }\end{array}$ & Norway & Sweden & Switzerland & $\begin{array}{c}\text { United } \\
\text { Kingdom }\end{array}$ & $\begin{array}{l}\text { United } \\
\text { States }\end{array}$ \\
\hline \multirow[t]{2}{*}{ Population, 2011} & Total Population $(1,000,000$ s of people) & 22.323 & 34.484 & 5.571 & 65.161 & 81.373 & 60.724 & 127.799 & 16.718 & 4.404 & 4.952 & 9.447 & 7.912 & 61.760 & 311.588 \\
\hline & Percentage of Population Over Age 65 & $13.7 \%$ & $14.7 \%$ & $17.1 \%$ & $17.1 \%$ & $20.7 \%$ & $21.0 \%$ & $23.3 \%$ & $15.9 \%$ & $13.3 \%$ & $15.2 \%$ & $19.3 \%$ & $17.1 \%$ & $16.2 \%$ & $13.2 \%$ \\
\hline \multirow{6}{*}{$\begin{array}{l}\text { Spending, } \\
2011 \text { unless } \\
\text { otherwise noted }\end{array}$} & Percentage of GDP Spent on Health Care & $8.9 \%$ & $11.2 \%$ & $11.1 \%$ & $11.6 \%$ & $11.3 \%$ & $9.2 \%$ & $9.6 \% a$ & $11.9 \%$ & $10.3 \%$ & $9.3 \%$ & $9.5 \%$ & $11.0 \%$ & $9.4 \%$ & $17.7 \%$ \\
\hline & Health Care Spending per Capita ${ }^{d}$ & $\$ 3,800^{\mathrm{a}}$ & $\$ 4,522$ & $\$ 4,485$ & $\$ 4,118$ & $\$ 4,495$ & $\$ 3,012$ & $\$ 3,213 a$ & $\$ 5,099$ & $\$ 3,182$ & $\$ 5,669$ & $\$ 3,925$ & $\$ 5,643$ & $\$ 3,405$ & $\$ 8,508$ \\
\hline & $\begin{array}{l}\text { Average Annual Growth Rate of Real Health Care } \\
\text { Spending per Capita, 2000-2011 }\end{array}$ & $2.74 \%$ & $3.0 \%$ & $2.7 \%$ & $1.8 \%$ & $2.1 \%$ & $1.2 \%$ & $3.0 \% c$ & $4.7 \%$ & $3.8 \%$ & $2.4 \%$ & $3.1 \%$ & $1.8 \%$ & $4.0 \%$ & $3.0 \%$ \\
\hline & Out-of-Pocket Health Care Spending per Capitad & $\$ 733^{a}$ & $\$ 666$ & $\$ 593$ & $\$ 307$ & $\$ 593$ & $\$ 542$ & $\$ 464 a$ & $\mathrm{n} / \mathrm{a}$ & $\$ 348$ & $\mathrm{n} / \mathrm{a}$ & $\$ 635$ & $\$ 1,455$ & $\$ 338$ & $\$ 987$ \\
\hline & Hospital Spending per Capitad & $\$ 1,532$ & $\$ 1,298$ & $\$ 1,960$ & $\$ 1,409$ & $\$ 1,304$ & $\mathrm{n} / \mathrm{a}$ & $\$ 1,484 a$ & $\$ 1,589$ & $\$ 1,242$ & $\$ 1,981$ & $\$ 1,704$ & $\$ 2,030$ & $\mathrm{n} / \mathrm{a}$ & $\$ 2,730$ \\
\hline & Spending on Pharmaceuticals per Capita $d$ & $\$ 587$ & $\$ 752$ & $\$ 300$ & $\$ 641$ & $\$ 633$ & $\$ 487$ & $\$ 652 a$ & $\$ 479$ & $\$ 298$ & $\$ 388$ & $\$ 474$ & $\$ 531$ & $\mathrm{n} / \mathrm{a}$ & $\$ 995$ \\
\hline \multirow{2}{*}{$\begin{array}{l}\text { Physicians, } \\
2011 \text { unless } \\
\text { otherwise noted }\end{array}$} & Number of Practicing Physicians per 1,000 Population & 3.31 & $\mathrm{n} / \mathrm{a}$ & $3.48^{\mathrm{b}}$ & 3.07 & 3.84 & 4.1 & $2.21 \mathrm{a}$ & $\mathrm{n} / \mathrm{a}$ & 2.64 & 3.72 & $3.86^{\mathrm{a}}$ & 3.83 & 2.81 & 2.46 \\
\hline & Average Annual Number of Physician Visits per Capita & 6.7 & $7.4^{\mathrm{a}}$ & $4.6^{\mathrm{a}}$ & 6.8 & 9.7 & $\mathrm{n} / \mathrm{a}$ & 13.1a & 6.6 & $n / a$ & $5.2^{\mathrm{b}}$ & 3.0 & $\mathrm{n} / \mathrm{a}$ & $5.0^{\mathrm{b}}$ & $4.1^{\mathrm{b}}$ \\
\hline \multirow{4}{*}{$\begin{array}{l}\text { Hospital } \\
\text { Spending, } \\
\text { Utilization, and } \\
\text { Capacity, } \\
2011 \text { unless } \\
\text { otherwise noted }\end{array}$} & Number of Acute Care Hospital Beds per 1,000 Population & 3.38 & 1.73 & 2.87 & 3.43 & 5.33 & 2.75 & 7.95 & 3.33 & 2.61 & 2.40 & 2.01 & 3.03 & 2.41 & 2.56 \\
\hline & Hospital Spending per Discharged ${ }^{d}$ & $\$ 9,611^{\mathrm{a}}$ & $\$ 15,433^{\mathrm{a}}$ & $\$ 11,374$ & $\$ 8,363$ & $\$ 5,339$ & $\mathrm{n} / \mathrm{a}$ & $\mathrm{n} / \mathrm{a}$ & $\$ 13,025$ & $\$ 8,478$ & $\$ 11,306$ & $\$ 9,894$ & $\$ 11,968$ & $\mathrm{n} / \mathrm{a}$ & $\$ 21,018^{\mathrm{a}}$ \\
\hline & Hospital Discharge per 1,000 Population & 159 & 82 & 172 & 169 & 244 & 129 & 111 & 122 & 147 & 175 & 163 & 170 & 136 & 125 \\
\hline & Average Length of Stay for Acute Care (days) & $5.0^{\mathrm{a}}$ & $7.7^{\mathrm{a}}$ & $\mathrm{n} / \mathrm{a}$ & 5.1 & 7.9 & 6.8 & 17.9 & 5.8 & 5.6 & $4.5^{\mathrm{a}}$ & 5.1 & 6.5 & 6.5 & 5.4 \\
\hline \multirow{2}{*}{$\begin{array}{l}\text { Medical } \\
\text { Technology, } \\
2011 \text { unless } \\
\text { otherwise noted }\end{array}$} & $\begin{array}{l}\text { Magnetic Resonance Imaging (MRI) Machines per } \\
\text { Million Population }\end{array}$ & 5.7 & 8.5 & 15.4 & 7.5 & $\mathrm{n} / \mathrm{a}$ & 23.7 & 46.9 & 12.9 & 11.1 & $\mathrm{n} / \mathrm{a}$ & $\mathrm{n} / \mathrm{a}$ & $\mathrm{n} / \mathrm{a}$ & 5.9 & 31.5 \\
\hline & MRI Exams per 1,000 Population & 24.1 & 49.8 & 61.5 & 67.5 & $95.2^{\mathrm{b}}$ & $\mathrm{n} / \mathrm{a}$ & $\mathrm{n} / \mathrm{a}$ & 49.9 & $\mathrm{n} / \mathrm{a}$ & $\mathrm{n} / \mathrm{a}$ & $\mathrm{n} / \mathrm{a}$ & $\mathrm{n} / \mathrm{a}$ & $\mathrm{n} / \mathrm{a}$ & 102.7 \\
\hline IT, 2012 & Physicians' Use of EMRs (\% of Primary Care Physicians) ${ }^{f}$ & $92.0 \%$ & $56 \%$ & $\mathrm{n} / \mathrm{a}$ & $67 \%$ & $82 \%$ & $\mathrm{n} / \mathrm{a}$ & $\mathrm{n} / \mathrm{a}$ & $98 \%$ & $97 \%$ & $98 \%$ & $88 \%$ & $41 \%$ & $97 \%$ & $69 \%$ \\
\hline \multirow{2}{*}{$\begin{array}{l}\text { Health Risk } \\
\text { Factors, } \\
2011 \text { unless } \\
\text { otherwise noted }\end{array}$} & Percentage of Adults Who Report Being Daily Smokers & $15.1 \%$ & $15.7 \%$ & $20.0 \%$ & $23.3 \%$ & $21.9 \%$ & $22.5 \%$ & $20.1 \%$ & $20.8 \%$ & $\mathrm{n} / \mathrm{a}$ & $17.0 \%$ & $13.1 \%$ & $\mathrm{n} / \mathrm{a}$ & $19.6 \%$ & $14.8 \%$ \\
\hline & Obesity Prevalence (BMI >30) & $28.3 \%$ & $25.4 \%$ & $13.4 \%$ & $12.9 \%$ & $14.7 \%$ & $10.0 \%$ e & $4.1 \%$ & $11.4 \%$ & $27.8 \%$ & $\mathrm{n} / \mathrm{a}$ & $11.0 \%$ & $\mathrm{n} / \mathrm{a}$ & $24.8 \%$ & $36.5 \%$ \\
\hline
\end{tabular}


Table 3. Selected Health Care System Performance Indicators for Eleven Countries

\begin{tabular}{|c|c|c|c|c|c|c|c|c|c|c|c|c|}
\hline & & Australia & Canada & France & Germany & Netherlands & $\begin{array}{c}\text { New } \\
\text { Zealand }\end{array}$ & Norway & Sweden & Switzerland & $\begin{array}{c}\text { United } \\
\text { Kingdom }\end{array}$ & $\begin{array}{l}\text { United } \\
\text { States }\end{array}$ \\
\hline \multirow[t]{5}{*}{ Adults' Access to Care, 2010} & Able to Get Same/Next Day Appointment When Sick & $65 \%$ & $45 \%$ & $62 \%$ & $66 \%$ & $72 \%$ & $78 \%$ & $45 \%$ & $57 \%$ & $\mathrm{n} / \mathrm{a}$ & $70 \%$ & $57 \%$ \\
\hline & Very/Somewhat Difficult Getting Care After-Hours & $59 \%$ & $65 \%$ & $63 \%$ & $57 \%$ & $33 \%$ & $38 \%$ & $45 \%$ & $68 \%$ & $43 \%$ & $38 \%$ & $63 \%$ \\
\hline & Waited Two Months or More for Specialist Appointment ${ }^{a}$ & $28 \%$ & $41 \%$ & $28 \%$ & $7 \%$ & $16 \%$ & $22 \%$ & $34 \%$ & $31 \%$ & $5 \%$ & $19 \%$ & $9 \%$ \\
\hline & Waited Four Months or More for Elective Surgery ${ }^{b}$ & $18 \%$ & $25 \%$ & $7 \%$ & $0 \%$ & $5 \%$ & $8 \%$ & $21 \%$ & $22 \%$ & $7 \%$ & $21 \%$ & $7 \%$ \\
\hline & Experienced Access Barrier Because of Cost in Past Year ${ }^{\mathrm{C}}$ & $22 \%$ & $15 \%$ & $13 \%$ & $25 \%$ & $6 \%$ & $14 \%$ & $11 \%$ & $10 \%$ & $10 \%$ & $5 \%$ & $33 \%$ \\
\hline Safety Problems Among Sicker Adults, 2011 & $\begin{array}{l}\text { Experienced Medical, Medication, or Lab Test Error in } \\
\text { Past } 2 \text { Years }\end{array}$ & $19 \%$ & $21 \%$ & $13 \%$ & $16 \%$ & $20 \%$ & $22 \%$ & $25 \%$ & $20 \%$ & $9 \%$ & $8 \%$ & $22 \%$ \\
\hline \multirow[t]{3}{*}{$\begin{array}{l}\text { Care Coordination and Transitions Among } \\
\text { Sicker Adults, } 2011\end{array}$} & $\begin{array}{l}\text { Experienced Coordination Problems with Medical Tests/ } \\
\text { Records in Past } 2 \text { Years } d\end{array}$ & $19 \%$ & $25 \%$ & $20 \%$ & $16 \%$ & $18 \%$ & $15 \%$ & $22 \%$ & $16 \%$ & $11 \%$ & $13 \%$ & $27 \%$ \\
\hline & Key Information Not Shared Among Providers in Past 2 Years & $12 \%$ & $14 \%$ & $13 \%$ & $23 \%$ & $15 \%$ & $12 \%$ & $19 \%$ & $18 \%$ & $10 \%$ & $7 \%$ & $17 \%$ \\
\hline & Experienced Gaps in Hospital Discharge Planning in Past 2 Years $\mathrm{e}$ & $55 \%$ & $50 \%$ & $73 \%$ & $61 \%$ & $66 \%$ & $51 \%$ & $71 \%$ & $67 \%$ & $48 \%$ & $26 \%$ & $29 \%$ \\
\hline \multirow[t]{2}{*}{ Chronic Care Management, 2011} & $\begin{array}{l}\text { In Past Year, Health Care Professional Has Helped Make } \\
\text { Treatment Plan You Could Carry Out in Your Daily Life }\end{array}$ & $61 \%$ & $63 \%$ & $53 \%$ & $49 \%$ & $52 \%$ & $58 \%$ & $41 \%$ & $40 \%$ & $74 \%$ & $80 \%$ & $71 \%$ \\
\hline & $\begin{array}{l}\text { Between Visits, Has Health Care Professional It Is Easy to Call } \\
\text { with Questions or to Get Advice }\end{array}$ & $59 \%$ & $62 \%$ & $54 \%$ & $55 \%$ & $70 \%$ & $71 \%$ & $63 \%$ & $73 \%$ & $68 \%$ & $81 \%$ & $77 \%$ \\
\hline \multirow{3}{*}{$\begin{array}{l}\text { Primary Care Practices Receive Performance } \\
\text { Feedback, } 2012\end{array}$} & Routinely Receives and Reviews Clinical Outcomes Data & $42 \%$ & $23 \%$ & $14 \%$ & $54 \%$ & $81 \%$ & $64 \%$ & $24 \%$ & $78 \%$ & $12 \%$ & $84 \%$ & $47 \%$ \\
\hline & $\begin{array}{l}\text { Routinely Receives and Reviews Patient Satisfaction and } \\
\text { Experience Data }\end{array}$ & $56 \%$ & $15 \%$ & $1 \%$ & $35 \%$ & $39 \%$ & $51 \%$ & $7 \%$ & $90 \%$ & $15 \%$ & $84 \%$ & $60 \%$ \\
\hline & $\begin{array}{l}\text { Routinely Receives Data Comparing Performance to } \\
\text { Other Practices }\end{array}$ & $25 \%$ & $15 \%$ & $45 \%$ & $25 \%$ & $32 \%$ & $55 \%$ & $5 \%$ & $55 \%$ & $35 \%$ & $78 \%$ & $34 \%$ \\
\hline \multirow[t]{3}{*}{ OECD Health Care Quality Indicators ${ }^{i}$} & $\begin{array}{l}\text { Diabetes Lower Extremity Amputation Rates per 100,000 } \\
\text { population, } 2009\end{array}$ & 11.0 & 9.5 & 12.6 & 33.7 & 12.0 & 7.0 & 9.8 & 5.7 & 7.4 & 4.8 & 32.9 \\
\hline & $\begin{array}{l}\text { Breast Cancer Five-Year Survival Rate, 2004-2009 } \\
\text { (or nearest period) }\end{array}$ & $\mathrm{n} / \mathrm{a}$ & $87.1 \%$ & $\mathrm{n} / \mathrm{a}$ & $83.3 \%$ & $84.4 \%$ & $84.5 \%$ & $86.5 \%$ & $86.0 \%$ & $\mathrm{n} / \mathrm{a}$ & $81.3 \%$ & $89.3 \%$ \\
\hline & $\begin{array}{l}\text { Mortality After Admission for Acute Myocardial Infarction per } \\
100 \text { Patients, } 20099\end{array}$ & 3.2 & 3.9 & $\mathrm{n} / \mathrm{a}$ & 6.8 & 5.3 & 3.2 & 2.5 & 2.9 & 4.5 & 5.2 & 4.3 \\
\hline Avoidable Deaths, 2006-07 & $\begin{array}{l}\text { Mortality Amenable to Health Care }{ }^{\mathrm{h}} \text { (Deaths per } \\
100,000 \text { Population) }\end{array}$ & 57 & $\mathrm{n} / \mathrm{a}$ & 55 & 76 & 66 & 79 & 64 & 61 & $\mathrm{n} / \mathrm{a}$ & 83 & 96 \\
\hline \multirow[t]{2}{*}{ Prevention, $2011^{i}$} & Percentage of Children with Measles Immunization & $94 \%$ & $98 \%$ & $89 \%$ & $97 \%$ & $96 \%$ & $93 \%$ & $93 \%$ & $97 \%$ & $92 \%$ & $90 \%$ & $92 \%$ \\
\hline & $\begin{array}{l}\text { Percentage of Population over Age } 65 \text { with Influenza } \\
\text { Immunization }\end{array}$ & $75 \%$ & $64 \%$ & $55 \%$ & $56 \%$ & $74 \%$ & $66 \%$ & $14 \%$ & $\mathrm{n} / \mathrm{a}$ & $46 \%$ & $74 \%$ & $67 \%$ \\
\hline \multirow[t]{3}{*}{ Public Views of Health System, 2010} & Works Well, Minor Changes Needed & $24 \%$ & $38 \%$ & $42 \%$ & $38 \%$ & $51 \%$ & $37 \%$ & $40 \%$ & $44 \%$ & $46 \%$ & $62 \%$ & $29 \%$ \\
\hline & Fundamental Changes Needed & $55 \%$ & $51 \%$ & $47 \%$ & $48 \%$ & $41 \%$ & $51 \%$ & $46 \%$ & $45 \%$ & $44 \%$ & $34 \%$ & $41 \%$ \\
\hline & Needs to be Completely Rebuilt & $20 \%$ & $10 \%$ & $11 \%$ & $14 \%$ & $7 \%$ & $11 \%$ & $12 \%$ & $8 \%$ & $8 \%$ & $3 \%$ & $27 \%$ \\
\hline
\end{tabular}

Sources (unless noted otherwise): 2010, 2011, and 2012 Commonwealth Fund International Health Policy Surveys.

a Base: Needed to see a specialist in past two years.

C Did not fill/skipped prescription, did not visit doctor with medical problem, and/or did not get recommended care.

$\mathrm{d}$ Test results/medical records not available at time of appointment and/or doctors ordered medical test that had already been done

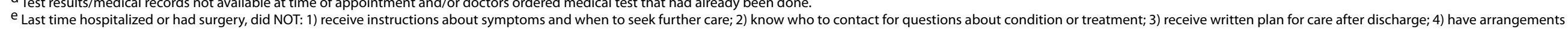

made for followup visits; and/or 5) receive very clear instructions about what medicines you should be taking. Base: hospitalized/had surgery in past two years.

made for followup visits; and/or 5) receive ver
$f_{\text {Base: }}$ Has a regular doctor or place of care.

9 In-hospital case-fatality rates within 30 days of admission

$\mathrm{h}$ Source: Nolte E, McKee M. Variations in amenable mortality-Trends in 16 high-income nations. Health Policy. 2011 Sep 12.

i Source: OECD Health Data 2013.

j 2008 
Table 4. Provider Organization and Payment in Twelve Countries

\begin{tabular}{|c|c|c|c|c|c|c|}
\hline & \multicolumn{2}{|c|}{ Provider Ownership } & \multicolumn{2}{|c|}{ Provider Payment } & \multicolumn{2}{|c|}{ Primary Care Role } \\
\hline & Primary Care & Hospitals & $\begin{array}{l}\text { Primary Care } \\
\text { Payment }\end{array}$ & Hospital Payment & $\begin{array}{l}\text { Registration with } \\
\text { GP Required }\end{array}$ & Gatekeeping \\
\hline Australia & Private & $\begin{array}{l}\text { Public ( } 67 \% \text { of } \\
\text { beds), private } \\
(\sim 33 \%)\end{array}$ & FFS & $\begin{array}{l}\text { Global budgets + case- } \\
\text { based payment in public } \\
\text { hospitals (includes physi- } \\
\text { cian costs); FFS in private } \\
\text { hospitals }\end{array}$ & No & Yes \\
\hline Canada & Private & $\begin{array}{l}\text { Mostly private } \\
\text { not-for-profit } \\
\text { or public; some } \\
\text { private-for-profit }\end{array}$ & $\begin{array}{c}\text { Mostly FFS, but some alter- } \\
\text { natives (e.g. capitation) }\end{array}$ & $\begin{array}{l}\text { Global budgets + case- } \\
\text { based payment in some } \\
\text { provinces (does not } \\
\text { include physician costs) }\end{array}$ & $\begin{array}{l}\text { Not generally, but yes for } \\
\text { some capitation models }\end{array}$ & $\begin{array}{l}\text { Incentives, varying } \\
\text { across provinces: } \\
\text { e.g., in Ontario, spe- } \\
\text { cialist physicians } \\
\text { have higher fees for } \\
\text { patients who have } \\
\text { been referred by } \\
\text { their GP }\end{array}$ \\
\hline Denmark & Private & Almost all public & Mix capitation/FFS & $\begin{array}{c}\text { Global budgets + } \\
\text { case-based payment } \\
\text { (includes physician costs) }\end{array}$ & $\begin{array}{l}\text { Yes (for } 98 \% \text { of } \\
\text { population) }\end{array}$ & $\begin{array}{l}\text { Yes (for } 98 \% \text { of } \\
\text { population) }\end{array}$ \\
\hline England & $\begin{array}{l}\text { Mainly private } \\
\text { (most GPs are } \\
\text { self-employed } \\
\text { or partners in } \\
\text { privately owned } \\
\text { practices) }\end{array}$ & $\begin{array}{l}\text { Mostly public, } \\
\text { some private }\end{array}$ & $\begin{array}{l}\text { Mix capitation/FFS/P4P; } \\
\text { salary payments for a } \\
\text { minority (the salaried GPs } \\
\text { are employees of private } \\
\text { group practices, not of } \\
\text { the NHS) }\end{array}$ & $\begin{array}{l}\text { Mainly case-based } \\
\text { payments plus service } \\
\text { contracts. All include } \\
\text { physician costs, drug } \\
\text { costs, etc. }\end{array}$ & Yes & Yes \\
\hline France & Private & $\begin{array}{l}\text { Mostly public } \\
\text { or private not- } \\
\text { for-profit, some } \\
\text { private for-profit }\end{array}$ & $\begin{array}{l}\text { Mix FFS/P4P/flat } 40 € \text { bo- } \\
\text { nus per year per patient } \\
\text { with chronic disease and } \\
\text { regional agreements for } \\
\text { salaried GPs }\end{array}$ & $\begin{array}{l}\text { Mainly case-based } \\
\text { payments (includes physi- } \\
\text { cian costs) + non-activity- } \\
\text { based grants for educa- } \\
\text { tion, research, etc. }\end{array}$ & $\begin{array}{l}\text { Yes (may be with a special- } \\
\text { ist or GP; in practice over } \\
95 \% \text { are with GPs) }\end{array}$ & $\begin{array}{l}\text { National incentives: } \\
\text { higher cost-sharing } \\
\text { for visits and pre- } \\
\text { scriptions without } \\
\text { a referral from the } \\
\text { gatekeeper }\end{array}$ \\
\hline Germany & Private & $\begin{array}{l}\text { Public ( } 50 \% \text { of } \\
\text { beds); private } \\
\text { nonprofit }(\sim 33 \%) ; \\
\text { private for-profit } \\
(\sim 17 \%)\end{array}$ & FFS & $\begin{array}{l}\text { Global budgets + case- } \\
\text { based payment (includes } \\
\text { physician costs) }\end{array}$ & No & $\begin{array}{l}\text { In some sickness } \\
\text { fund programs }\end{array}$ \\
\hline Italy & $\begin{array}{l}\text { Private (primary } \\
\text { care providers } \\
\text { (i.e., GPs and } \\
\text { pediatricians) are } \\
\text { self-employed) }\end{array}$ & $\begin{array}{l}\text { Mostly public, } \\
\text { some private }\end{array}$ & Mix capitation/FFS & $\begin{array}{c}\text { Global budgets + case- } \\
\text { based payment (includes } \\
\text { physician costs) }\end{array}$ & Yes & Yes \\
\hline Japan & Mostly private & $\begin{array}{l}\text { Private nonprofit } \\
\text { ( } 55 \% \text { of beds) } \\
\text { and public }\end{array}$ & $\begin{array}{l}\text { Most FFS, some per-case } \\
\text { daily or monthly payments }\end{array}$ & $\begin{array}{l}\text { Case-based per diem } \\
\text { payments+FFS or FFS } \\
\text { (includes physician costs) }\end{array}$ & No & No \\
\hline Netherlands & Private & $\begin{array}{l}\text { Mostly private, } \\
\text { nonprofit }\end{array}$ & Mix capitation/FFS & $\begin{array}{l}\text { Global budgets + case- } \\
\text { based payment (include } \\
\text { physician costs) }\end{array}$ & Yes & Yes \\
\hline New Zealand & Private & $\begin{array}{l}\text { Mostly public, } \\
\text { some private }\end{array}$ & Mix capitation/FFS & $\begin{array}{l}\text { Global budgets + case- } \\
\text { based payment (includes } \\
\text { physician costs) }\end{array}$ & $\begin{array}{l}\text { Yes (for } 96 \% \text { of } \\
\text { population) }\end{array}$ & Yes \\
\hline Norway & Private & Almost all public & $\begin{array}{l}\text { Mixed income from } \\
\text { municipal contracts, user- } \\
\text { charges (in accordance } \\
\text { with cost-sharing caps) } \\
\text { and government spon- } \\
\text { sored FFS payments }\end{array}$ & $\begin{array}{c}\text { Global budgets }+ \text { case- } \\
\text { based payment }(40 \% \text { of } \\
\text { DRG; includes physician } \\
\text { costs) }\end{array}$ & Yes & Yes \\
\hline Sweden & Mixed & Almost all public & Mix capitation/FFS/P4P & $\begin{array}{c}\text { Global budgets + case- } \\
\text { based payment (includes } \\
\text { physician costs) }\end{array}$ & Yes (except Stockholm) & Some incentives \\
\hline Switzerland & Private & $\begin{array}{l}\text { Mostly public, } \\
\text { some private }\end{array}$ & $\begin{array}{l}\text { Most FFS, but some } \\
\text { capitation }\end{array}$ & $\begin{array}{l}\text { National diagnosis related } \\
\text { groups (Swiss DRG) pay- } \\
\text { ment system for (somatic) } \\
\text { acute inpatient care }\end{array}$ & No & $\begin{array}{l}\text { Free access (without } \\
\text { referral) to specialists } \\
\text { unless enrolled in a } \\
\text { gatekeeping } \\
\text { managed care plan }\end{array}$ \\
\hline United States & Private & $\begin{array}{l}\text { Mix of nonprofit } \\
\text { ( 70\% of beds), } \\
\text { public ( } 15 \%), \\
\text { and for-profit } \\
(\sim 15 \%)\end{array}$ & $\begin{array}{l}\text { Most FFS, some capitation } \\
\text { with private plans }\end{array}$ & $\begin{array}{l}\text { Per diem and case-based } \\
\text { payment (usually does not } \\
\text { include physician costs) }\end{array}$ & No & $\begin{array}{l}\text { In some insurance } \\
\text { programs }\end{array}$ \\
\hline
\end{tabular}





\title{
The Australian Health Care System, 2013
}

\author{
Judith Healy and Paul Dugdale, Australian National University
}

\section{What is the role of government?}

The Australian government plays a strong role in national policymaking but generally funds, rather than provides, health services. The federal government funds and administers the national health insurance scheme, Medicare (previously a statutory authority and now a government agency), and pharmaceutical benefits; funds public hospitals and population health programs (with the states/territories); regulates much of the health system, including private health insurance ( $\mathrm{PHI}$ ), pharmaceuticals, and medical services; and has the main funding and regulatory responsibility for government-subsidized residential care facilities. Under the National Health Reform Agreement, endorsed by the Council of Australian Governments in 2011, the role of the Australian government has been strengthened in relation to the funding and governance of public hospitals and primary care (see below). The eight states and territories ("states") administer public hospitals and regulate all hospitals and community-based health services. Local government is involved in environmental health and some public health programs, but not clinical services.

\section{Who is covered?}

Australia's national public health insurance scheme, Medicare, provides universal health coverage for citizens and permanent residents, as well as automatic coverage for people with temporary visas from countries with whom Australia has reciprocal arrangements. All overseas students are required to enroll in Overseas Student Health Cover. The Department of Veterans' Affairs covers eligible veterans and dependents by directly purchasing public and private health care services. The Australian government provides some assistance for asylum seekers while their applications are processed.

Voluntary private health insurance plays a mixed complementary and supplementary role, offering people access to treatment in private hospitals and covering some ancillary health care services. Policies are taken out by individuals or families, encouraged through tax penalties for high-income earners and tax rebates for lowand middle-income earners.

\section{What is covered?}

Services: Public inpatient care in public hospitals is free under the National Health Act of 1953, but people may choose to pay for private care in public or private hospitals. Medicare provides free or subsidized access to most medical services (and some allied health services if the patient is referred by a medical practitioner); it also covers prescription pharmaceuticals. The Australian government defines Medicare subsidies for outpatient care and outpatient physician services under the Medical Benefits Schedule published by the Department of Health (DoH), and for medication under the Schedule of Pharmaceutical Benefits, published by the Pharmaceutical Benefits Scheme (PBS); home health care for older people is provided through the Home and Community Care Program. The Australian government also, usually jointly with the state and territory governments, funds a wide range of other health services, including population health, mental health, limited dental and physical therapy services, rural and indigenous health programs, and health services for war veterans. 
Cost-sharing: Medicare usually reimburses 85 percent to 100 percent of its fee schedule for ambulatory services. It also reimburses 75 percent of the medical fee schedule (but not accommodation, surgery theater fees, or medicines) for private patients in public hospital services-any amount above this is paid by the patients. Doctors can treat patients and bill Medicare directly for the amount of the subsidy with no patient charge (referred to as "bulk billing"). Doctors' fees are not otherwise regulated and they are free to charge above the Medicare fee schedule. However, incentive schemes introduced to reverse a reduction in bulk billing by general practitioners (GPs) offer additional payment for bulk billing the care provided to concession card holders (low-income, older people), children under 16 years of age, and residents of rural and remote areas. Prescription pharmaceuticals approved by the PBS have a standard copayment of AUS\$36.10 (US\$34) (in 2013) for the general public, with a reduced rate of AUS $\$ 5.90$ (US\$5.60) for concession card holders. The Repatriation Pharmaceutical Benefits Scheme subsidizes access to pharmaceuticals for war veterans and their dependents.

Safety net: When the annual threshold of AUS $\$ 421.70$ (US\$402) (in 2013) for "gap expenses" (the difference between the Medicare benefit and the fee schedule) is reached, the Medicare payment is increased from 85 percent to 100 percent of the Medicare fee schedule for the remainder of the calendar year. The Extended Medicare Safety Net provides additional coverage for patients who incur high health care costs: once a threshold for total out-of-pocket costs is reached (AUS\$610.70 [US\$582] for individuals with concession cards and low-income families, and AUS\$1,221.90 [US\$1,164] for general patients), the patient has 80 percent of his or her out-ofpocket costs reimbursed for the remainder of the calendar year. Families can register to have their gap expenses and out-of-pocket costs combined to reach the applicable threshold amount sooner. People who exceed an annual safety-net threshold for pharmaceutical costs (PBS-listed medicines) are eligible for additional subsidies: the patient copayment per item decreases to the concessional rate of AUS $\$ 5.80$ (US $\$ 5.50$ ) once expenditure exceeds AUS $\$ 1,391$ [US\$1,325]) (as of 2013) in a calendar year. For concessional patients, the copayment is not required once expenditure on PBS items exceeds AUS\$354 (US\$337).

\section{How is the health system financed?}

Publicly financed health care: Australia spent 8.9 percent of its GDP on health care in 2010-11 (OECD 2013). Medicare is funded mostly from general tax revenue, including a value-added tax; from patient fees and other private sources; and from a 1.5 percent levy on taxable income, although some low-income individuals are exempt or pay a reduced levy. For the financial year 2010-11, government funding amounted to 69.1 percent of total health expenditure-42.7 percent by the Australian government and 26.4 percent by the states/territories.

Privately financed health care: Nongovernment sources provided 30.9 percent of health expenditure in 2010-11, including out-of-pocket spending (18.3 percent; mostly spent on medications not covered by the PBS, dental services, aids and appliances, and copayments). Private health insurance (PHI) offers choice among private hospitals, private care in public hospitals, in-hospital specialists, and practitioners of ancillary services such as dental care, optometry, and complementary medicine. It also offers choice in the timing of procedures. Since 2007, private insurers have been able to cover out-of-hospital services that substitute for or prevent in-hospital care, and disease management programs are now offered by most insurers. Private health insurance accounted for 7.6 percent of total health expenditure in 2010-11, and in June 201347.0 percent of the population had private hospital insurance and 54.9 percent had general treatment coverage (which includes ancillary services). Government policy encourages people to take out private health insurance early in life: the Lifetime Health 
Coverage program offers people who join a private insurance fund before age 31 a relatively lower premium throughout their lives, regardless of health status. People over age 30 face a 2 percent increase in premiums over the base rate for every year they delay joining. Consequently, private health insurance participation increases markedly above age 30 and rolls off sharply after retirement. In July 2012 the subsidy that the Australian government has been paying since 1999 to individuals toward the cost of private insurance premiums became linked to income. The rebates are reduced based on income and age for singles and families with annual incomes over AUS $\$ 88,000$ (US $\$ 83,838$ ) and AUS $\$ 176,000$ (US\$167,677), respectively, as of July 2013 . Those with these higher incomes who do not take out private hospital insurance must also pay a Medicare levy surcharge of an additional 1.0 percent to 1.5 percent of taxable income.

\section{How are health services organized and financed?}

Primary care: In 2010, there were 44,600 GPs and 29,300 specialists employed in health occupations (AIHW 2012). Most GPs are self-employed and work in multi-provider practices. Some "corporatization" is under way as 8 percent of GPs are employed under contract with private agencies. GPs are paid fee-for-service (FFS) and the majority bulk-bill Medicare. In addition, general practices receive incentive payments for being accredited against the Royal Australian College of General Practitioners (RACGP) practice standards, meeting certain benchmarks for health information technology, providing appropriate care for some chronic diseases, teaching students, and performing some other activities. Individuals are not required to register with a primary care physician and are free to consult any GP, to seek a second opinion, or to shift to another GP practice at any time. Doctors with busy practices, however, may decide not to accept new patients. GPs play an important gatekeeping role as Medicare will reimburse specialists the schedule fee payment only for consultations referred by GPs. Nurses play an important role in the majority of practices, where they are funded by practice earnings and some nurse-specific Medicare benefits and practice incentive payments.

Outpatient specialist care: Medicare allows individuals to choose their specialist for out-of-hospital carealthough their GP must provide a referral letter to the specialist. Specialists are paid FFS with benefit levels set by the Commonwealth and patient copayments set between the doctor and the patient. Specialists practice in both the private and the public sector; many work in both sectors.

After-hours care: GP clinics vary considerably in the extent to which they provide after-hours care; it is often provided by a private company through arrangements with GP practices. For example, doctors in Canberra set up a nonprofit company in 1971 (CALMS Ltd), now also supported by the Australian Capital Territory government, where each member doctor agrees to participate on a roster to provide appropriate after-hours medical care to people in the territory. The Australian government also has offered grants to GPs to provide after-hours services. Medicare Locals (described below) also are contracted to improve access to after-hours care and this is now leading to improved arrangements in some regions.

Hospitals: There is a mix of public, private, and not-for-profit hospitals. In 2010-11 there were 735 public acute hospitals, 17 public psychiatric hospitals, 303 private day hospitals, and 285 other private hospitals. Public hospitals are funded jointly by the Australian government and state/territory governments in addition to receiving funds from treating private patients. Private hospitals (including freestanding ambulatory day centers) can be either for-profit or nonprofit, and their income is derived chiefly from patients with private health insurance. 
Under the 2011 National Health Reform Agreement, 136 local hospital networks have been formed, each consisting of one to four public hospitals, run by boards with local clinician input. State health departments continue to be the overall managers of their public hospitals and state governments have been funding hospitals largely on a prospective, capped activity-based formula from the past 20 years, using Diagnosis Related Groups. Through the National Hospital Funding Authority, the Australian government now pays state governments a percentage (rising from $40 \%$ in 2011 to $50 \%$ after 2016-17) of the "efficient" cost, as calculated by the Independent Hospital Pricing Authority, for each service provided to public patients. The remaining costs will continue to be paid by state governments. Transition arrangements toward retrospective, open-ended activitybased funding for hospitals have now also been set in place for the Commonwealth's share of public hospital funding, provided to the states through the Council of Australian Governments Health Reform Agreement (August 2011). The Commonwealth plus the state funding covers the whole episode of care for each occasion of hospitalization, as public hospital services are free to public patients under the Commonwealth-state arrangements.

Physicians in public hospitals either are salaried (but may also have private practices and additional FFS income, of which they usually contribute a portion from the fees to the hospital), or are private specialist physicians who do some work in public hospitals, where they are paid on a per-session or FFS basis for treating public patients. Australia also has many specialist physicians who work purely in private practice, with admitting rights at several private hospitals. For private hospital coverage, private insurers list their preferred providers and doctors, with whom the patient will not face high out-of-pocket costs. Rural general practitioners often have admitting rights at their local public hospital, but this is rare for urban general practitioners.

Long-term care: The majority of care for older people with long-term health conditions is provided by relatives and friends, although there is an allowance available to other caregivers in some cases. For people assessed as having a high level of dependency, the Australian government subsidizes assistance through either community care services or residential aged care homes. The Australian government subsidy for aged residential care is means-tested, and the amount of subsidy is based on the extent of a person's dependency (low, medium, high) and total assessable income. As of July 2013, under the current funding formula, the maximum income-tested fee for standard care for a single resident was AUS\$48.21 (US\$45.95) per day. In 2010-11, 60 percent of residential aged care providers were not-for-profit (such as religious and community organizations), 30 percent were private for-profit, and the remaining 10 percent were state and local government facilities.

The Home and Community Care (HACC) program, previously an intergovernmental program, subsidizes services that aim to support people in their own homes. Following the 2011 National Health Reform Agreement, the Australian government fully funds Home and Community Care services (except in Victoria and Western Australia, which did not sign up to the agreement) from July 1, 2012. The program includes individual budgets that allow patients to tailor services to their needs. The Health and Community Care program is complemented by several smaller Commonwealth and state programs.

Palliative care services are provided by government and nongovernment providers to people in their own homes, in community-based settings such as nursing homes, in palliative care units, and in hospitals. The National Palliative Care program also funds initiatives to ensure palliative care quality and access. 
Mental health care: A variety of public and private health care providers deliver mental health services. Nonspecialized services are offered through GPs, and specialized services are provided through psychiatrists, psychologists, community-based mental health services, psychiatric hospitals, psychiatric units within general acute hospitals, and residential care facilities. Mental health-related GP and specialist consultations are reimbursed by Medicare. Inpatient admissions to public hospitals for mental health problems are free to the patient and funded through intergovernmental hospital funding agreements. There are nearly 20 remaining public psychiatric hospitals that treat and care for admitted patients with psychiatric, mental, or behavior disorders. Private insurers subsidize admissions to private hospitals. Community services include crisis, mobile assessment and treatment services, day programs, outreach services, and consultation services. Nongovernmental organizations also provide information, treatment, and advocacy services for mental health care.

\section{What are the key entities for health system governance?}

The main national governance agencies relating to health are the Council of Australian Governments' Health Ministers Conference and its extensive committee structure, together with the Department of Health. Quality and safety standards and guidelines are set by the Commission on Safety and Quality in Health Care. The National Safety and Quality Health Service Standards were endorsed by the health ministers in 2011. Public health and clinical guidelines are produced by the National Health and Medical Research Council and a range of professional associations. The Australian Council on Healthcare Standards (an NGO) is the main accreditation body for hospitals and other health facilities and also sets its own accreditation standards. The Aged Care Standards and Accreditation Agency (a government-owned company) manages the accreditation process for aged care services as set out in the 2011 Accreditation Grant Principles. The Therapeutic Goods Administration (an operating division of the $\mathrm{DoH}$ ) is responsible for marketing approval and postmarketing surveillance of therapeutic goods. The Pharmaceutical Benefits Advisory Committee (an independent statutory body) advises the national minister for health on the evaluation of comparative effectiveness and cost-efficiency of drugs proposed for the government subsidy list. The DoH then uses these assessments to negotiate prices with manufacturers. The Independent Hospital Pricing Authority was established in December 2011 to set the national "efficient" price for public hospital services. The National Health Performance Authority was established as a statutory authority through the National Health Reform Act 2011 to report on the performance of all local hospital networks, public and private hospitals, and Medicare Locals. The Health Practitioners Regulation Agency (established under legislation in 2010) is an oversight body for the 14 current health professions.

\section{What is being done to ensure quality of care?}

The past decade has seen much more attention being paid by a range of regulatory actors and strategies to ensuring quality of care (Healy 2011). The principal body in this area, the Australian Commission on Safety and Quality in Health Care (which became a statutory body in 2011), publicly reports on the safety and quality of health care performance against national standards, disseminates knowledge, identifies policy directions, and develops and promotes programs. The National Health Performance Authority will monitor trends in the performance of health service providers against standards set out in the National Health Performance Framework.

Most general practices in Australia (over 85\%) are now accredited against standards set by the RACGP. Medicare also offers financial incentives, rewarding practices deemed to be working toward meeting the 
College's standards. Residential aged care must be accredited to be eligible for government subsidies, and provider organizations are subject to licensing and approval processes.

Health care organizations as employers run a variety of quality improvement programs, and most professional boards now require members to participate in professional development programs in order to maintain professional registration.

\section{What is being done to improve care coordination?}

Large practices with several partners may employ a practice manager and some employ nurses; the Australian government, through the Practice Incentives Program, subsidizes the employment of practice nurses. In addition, practice nurses are able to bill an increasing number of Medicare services, and Medicare allows GPs to claim for specified tasks undertaken by a practice nurse under the direction of the GP. Multidisciplinary teams are the norm in community health centers. Also, in accordance with the 2011 National Health Reform Agreement, the government provides primary care providers with funds to operate 61 Medicare Locals, which are primary care organizations centered around GPs. These organizations have a representational and planning role for primary health care, and some of them also provide services such as after-hours care or care coordination.

\section{What is being done to reduce health disparities?}

The Australian government and the states work in partnership with indigenous communities in order to close long-standing health gaps through a range of programs and targeted health care funding. Extra subsidies for services, training programs, and outreach services are also being directed to people in rural areas and a safety net is in place to improve access to care for low-income people. The reporting framework of the National Health Performance Authority requires government service providers to report on measures of equity and access, including targeted reporting on particular groups such as Indigenous Australians. The Australian Institute of Health and Welfare also publishes regular reports on the health and welfare of Indigenous Australians.

\section{Who is responsible for population health?}

Historically, state governments have the major responsibility for population health, including preventive regulation and campaigns, environmental health, occupational health and safety, and communicable disease control. Preventive services, such as free screenings, are provided mainly through state government programs. The inspection function for environmental and food safety is carried out by local government. The Commonwealth is strongly active in coordination of policy between states, e.g., through the development of model legislation, national data collection, and coordination of action across state boundaries in disaster response and outbreak control. The Commonwealth has lead responsibility for vaccinations, quarantine, and chemical safety. It has also recently established the Australian National Preventive Health Agency (see below). GPs also provide preventive services such as immunizations and some health checks, which are wholly or partly subsidized by Medicare or other national programs. 


\section{What is the status of electronic health records?}

Most general practices and many public sector health service providers use electronic health records. DoH is now providing Personally Controlled EHRs to all citizens and permanent residents upon request. The National E-Health Strategy, an intergovernmental strategy on health information technology, has been published, and the National E-Health Transition Authority has been set up in order to develop patient identifiers, interoperable systems between providers, and a clinical terminology and information service. The Authority reported that 4,500 organizations (not including hospitals) were registered to use Personally Controlled EHRs in July 2013. The national strategy on health information is managed by the Australian Health Ministers' Advisory Committee (an intergovernmental committee of senior health administrators), and the National Health Information Agreement in place between governments and other key agencies aims to develop, collect, and exchange data in order to improve the health of the population and the delivery of health services.

\section{How are costs controlled?}

Costs are controlled by various market, financing, and managerial mechanisms. Australia has a mature generic pharmaceuticals market. The Australian Government is a near-monopolist purchaser of patent medicines which, combined with tight prescribing requirements, allows it to control pharmaceutical pricing. New pharmaceuticals have to meet cost-effectiveness criteria and are subject to nationally negotiated pricing before inclusion in the formulary of publicly subsidized medicines. Public hospitals are managed with broadly capped global prospective budgets which effectively control costs, but have at times caused waiting lists for elective access. Health insurance funds negotiate and publish agreed-upon prices with their preferred private hospitals and other service providers. Additional measures include controlling the growth in cost of some large-volume diagnostic services through industry agreements with the relevant medical specialty; controlling access to specialist services through "gatekeepers" such as GPs; and limiting the number of providers with access to some "high-tech" services, such as MRIs.

\section{What major innovations and reforms have been introduced?}

Health Workforce Australia was set up in 2006 by the Council of Australian Governments to deliver programs across four main areas: workforce planning, policy, and research; clinical education; innovation and reform of the health workforce; and the recruitment and retention of international health professionals. The regulation of health care professionals, previously a function of state-level boards, has been overhauled: the Australian Health Practitioners Regulation Agency was established in 2010 to oversee new national boards and to administer the Health Practitioner National Law Act 2009 for each of the 14 current health occupational groups.

The Australian National Preventive Health Agency was established in January 2011 to develop strategic partnerships across all sectors, to provide technical advice and assistance, and to promote health and reduce health risk and inequalities. One step it has taken so far has been to introduce plain packaging for cigarettes in December 2012.

As described above, the Council of Australian Governments agreed on a hospital reform strategy including changes to the funding formula in August 2011, the National Health Reform Agreement, after several years of debate. One hundred thirty-six Local Hospital Networks have been formed with local boards, although state health departments continue to be the overall administrators of their public hospitals. The National Health 
Performance Authority was set up as a statutory authority in 2011 to collect information on and monitor trends in the performance of health service providers, and monitors the performance of public hospitals against the National Health Performance Framework. The National Mental Health Commission was set up in January 2012 to report on the delivery of mental health reforms. Last, the National Disability Insurance Agency was established by the Australian government in 2013 to implement the National Disability Insurance Scheme. The first stage commenced from July 2013 in launch sites in several states to provide care and support initially for an estimated 20,000 people with significant and permanent disabilities.

\section{References}

Australian Institute of Health and Welfare (2012). Health expenditure Australia 2010-11. Health and welfare expenditure series no. 47. Cat. no. HWE 56. Canberra: AIHW.

Australian Institute of Health and Welfare (2012). Residential aged care in Australia 2010-11: a statistical overview. Aged care statistics series no. 36. Cat. no. AGE 68. Canberra: AIHW.

Australian Institute of Health and Welfare (2011). Australia's Welfare 2011. Canberra: AIHW.

Australian Institute of Health and Welfare (2012). Australia's Health 2012. Department of Health and Ageing, Residential Care. Accessed Sept. 23, 2011.

http://www.health.gov.au/internet/main/publishing.nsf/Content/Residential+Care-2.

Healy, J., Sharman, E., and Lokuge, B. (2006). “Australia: Health System Review," Health Systems in Transition 8(5):1-158.

Healy, J. (2011). Improving Health Care Safety and Quality: Reluctant Regulators (England, U.S.: Ashgate).

OECD Health Data 2013.

Private Health Insurance Administration Council (2013). March Statistics 2013. 


\title{
The Canadian Health Care System, 2013
}

\author{
Sara Allin and David Rudoler, University of Toronto
}

\section{What is the role of government?}

The Canadian provinces and territories have primary responsibility for organizing and delivering health services and educating, accrediting, and licensing health care providers. Many provinces and territories have established regional health authorities that plan and deliver publicly funded health services on a local basis. Generally, these regional health authorities are responsible for the funding and delivery of hospital, community, and long-term care, and mental and public health services. Some jurisdictions have consolidated a number of these authorities in recent years. Health care providers are almost entirely private. The federal government cofinances provincial/territorial health insurance programs through the Canada Health Transfer (described below). Federal funding is conditional on the provinces'/territories' adhering to the five criteria of the Canada Health Act, which sets pan-Canadian standards for hospital, diagnostic, and physician services. The federal government also regulates the safety and efficacy of medical devices, pharmaceuticals, and natural health products; funds health research; and administers several public health functions.

\section{Who is covered?}

The Canadian provinces and territories administer their own universal health insurance programs, covering all provincial and territorial residents. Each province and territory is responsible for establishing its own specific residency requirements; undocumented immigrants, including denied refugee claimants, those who stay in Canada beyond the duration of a legal permit, and those who enter the country "illegally," are not covered in any federal or provincial program, although the provinces/territories do provide some limited services. The federal government administers a range of health services, such as prescription drugs, ancillary health services, and community health services for First Nations and Inuit ${ }^{1}$, members of the Royal Canadian Mounted Police and the Canadian Forces, veterans, refugee claimants ${ }^{2}$, and inmates in federal penitentiaries. Around twothirds of Canadians also have private health insurance, which covers services that are not covered under the public programs (see below).

\section{What is covered?}

Services: To qualify for federal financial contributions under the Canada Health Transfer block grants, provincial and territorial health insurance plans must provide first-dollar coverage of medically necessary physician, diagnostic, and hospital services (including inpatient prescription drugs), for all eligible residents. There is no nationally defined statutory benefits package; most public coverage decisions are made by provincial/territorial governments in conjunction with the medical profession. Provincial and territorial governments provide

1 In British Columbia the funding and governance of aboriginal health care will be transferred from the federal government to the newly formed First Nations Health Authority in 2013, including CAD\$2.5 billion (US\$2.4 billion) over the next five years.

2 In June 2012 the federal government implemented changes to health coverage for refugee claimants. All refugee claimants lost access to medication, vision, and dental coverage; and claimants from designated countries-those not determined by the Minister of Citizenship and Immigration to be refugee-producing countries-lost access to all health coverage unless their conditions pose a public safety concern or a risk to public health. 
varying levels of additional benefits, such as outpatient prescription drug coverage, vision care, dental care, home health care, physiotherapy, aids to independent living, and ambulance services. They also provide public health promotion and prevention services (including immunizations) as part of their public programs, while the federal government directly provides and funds a wide range of preventive services through the Public Health Agency. The federal government licenses medical devices and equipment, but purchasing decisions are made at the provincial or territorial level.

Cost-sharing: There is no cost-sharing for publicly insured physician, diagnostic, and hospital services. All prescription drugs provided in hospital settings are covered through the public program, with variable additional outpatient coverage offered by provinces/territories. Physicians are not allowed to charge patients prices above the negotiated fee schedule.

Safety net: Cost-sharing exemptions vary among the provinces/territories. There are no caps on out-of-pocket (OOP) spending. However, the federal government supports tax credits for medical expenses through the Medical Expense Tax Credit, which applies to individuals who have significant medical expenses (above $3 \%$ of income) for themselves or their dependents. A disability tax credit and an attendant care expense deduction also provide relief to individuals (or their dependents) who have prolonged mental or physical impairments, and to those who incur expenses for care that is needed to allow them to work.

\section{How is the health system financed?}

Publicly financed health care: Public funding accounted for an estimated 70 percent of total health expenditures in 2012 (Organisation for Economic Co-operation and Development, 2013). Public programs are funded by general taxation. The federal government contributes cash funding to the provinces and territories on a per capita basis through the Canada Health Transfer-block grants estimated to account for 19 percent of total provincial and territorial health expenditures in 2012-2013. Current provisions to compensate for smaller tax bases in some less wealthy provinces/territories will be abolished after 2014 (see below).

Privately financed health care: In 2010, OOP payments by private households represented about 15 percent of total health spending (OECD, 2013). The main components of OOP spending in 2010 were dental care (20\%), nonhospital institutions (mainly long-term care homes) (20\%), prescription drugs (17\%), vision care (12\%), and over-the-counter medications (10\%) (Canadian Institute for Health Information, 2012a). Private health insurance covers about two-thirds of the population (23 million people). In 2010, it accounted for approximately 12 percent of total health spending (CIHI, 2012a). Private health insurance covers services such as vision and dental care, prescription drugs, rehabilitation services, home care, and private rooms in hospitals (which are not covered by public programs). In 2011, approximately 85 percent of premiums for private health plans were paid through group contracts with employers, unions, or other organizations (Canadian Life and Health Insurance Association Inc., 2012). Supplementary private insurance to provide faster access to publicly funded physician and hospital services is not available. Providers set their own fees for services covered by private insurance, and each insurer sets its own reimbursement level (e.g., based on the lowest fee among representative providers in a geographical area). Contributions to employer-sponsored private insurance are deductible from income for federal tax purposes, and for provincial tax purposes in all provinces but Quebec. Premiums paid to any private insurance plan qualify as expenses eligible for the federal Medical Expense Tax Credit. 


\section{How are health services organized and financed?}

Primary care: In 2010 , of the total number of doctors $(69,699)$, about half were family doctors and half were specialists (CIHI, 2011). Primary care physicians largely act as gatekeepers for further care. Most physicians are in private practices and are remunerated on a fee-for-service (FFS) basis, although an increasing number of family doctors receive alternative forms of public payment such as capitation, salary, and blended funding. In 20102011, FFS payments made up 50 percent of payments to family physicians in Ontario, compared with 70 percent in Quebec and 86 percent in British Columbia (CIHI, 2012b). Physicians in community clinics are salaried. Some new primary care teams paid partly by capitation must require patients to register in order to receive those partial payments; otherwise registration is not required. Patients have free choice of primary care doctor, although in some areas choices are restricted owing to limited supply. Provincial and territorial Ministries of Health (MoHs) negotiate physician fee schedules (for primary care and specialist physicians) with provincial and territorial medical associations.

In some provinces, such as Ontario, payment incentives have been linked to performance, and encourage the provision of a number of services including, but not limited to, delivering "guideline-based" care for specified chronic conditions, offering preventive services such as immunizations and cancer screening, developing care plans for complex patients, contacting patients to schedule appointments, and enrolling complex or vulnerable patients. Currently, no province supports bundled payments for primary care physicians to coordinate care across health care settings.

Multidisciplinary primary care has become more common in Canada (see section on care coordination). Other health professionals in these models include nurse practitioners, nurses, pharmacists, social workers, mental health workers, and dietitians. The composition of each team varies from practice to practice, and these providers are generally employed by the practice and compensated via a salaried payment structure.

Outpatient specialist care: The majority of specialist care is provided in hospitals, although there is a trend toward providing specialist services in private nonhospital facilities. Specialists are paid mostly on an FFS basis. Patients can choose, and have direct access to, a specialist, but it is common for family physicians to refer patients to specialty care because many provinces pay lower fees for nonreferred consultations.

After-hours care: After-hours care is generally provided by physician-led (and mainly privately owned) walk-in clinics and hospital emergency rooms. In most provinces and regions a free telephone service ("telehealth") is available 24 hours per day for health advice from a registered nurse. Traditionally, primary care physicians were not required to provide after-hours care, although many of the government-enabled group practice arrangements have requirements or financial incentives for providing after-hours care to patients registered with the practice. For example, in Ontario, many primary care physicians receive a 20 percent premium for the provision of specific primary care services to patients after hours. The Commonwealth Fund International Health Policy Survey (2012) of physicians found that only 46 percent of physician practices in Canada had arrangements for patients to see a doctor or nurse after hours, with the highest rate seen in Ontario, at 67 percent (Health Council of Canada, 2013). The same survey found that only 30 percent of physicians received notification when patients had been in a hospital emergency department, and about a quarter received a full report on their patients after they had consulted a specialist. 
Hospitals: Hospitals are a mix of public and private, predominantly not-for-profit, organizations, often managed locally by regional health authorities or hospital boards representing the community. They generally operate under annual, global budgets, negotiated with the provincial/territorial $\mathrm{MoH}$ or regional health authority. However, two provinces-British Columbia and Ontario-are beginning to introduce activity-based funding for hospitals. Activity-based funding has also been used to provide additional funding for services targeted in national efforts at addressing waiting times for services such as cancer treatment and cataract surgery. Hospital-based physicians generally are not hospital employees and are paid on an FFS basis.

Mental health care: The Canadian system includes universal health care coverage for physician-provided mental health care, alongside a fragmented system of allied mental health services. Hospital mental health care is provided in specialty psychiatric hospitals and in general hospitals that have adult mental health beds. The Canada Health Act does not mandate public coverage of nonphysician mental health services (such as services of psychologists or social workers) outside of hospitals, but the provinces/territories all provide a range of community mental health and addiction services. Psychologists may work privately, and are paid OOP or through private insurance, or under salary in publicly funded organizations.

Long-term care: Long-term care (LTC) services and end-of-life care provided in nonhospital facilities and in the community are not considered insured services under the Canada Health Act. Provinces and territories can choose to fund services, and all do, but coverage varies among and within provinces/territories. Financing for LTC institutions is mostly public (72\%); spending on nonhospital institutions accounted for about 10 percent of total health expenditure in 2010 (CIHI, 2012). Some provinces have established minimum periods of residency as a condition for being eligible for admission to a facility. A mix of private for-profit, private not-for-profit, and public facilities provides LTC, with variation in ownership across the country. About half of the provinces and territories provide some home care services without means testing, but access may depend both on assessed priority and on availability within capped home care budgets. Supply shortages limit the availability of publicly funded services, increasing the demand for private home care services. Most provinces charge user fees for nonprofessional home care services (e.g., homemaking, transportation, meal delivery, respite care). The provinces and territories are responsible for delivering palliative and end-of-life care in hospitals, and many provide some coverage for professional services outside those settings (e.g., doctors, nurses, and drug coverage in institutions such as hospices and long-term care homes, as well as in the home). Funding for palliative and end-of-life care varies among provinces, but the majority of costs occur in institutional settings. For example, latest estimates from British Columbia show that the majority of care costs incurred in the last two years of life are attributable to residential care days (43\%), acute care days (33\%), and physician visits (12\%) (CIHI, 2008).

\section{What are the key entities for health system governance?}

Because of the highly decentralized nature of health care in Canada, the provinces have primary jurisdiction over administration and governance of their health systems. Most provinces have established statutory relationships with devolved purchasing organizations; some of these arrangements include performance management within the broader context of accountability agreements. At the national level, several intergovernmental, nonprofit organizations have been established in the past decade to improve overall system governance by monitoring and reporting on health system performance (the Health Council of Canada, for which funding will be discontinued in 2014); disseminating best practice in patient safety initiatives (the Canadian Patient Safety 
Institute); and providing information on health and health care and standardizing health data collection (the Canadian Institute for Health Information). Nongovernmental organizations that play important roles in system governance include the professional organizations (e.g., the Canadian Medical Association), the provincial regulatory colleges responsible for governing the professions through their licensing role and by developing and enforcing standards of practice, and Accreditation Canada, which manages the voluntary accreditation of health care organizations including regional health authorities, hospitals, long-term care facilities, and community organizations. Most health care providers are self-governing under provincial/territorial law; they are registered with professional associations that ensure that education, training, and quality-of-care standards are met.

\section{What is being done to ensure quality of care?}

Over the past decade, as part of the 10-Year Plan to Strengthen Health Care (2004-2014), the federal government has increasingly earmarked some of the funds it provides to the provinces/territories for supporting innovation and stimulating systemwide improvements in quality. For example, the federal Wait Time Reduction Fund (CAD $\$ 5.50$ billion [US $\$ 5.2$ billion] over 10 years) led to significant, though mostly short-term, reductions in surgical and diagnostic wait times in its priority areas (cancer care, cardiac care, sight restoration, joint replacement, and imaging). All provinces publicly report waiting-time data and provide the CIHI with comparable data; however, the waiting time between a patient's receiving a referral and the subsequent visit with a specialist is not yet being measured.

There is increasing use of health technology assessment in Canada to support and inform purchasing decisions, service management, and clinical practice. Health technology assessment organizations include the Canadian Agency for Drugs and Technologies in Health (CADTH, a national body) and specialized provincial agencies in Alberta, Ontario, and Quebec. CADTH's health technology assessment program produces information about the clinical effectiveness, cost-effectiveness, and broader impact of drugs, medical technologies, and health systems. The Common Drug Review at CADTH reviews the clinical effectiveness and cost-effectiveness of drugs, and provides common formulary recommendations to the publicly funded drug plans in Canada (except in Quebec). These nonbinding recommendations support greater consistency of public drug plan access and evidence-based resource allocation.

The federally funded Canadian Patient Safety Institute promotes best practices and develops strategies, standards, and tools. Another program, the Optimal Use Projects program, operated by CADTH, provides recommendations (though not formal clinical guidelines) to health care providers and consumers in order to encourage the appropriate prescribing, purchasing, and use of medications.

There is no information available on doctors' performance, but the CIHI produces regular reports on health system performance. Many quality improvement initiatives take place directly at the provincial and territorial level, with many jurisdictions having established quality councils to monitor and publicly report on health system performance. There is no system of professional revalidation for physicians in Canada, but each province has its own process of ensuring that physicians engage in lifelong learning, such as requiring them to participate in a continuing education program, and peer review. 
Few formal disease registries exist, although many provincial cancer care systems maintain some type of patient registry. Provincial cancer registries feed data to the Canadian Cancer Registry, a national administrative survey that collects information on cancer incidence.

\section{What is being done to improve care coordination?}

The number of doctors practicing in multidisciplinary teams is growing. In 2004, as part of the 10-Year Plan to Strengthen Health Care, all provincial/territorial governments agreed to provide at least half of their respective populations with access to multidisciplinary primary care teams by 2011 . By 2007 about three-quarters of family physicians were working in physician-led multi-professional practices (Marchildon, 2013a); most progress has been seen in Ontario (with 200 Family Health Teams serving about one-quarter of the population), Alberta (where about three-quarters of the province's family physicians work in 40 Primary Care Networks), and Quebec (with plans for 300 Family Medicine Groups to serve three-quarters of the population) (Hutchison et al., 2011). There were significant financial incentives to participate in these multi-professional practices. In Ontario, for example, with the shift from FFS to blended capitation funding models, there was a 58 percent increase (inflation-adjusted) in payments to physicians in 2003-2004 and 2008-2009 (Henry et al., 2012). In 2012, the government of Nova Scotia established new legislation to create the Regulated Health Professions Network, where health professions can voluntarily work together to determine scopes of practice that will facilitate the functioning of interprofessional teams.

Some reforms have aimed at improving the systematic management of disease. Organized at the provincial level, many include incentive payments for physicians: British Columbia recently introduced its Full Service Family Incentive Program to support the management of congestive heart failure, diabetes, and hypertension; physicians receive annual payments for each patient with one of these conditions whose clinical management is consistent with recommendations in provincial clinical practice guidelines. In 2010 , the Ontario government implemented the Excellent Health Care for All Act, which included provisions to expand the mandate of the provincial quality council (Health Quality Ontario, or HQO) to include recommendations to health care organizations on standards of care based on clinical practice guidelines.

\section{What is being done to address health disparities?}

Health disparities are a significant issue in health policy in Canada, where some demographic groups suffer from a higher burden of illness than other residents. Poor people, homeless people, and the approximately 1 million Canadian aboriginals face, on average, poorer housing conditions, fewer educational and employment opportunities, and a significantly higher burden of illness than does the general population. There is no single or central body responsible for addressing health disparities, but several provincial or territorial governments have recently established departments and agencies devoted to addressing population health issues and health inequities (see section on population health). Aboriginal health is a priority for both the federal and provincial/ territorial governments; recent federal initiatives include the Aboriginal Diabetes Initiative, the National Aboriginal Youth Suicide Prevention Strategy, and the Maternal Child Health Program. In 2013, the federal government included in its budget investments for First Nations health services, including mental health services. The 2013 budget also included renewed funding for the Homelessness Partnership Strategy for five years (CAD\$119 million [US\$114 million] per year) to support local efforts to tackle homelessness. Research and data collection are other areas where efforts have been made to better understand Canadian health disparities. The 
Public Health Agency of Canada includes in its mandate reporting on health disparities among the population. Also, the CIHI hosts the Canadian Population Health Initiative, which was established to examine population health patterns and help inform policies to reduce inequities and improve health.

\section{Who is responsible for population health?}

In Canada, responsibility for population health is spread across levels of government. At the federal level, the Public Health Agency of Canada, established in 2004, is responsible for public health, emergency preparedness and response, and infectious and chronic disease control and prevention. Health Canada plays a role in promoting health, disease surveillance and control, food and drug safety, and the review of medical devices and technology.

Meanwhile, provincial governments set province-wide priorities for population health, while health regions are responsible for establishing local priorities and for the health of a population in a given geographic area. However, there is variation in the scope of responsibilities that have been devolved by central governments to regional health authorities in each province, e.g., Ontario, where public health remains separate from the regional purchaser.

\section{What is the status of electronic health records?}

Canada Health Infoway, a federally funded independent not-for-profit organization, works with governments and health organizations to accelerate the adoption of electronic health records and other electronic health information systems (e.g., telehealth, public health surveillance). Uptake of health information technologies has been slowly increasing in recent years. The Commonwealth Fund International Health Policy Survey (2012) of physicians showed that 57 percent of primary care physicians used computerized patient charts, with a range of 26 percent to 74 percent across the provinces (Health Council of Canada, 2013). The provinces/territories are responsible for developing their electronic health information systems, with support from Canada Health Infoway; there is no national patient identifier. Six electronic data collection systems have been identified as requisites of an electronic health record: client and provider demographics, diagnostic images, dispensed drugs, laboratory test results, and clinical reports on immunizations. These systems are in place for about 55 percent of Canadians, with variations among provinces/territories (Canada Health Infoway, 2013).

\section{How are costs contained?}

Costs are controlled principally through single-payer purchasing power, and increases in real spending mainly reflect government investment decisions and/or budgetary overruns. Cost control measures include mandatory annual global budgets for hospitals and regional health authorities, negotiated fee schedules for health care providers, drug formularies, and reviews of the diffusion of technology. They also include human resource restrictions vis-à-vis physicians and nurses.

The federal Patented Medicine Prices Review Board, an independent, quasi-judicial body, regulates the introductory prices of new patented medications in Canada. The Review Board's mandate is to ensure that patented drug prices are not "excessive," on the basis of their "degree of innovation" and through a comparison with the prices of existing medicines in Canada and in seven other countries including the United States and the United Kingdom. The Review Board regulates the "factory gate" prices but does not have jurisdiction over prices 
charged by wholesalers or pharmacies, or over pharmacists' professional fees. However, the review of prices of all patented drugs is conducted on a regular basis and the Review Board can intervene if price increases are deemed excessive. Jurisdiction over prices of generic drugs and control over pricing and purchasing under public drug plans (and, in some cases, pricing under private plans) is held by the provinces, leading to some interprovincial variation in drug prices.

\section{What major innovations and reforms have been introduced?}

Financing reforms: In December 2011 the federal government made a unilateral decision to reform the Canada Health Transfer block grants in fiscal year 2013-2014 (the end date of the 10-Year Plan to Strengthen Health Care). After 2014, federal funding will be distributed to provinces on a purely per capita basis, ending the current provisions to compensate for variations in tax bases across provinces that benefited the less wealthy provinces.

Mental health: In May 2012, the federally funded Mental Health Commissions of Canada (set up in 2007) published the first national mental health strategy, Changing Directions, Changing Lives: The Mental Health Strategy for Canada. The strategy calls for, among other things, an increase in federal and provincial funding for mental health.

Cost containment: Following the recent economic recession, federal and provincial/territorial governments face harder budget constraints. Recent reforms aim to contain costs and to achieve better value for money (Stabile et al., 2013). Many provinces have reduced the prices of generic drugs in recent years, and in 2013 all provinces/territories but Quebec initiated bulk purchasing of six of the highest-selling generic drugs. Other areas, such as Saskatchewan and Manitoba, have applied "lean" production methodologies to health care delivery, following the lead of the Institute for Healthcare Improvement (Marchildon, 2013b).

Integrating care: Several provinces are also making efforts to integrate funding and the delivery of care across the health care continuum. For example, the Ontario government recently announced the creation of "Health Links," which aim to improve the coordination of care for the top $1 \%-5 \%$ of users of the health care system by giving joint responsibility to organizations across multiple sectors. Lead organizations have been assigned to pull together these partners to help coordinate care in a given geographic location.

The authors would like to acknowledge Diane Watson as a contributing author to earlier versions of this profile.

\section{References}

Canada Health Infoway (2013). Annual Report 2012-2013. Ottawa: Canada Health Infoway.

Canadian Institute for Health Information (2012a). National Health Expenditure Trends 1975-2012. Ottawa: Canadian Institute for Health Information.

Canadian Institute for Health Information (2011). Scott's Medical Database, 2010. Ottawa: Canadian Institute for Health Information.

Canadian Institute for Health Information (2012b). National Physician Database, 2010-2011. Ottawa: Canadian Institute for Health Information. 
Canadian Institute for Health Information (2008). Health Care Use at the End of Life in British Columbia. Ottawa: Canadian Institute of Health Information.

Canadian Life and Health Insurance Association Inc. (CLHIA) (2012). Facts \& Figures: Life and Health Insurance in Ontario.

Health Council of Canada (2013). .

Henry, D.A., Schultz, S.E., Glazier, R.H., Bhatia, R.S., Dhalla, I.A., and Laupacis, A. (2012). Payments to Ontario Physicians from Ministry of Health and Long-Term Care Sources 1992/93 to 2009/10. Toronto: Institute for Clinical Evaluative Sciences.

Marchildon, G.P. (2013a). Canada: Health system review. Copenhagen: WHO Regional Office for Europe on behalf of the European Observatory on Health Systems and Policies.

Marchildon, G.P. (2013b) “Implementing Lean Health Reforms in Saskatchewan,” Health Reform ObserverObservatoire des Réformes de Santé vol 1, iss. 1, article 1. Available at: http://digitalcommons.mcmaster.ca/hro-ors/ voli/issi/1

Stabile, M., Thomson, S., Allin, S., et al. (2013). "Health Care Cost Containment Strategies Used in Four Other High-Income Countries Hold Lessons for the United States.," Health Affairs 32 (4):643-652.

OECD Health Data, 2013. 


\title{
The Danish Health Care System, 2013
}

\author{
Karsten VRangbaek, University of Copenhagen
}

\section{What is the role of government?}

The Danish national government sets the regulatory framework of health services, and is in charge of their general planning and supervision. Five regions are responsible for planning and delivery of specialized health services. The regions own, manage, and finance hospitals and finance the majority of services delivered by general practitioners (GPs), office-based medical specialists, physiotherapists, dentists, and pharmacists. Ninety-eight municipalities are responsible for nursing homes, home nurses, health visitors, municipal dentists (children's dentists and home dental services for physically and/or mentally disabled people), school health services, home help, and the treatment of drug abuse.

\section{Who is covered?}

Coverage is universal. All those registered as residents in Denmark are entitled to publicly financed health care that is largely free at the point of use. In principle, undocumented immigrants or visitors (estimated to number below 2,000) are not covered, but a national voluntary and privately funded initiative by Danish doctors provides access to health care for that population; the Doctors' Association, the Danish Red Cross, and Danish Refugee Aid also support participating clinics. Complementary private voluntary health insurance (VHI), provided by a not-for-profit organization, Danmark, covers cost-sharing for pharmaceuticals, dental care, physiotherapy, and corrective lenses. Almost 40 percent of the population is covered by this type of cost-sharing insurance. Various supplementary VHI plans, offered typically by employers, provide access to private treatment facilities and provide lump sums in case of critical illness. This type of insurance is held mostly by persons employed in the private sector, although some public sector employees are also covered. Persons outside the job market (students, pensioners, the unemployed, etc.) are generally not covered by supplementary VHI, as this type of insurance is mostly provided as a fringe benefit.

\section{What is covered?}

Services: The publicly financed health system covers all primary, specialist, and hospital services. Preventive services, mental health services, and long-term care are also fully covered. Dental services are fully covered for children under 18. There is subsidized coverage of outpatient prescription drugs, adult dental care, physiotherapy, home care, and optometry services as described further below. Temporary home care is not covered, but permanent home care coverage provided by the municipalities is need-based (and not means-tested). The municipalities are obliged to organize markets for home care services, and patients may choose between public or private providers. In practice, it has been difficult to attract private providers to some remote municipalities, while that "market" functions relatively well in other municipalities; a considerable number of the elderly choose private providers.

Decisions about service level and the introduction of new medical treatments are made by the regions, but are based on national recommendations and guidelines. Municipalities decide on the service level for most other welfare services including social care, care for older people, prevention, and some rehabilitation. The regional 
and municipal authorities make their decisions within a framework of national legislation, national agreements, and national guidelines and standards. There is no defined benefits package, and very few restrictions exist for treatments that are evidence-based and clinically proven.

Cost-sharing: There is no cost-sharing for hospital and primary care services. Cost-sharing is applied to dental care for those age 18 and older (coinsurance of $35 \%$ to $60 \%$ of the cost of treatment), outpatient prescriptions, and corrective lenses. An individual's annual outpatient drug expenditure is reimbursed at the following levels: below DKK865 (US\$157), no reimbursement (60\% reimbursement for minors); DKK865-1,410 (US\$157-255), 50 percent reimbursement (60\% reimbursement for minors); DKK1,410- DKK3,045 (US\$255-551), 75 percent reimbursement; above DKK3,045 (US\$551), 85 percent reimbursement (Mutual Information System on Social Protection, 2011). Private specialists, hospitals, and dentists are free to set their own fees for private patients, who often pay out of pocket for minor interventions but are usually covered through VHI for major (inpatient) interventions.

Safety net: There are maximum cost-sharing limits for children, and municipalities provide means-tested social assistance to older persons ( $85 \%$ of all prescription drug costs are covered if personal wealth is DKK 77,500 [US\$14,031] or below). Chronically ill people with high prescription drug usage and costs can apply for full drug expenditure reimbursement above an annual out-of-pocket ceiling of DKK3,410 (US\$617). Those who are terminally ill can also apply for full coverage of prescriptions. Municipalities may grant financial assistance to persons certified as otherwise unable to pay for needed medicine.

\section{How is the health system financed?}

Publicly financed health care: Public expenditure accounted for around 85.3 percent of total health expenditure in 2011 (Organisation for Economic Co-operation and Development, 2013). A major administrative reform in 2007 (further described below) gave the central government responsibility for financing health care, whereas previously, regional governments held that responsibility and received income through taxes and block grants from the state in order to do so. Health care is now financed mainly through a centrally collected "health tax" set at 8 percent of taxable income. The central government reallocates tax income to the regions and municipalities, mostly as block grants based on a complex formula that takes the demographic and social differences between the municipalities and regions into consideration (a sort of risk-adjusted capitation formula). Around 80 percent of the regional health expenditures are financed through block grants. A minor portion of the state funding for regional and municipal activities is activity-based or tied to specific political priority areas, which are often defined in the annual "economic agreements" entered between the government and the municipalities/regions. Around 20 percent of regional hospital services are financed by a municipal activity-based copayment introduced in 2007.

Privately financed health care: The total share of private expenditure for health care was 14.7 percent in 2011 (OECD, 2013). Out-of-pocket payments represented 12.8 percent of total health expenditures. Private expenditure for outpatient drugs, corrective lenses and hearing aids, and doctor and dentist treatments accounted for 4.2 percent, 2.4 percent, and 6.0 percent of total health expenditure, respectively. Complementary VHI, purchased on an individual basis and covering the costs of statutory copayments (mainly for pharmaceuticals and dental care) and services not fully covered by the state (some physiotherapy, etc.), has been common since the 
1970s and is provided exclusively by the not-for-profit organization Danmark. This scheme covered around 2 million people in 2007 (36\% of the population).

The past decade has seen a rapid growth in the number of people covered by supplementary VHI policies offering access to private providers; that number rose from 130,000 in 2002 to almost 1 million in 2008 . The policies are purchased mostly from among seven for-profit insurers on a group basis and are provided through employers as a fringe benefit. A further 2.2 million policies provide a lump sum in case of critical illness. One goal of the liberal-conservative government (2002-2011) was to facilitate a stronger role for private actors in health care, e.g., by exempting supplementary VHI provided by employers from taxation. Interestingly, this type of VHI has declined only slightly since the current government removed the tax exemption in 2011.

\section{How are health services organized and financed?}

Primary care: All GPs are self-employed and are paid by the regions via a combination of capitation (30\%) and fee-for-service (FFS, 70\%). The FFS system provides financial incentives and is used as a tool to prioritize services: it recently introduced fees for e-mail consultation and a "bundled payment" for providing and documenting services to diabetes patients according to an evidence-based disease management program. Practice structure is gradually shifting from solo to group practice; more and more practices operate in teams. The number of nurses employed in general practice has increased in the past decade. They are paid by the practice and have gradually taken over many simple tasks such as blood sampling and vaccination. Colocation is also on the rise, with municipal services, physiotherapists, GPs, and office-based specialists operating from the same facilities but with separate management.

Registration with a GP is required for anyone who chooses the Group 1 coverage option (98\% of the population), under which GPs act as gatekeepers for secondary care. People can register with any available local GP. The alternative is Group 2 coverage, which provides free choice of GP and access to practicing specialists without a referral but requires a copayment. Under both groups, access to a hospital requires a referral.

Outpatient specialist care: Outpatient specialist care is delivered through hospital-based ambulatory clinics (fully integrated and funded, as are other public hospital services) or is provided by self-employed specialists in privately owned facilities. Services from self-employed private providers are paid for by the regions on an FFS basis for referred public patients. The fees are set through negotiations with the regions and are based on regional priorities and resource assessments. Private specialists are paid negotiated individual FFS rates for VHI and out-of-pocket services. Denmark has had a significant reduction in average length of stay in hospital: down from 4.4 days in 2008 to 3.7 in 2012 (Ministry of Health, 2013).

After-hours care: The regions are required to organize after-hours care. In most regions this is done by agreement with GPs on a collective basis, while the Copenhagen region has changed to a system with employed staff, including specialized nurses who do the initial screening of calls. GPs can volunteer to take on more or less responsibility within this scheme, and receive a higher rate of payment for after-hours than for normal care. The first line of contact is a phone service, with a GP (or a specialized nurse in the Copenhagen region) deciding whether to refer the patient for a home visit or to an after-hours clinic, which is usually colocated with hospital 
emergency departments. Home visits are carried out for acute cases and for patients who are not mobile. Information on patient visits is sent routinely to GPs.

Hospitals: Almost all hospitals are publicly owned (approximately $97 \%$ of hospital beds). The regions decide on budgeting mechanisms for hospitals and generally use a combination of fixed-budget and activity-based funding based on diagnosis-related groups (DRGs). The activity-based funding is usually combined with target levels of activity and declining rates to maintain control of the overall expenditure. This strategy has succeeded in increasing both activity levels and productivity by an average of 5 percent annually from 2009 to 2011 . Bundled payments are considered, but are not yet used extensively by the regions. Hospital physicians are salaried and employed by the regions. Health care professionals in hospitals and in most municipal health services are paid a salary. Patients can choose what public hospital to go to when referred by a GP, and the payment follows the patient to the receiving hospital if the hospital is located in another region. For all procedures, a waiting time guarantee extends choice to private facilities in cases where expected waiting times exceed threshold levels of 1-2 months from referral to treatment. Physicians at public hospitals are not allowed to see private patients.

Mental health care: There is no cost-sharing for inpatient psychiatric care, which is organized regionally as part of the hospital system and funded by DRGs, but there is some cost-sharing (which may be covered by VHI) for psychologists in private practice. Social psychiatry and care are a responsibility of the municipalities, which can choose to contract with a combination of private and public service providers, but most are public and work on a salary basis.

Long-term care: Responsibility for chronic care is shared between regional hospitals, GPs, and municipal institutional and home-based services. Hospital-based ambulatory chronic care is financed in the same way as other hospital services. Long-term care outside of hospitals is needs-based, and is organized and funded by the municipalities. Most municipal long-term care takes place in citizens' own homes, while the role of institutionalized care (nursing homes, "protected housing," etc.) has been reduced over the past three decades because of conscious policy efforts to support citizens in "staying in their own home" as long as possible. Home nursing (hjemmesygepleje) is fully funded after medical referral. Permanent home care (hjemmehjælp) is free of charge, while temporary home care can qualify for cost-sharing if income is above DKK138,600 (US $\$ 25,093$ ) for singles and DKK208,200 (US\$37,694) for couples. The municipalities are obliged to organize markets with open access for both public and private providers of home care (personal and practical help), in order to accommodate free choice of home care services. A few municipalities have also contracted with private institutions for institutional care of older people, but more than 90 percent of residential care institutions (nursing homes) remain public. Citizens pay 10 percent of their income ( $20 \%$ of income above DKK145,600 [US $\$ 26,361$ ]) plus heating and electricity charges for staying in residential care institutions.

Hospices are organized by the regions and funded by the regions and municipalities, and may be public or private. There is free choice of hospice upon referral.

\section{What are the key entities for health system governance?}

General regulation, planning, and supervision of health services take place at the national level through the Ministry for the Interior and Health and the Danish Health and Medicines Authority. The Danish Health and 
Medicines Authority is responsible for general supervision of health personnel, and also undertakes important tasks in developing quality management in line with national clinical guidelines and standards for the national quality program, etc. These activities usually take place in close collaboration with representatives from medical societies. The Danish Health and Medicines Authority also has important roles in planning the location of specialist services, approving regional hospital plans, and making mandatory "health agreements" between regions and municipalities to coordinate service delivery. Hospital productivity comparisons are published on a regular basis by the Danish Health and Medicines Authority, allowing regions and hospital managers to benchmark performance of individual hospital departments.

Regions are in charge of defining and running hospital services and supervising and paying GPs and practicing specialists. Municipalities have important roles in regard to prevention, health promotion, and long-term care.

Apart from the government, semi-independent organizations also play a governance role. The Danish Healthcare Quality Programme (DDKM) consists primarily of medical professionals, and works to develop extensive accreditation standards that influence quality across all health care sectors. It is developed, planned, and managed by the Danish Institute for Quality and Accreditation in Healthcare (IKAS), a board that comprises representatives from the Danish Health and Medicines Authority, the Danish regions, and the Ministry of Health. The International Society for Quality in Healthcare (ISQua) in turn oversees both the DDKM and the IKAS.

\section{What is being done to ensure quality of care?}

The DDKM, which is based on extensive accreditation standards, has now been implemented in all hospitals, and is in the process of being introduced in primary care and pharmacies. It aims to include all health care delivery organizations, and applies both organizational and clinical standards. The core of the program is a system of accreditation based on annual self-assessment and external evaluation (every third year) by a professional accreditation body. The self-assessment involves reporting of performance against national input, process, and outcome standards, which allows comparison over time and between organizations. The external evaluation considers the self-assessment when determining the status of providers' overall quality improvement activities and opportunities. Quality data for a number of treatment areas are captured in clinical databases and published on the Web. The data are used for a variety of purposes, including patients' choice of hospitals and the management of hospital quality.

Standard treatment packages (patient pathway descriptions) have been established, with priorities that include targeting chronic diseases with prevention and follow-up interventions. In 2007, the Danish government, regions, and municipalities committed to developing and implementing national care pathways for all types of cancer, based on national clinical guidelines, with the aim of ensuring that all cancer patients receive fasttracked care through all stages of care. At the end of 2008, pathways for 34 cancers had been finalized and implemented, covering almost all cancer patients. The Danish Health and Medicines Authority also monitors the pathways and the speed at which patients are diagnosed and treated. The DDKM's standards enforce the use of these pathway programs and national clinical guidelines, where available. A national unit within the Danish Health and Medicines Authority is gradually developing such guidelines for all major disease types. The regions develop more-specific practice guidelines for hospitals and other health organizations, based on 
general national recommendations. There are no explicit standardized sanctions or economic rewards tied to performance monitoring. The regions take action in case of poor results, and may fire hospital managers or introduce other measures to support quality improvement. The Danish Health and Medicines Authority may step in if entire regions fail to live up to standards.

Health technology assessments are made locally, regionally, and nationally. They are facilitated and financially supported by a national unit within the Danish Health and Medicines Authority and provide important input to decision-making in health policy at all levels.

One of the Danish Health and Medicines Authority's main responsibilities, supported by the regions, is patient safety. Health care staff members at all levels (including GPs and municipal health services staff) are obliged to report accidents and near-accidents to regional authorities, who evaluate incidents and send anonymized reports to the Danish Health and Medicines Authority. The information is then published in an annual database. The system is geared toward learning rather than sanctioning.

\section{What is being done to improve care coordination?}

Mandatory health agreements between municipalities and regions were introduced in 2007 to promote coordination across municipal care services, primary care and hospital care. These agreements include a number of mandatory topics related to admission and discharge from hospitals, rehabilitation, prevention, psychiatric care and IT support systems. Formal targets for progress must be included in the next generation of agreements to be finalized in 2014. The agreements are formalized at least once in each four-year election term for municipal and regional councils, and must be approved by the Danish Health and Medicines Authority. The performance of regions and municipalities in reaching the goals of the agreements is measured by national indicators published on the internet (www.esundhed.dk). The agreements generally take the form of shared standards for action in different parts of the patient journeys in the system. They are partially supported by IT systems with information that is shared between the different care givers.

The regions and municipalities have implemented many different organizational measures to promote integration of care. Examples include the use of outreach teams from hospitals doing follow up visits in patients' homes after discharge; training programs provided by the regions for municipal nursing and care staff; establishing municipal units located within hospitals to facilitate communication, particularly in regards to discharge; and the use of "GP practice coordinators" to facilitate communication.

More and more practices employ specialized nurses, and several municipalities and regions have provided financial support to set up multi-specialty facilities, commonly called "health houses." The models vary across the country, but often include GPs, practicing specialists, physiotherapists, and others. Medical homes are encouraged in the sense that GPs are intended to function as coordinators of care for patients, and to develop a comprehensive view of their patients' individual needs in terms of both prevention and care. This principle is commonly accepted, and is supported by the general national-level agreements between GPs and the regions. GPs participate in various formal and informal network structures and are included in the health service agreements made between the regions and the municipalities to facilitate cooperation and improve patient 
pathways. All GPs are linked to electronic information systems that provide discharge letters and can be used for electronic referrals and pharmacy prescriptions.

\section{What is being done to address health disparities?}

A government-initiated report in 2011 on the determinants of health disparities led to the formulation of a general action plan with initiatives including: higher taxes on tobacco and unhealthy food; targeted interventions to promote smoking cessation; prohibition of the sale of strong alcohol to young people; establishment of antialcohol policies in all educational institutions; further encouragement of municipal disease prevention activities (e.g., through increased municipal cofinancing of hospital care for residents, which in principle creates economic incentives for municipalities to keep their citizens healthy and out of hospitals); an action plan for improved psychiatric care; and a mapping of health profiles in all municipalities, to be used as a tool for targeting municipal disease prevention and health promotion activities.

\section{Who is responsible for population health?}

The responsibility for population health is shared between the various levels of the health system. National authorities (the Danish Health and Medicines Authority and SSI Statens Serum Insitut) monitor the health status of the population, and the former is responsible for intervening if regions and municipalities do not deliver adequate services. These authorities also organize a system of health officers placed in the five regions with responsibility for monitoring and intervening in the event of general health threats such as epidemics or environmental health hazards.

The municipalities are responsible for general population-oriented prevention and health promotion activities. They are generally focusing on the so-called "KRAM" factors of nutrition, drugs, alcohol, and exercise but may also select other target areas. The municipalities have autonomy to design interventions, and there are no binding national goals. A recent report from the General Accounting Office recommended that such targets should be introduced by the national authorities (Rigsrevisionen, 2013).

\section{What is the status of electronic health records?}

Information technology (IT) is used at all levels of the health system. The national strategy for use of IT in health care is supported by the National Agency for Health IT, National Sundheds-it. Each region has developed its own electronic patient record system for hospitals, with adherence to national standards for compatibility. Danish GPs were ranked first in a 2008 report by the European Commission on the use of health IT in Europe. All citizens in Denmark have a unique personal ID, which is used for identification in all public registries including health databases. A shared, e-based "medical card" with all information on a person's prescriptions and use of drugs is currently being implemented (although with some delays). GPs also have access to an online medical handbook with updated information on diagnosis and treatment recommendations. Another initiative is the gradual implementation of clinical databases to monitor quality in the primary care sector (DataFangst). In addition, Sundhed.dk is a national IT portal, with differentiated access for health staff and the wider public, that provides general information on health and treatment options and access to individuals' own medical records and history. For professionals, the site serves as an entry to medical handbooks, scientific articles, treatment guidelines, hospital waiting times and treatments offered, etc. They may also use the system to view records and laboratory test results for their own patients. The portal also provides access to the available quality 
data for primary care clinics, all of which use IT for electronic records and communication with regions, hospitals, and pharmacies.

\section{How are costs controlled?}

Annual negotiations between the central government, regions, and municipalities result in agreements on the economic framework and a national budget cap for the health sector, including overall levels of taxation and expenditure targets. These are further reinforced by a recently introduced "budget law" (2012) that sets budget levels for regions and municipalities, and specifies automatic sanctions if they are exceeded. At the regional and municipal levels, management tools used to control expenditure include hospital contracts, reductions in DRG rates paid to hospitals beyond predetermined threshold levels of activity, and general expenditure monitoring. Policies to control pharmaceutical expenditure include generic substitution by doctors and pharmacists, prescribing guidelines, and assessment by the regions of deviations in physicians' prescribing behavior.

Pharmaceutical companies report prices to the Danish Health and Medicines Authority on a monthly basis. The price list is provided to pharmacies, and they are obliged to choose the cheapest alternative with the same active ingredient, unless the prescribing doctor has explicitly stated that he or she prefers a specific drug. Patients may choose more-expensive drugs, but have to pay the difference in price. Pharmaceutical expenditure at the hospital level is controlled through monitoring and guidelines at the clinical level and coordinated purchasing strategies at the hospital level.

\section{What major innovations and reforms have been introduced?}

The 2007 structural reform sought to centralize the administration of hospital care in order to enhance the coordination of service delivery and to improve quality and efficiency. It merged the 14 counties to create five regions and reduced the number of municipalities from 275 to 98 . The regions are currently reorganizing their hospital systems, closing or amalgamating small hospitals and building new hospital infrastructure, at a total cost of DKK40 billion (US\$7.2 billion). Reorganization of acute care with stronger pre-hospital services and larger specialized emergency departments is an important aspect of this new structure. The Danish Health and Medicines Authority has also issued new guidelines for the localization of specialized treatments and departments; generally these guidelines support centralization. The structural reform also introduced municipal costsharing (about $20 \%$ of the cost of treatment) for hospital services to encourage municipalities to pay more attention to prevention and health promotion. Mandatory agreements between municipalities and regions are also intended to promote collaboration. These agreements are formalized at least once in each four-year election term for municipal and regional councils, and must be approved by the Danish Health and Medicines Authority.

\section{References}

Ministry for Health and Prevention (Web site: http://www.sum.dk). Copenhagen.

Ministry of Health, 2013. Øget fokus på gode resultater på sygehusene http://www.sum.dk/Aktuelt/Nyheder/ Tal_og_analyser/2013/Maj/ /media/Filer\%20-\%20Publikationer_i_pdf/2013/Oeget-fokus/oeget-fokus-paa-goderesultater-paa-sygehusene-maj-2013.ashx 
MISSOC (2011). "The coordination of healthcare in Europe-Rights of insured persons and their family members under regulations."

National Agency for Health IT (National Sundheds-it [NSI]) (Web site: http://www.ssi.dk/Sundhedsdataogit/ National\%2oSundheds-it.aspx). Copenhagen.

Danish Health and Medicines Authority (Web site: http://www.sundhedsstyrelsen.dk). Copenhagen.

OECD Health Data, 2013.

Rigsrevisionen (2013). "Beretning om borgerrettet forebyggelse på sundhedsområdet.” http://www.rigsrevisionen.dk/publikationer/2013/102012/. Accessed June 20, 2013.

Strandberg-Larsen, M., Nielsen, M.B., Vallgårda, S., Krasnik, A., Vrangbæk, K., and Mossialos, E. (2007). "Denmark: Health System Review," Health Systems in Transition 9(6):1-164.

Sundhed.dk national portal for patients and providers (Web site: https://www.sundhed.dk). Copenhagen.

The Danish Healthcare Quality Programme (Web site: http://www.ikas.dk). Copenhagen. 


\title{
The English Health Care System, 2013
}

\author{
Anthony Harrison, The King's Fund, London
}

\section{What is the role of government?}

Responsibility for health legislation and general policy rests with Parliament, the Secretary of State for Health, and the Department of Health. The National Health Service (NHS) provides care, including hospital and physician services and prescription drugs, to all residents. Under the terms of the NHS Health and Social Care Act 2012, day-to-day responsibility for running the NHS has been handed over by the Department of Health and the Secretary of State for Health to a new governmental organization, the NHS Commissioning Board, subsequently renamed NHS England.

NHS England is responsible for managing the NHS budget, overseeing the newly created Clinical Commissioning Groups (CCGs), and ensuring that the objectives set out in a so-called mandate by the Secretary of State for Health are met by the NHS, including both efficiency and health goals. CCGs have replaced Primary Care Trusts as local health care purchasing organizations: the intention was that they should be clinically led, but although the clinical contribution has been strengthened, other professionals-e.g., managers and accountants-remain important. Budgets for public health have been handed over by the Department of Health to local government authorities; the 2012 Act requires them to establish Health and Wellbeing Boards to improve coordination of local services, with particular reference to the need to reduce health disparities.

\section{Who is covered?}

Coverage is universal. All those "ordinarily resident" in England are automatically entitled to health care that is largely free at the point of use through the NHS. People from most European countries are also entitled to free care if they have a European Insurance Card. Only treatment in an emergency department and for certain infectious diseases is free to people not ordinarily resident, such as visitors or illegal immigrants (Department of Health, 2010a). Most private hospital care-largely for elective conditions-is financed through supplementary private voluntary health insurance. The usual reason for acquiring such insurance is that it offers more rapid and convenient access to care.

\section{What is covered?}

Services: The precise scope of the NHS is not defined in statute or regulation. In practice, it provides or pays for: preventive services, including screening, immunization, and vaccination programs; inpatient and outpatient hospital care; physician services; inpatient and outpatient drugs; some dental care; some eye care; mental health care, including some care for those with learning disabilities; palliative care; some long-term care; rehabilitation, including physiotherapy (e.g., after-stroke care); and home visits by community-based nurses. Personal health budgets are available for those with continuing health needs, and will be more widely available in 2014. Personal budgets are already available for those receiving social care.

Cost-sharing: There are only a few cost-sharing arrangements for publicly covered services. Outpatient prescription drugs are subject to a copayment (currently $£ 7.85$ [US\$12.62] per prescription in England); drugs prescribed 
in NHS hospitals are free. NHS dentistry services are subject to copayments of up to a maximum of £214 (US\$344)per course of treatment. These charges are set nationally by the Department of Health.

Safety net: The following people are exempt from prescription drug copayments: children under the age of 16 years and those in full-time education aged 16-18; people age 60 or older; people with low income; pregnant women and those who have had a baby in the past 12 months; and people with cancer, certain long-term conditions, and/or disabilities. Patients who need a large number of prescription drugs on a regular basis can buy prepayment certificates costing $£ 29.10$ (US\$48) for a period of three months and $£ 104$ (US\$167) for 12 months. Users incur no further charges for the duration of the certificate, however many prescriptions they need. Fewer than 6 percent of prescriptions actually incur the full charge at the point of dispensing (NHS Information Centre, 2012a). Young people, students, pregnant and recently pregnant women, prisoners, and those with low incomes are not liable for dental copayments. Sight tests are free for young people, those over 60 and people on low incomes, and financial support is available to young people and those on low incomes to meet the cost of corrective lenses. Transportation costs to and from provider sites are also covered for people with low incomes.

\section{How is the health system organized and financed?}

Publicly financed health care: In 2011, England spent about 9.4 percent of its GDP on health care. Public expenditure, mainly on the NHS, accounted for about 83 percent of that amount (ONS, 2013). Around 76 percent of NHS funding comes from general taxation and 18 percent from national insurance (a payroll tax). The NHS also receives income from copayments, those using NHS services as private patients, and some other minor sources.

Privately financed health care: Most private expenditure is for over-the-counter drugs and other medical products (which together account for just over half of private spending) and private hospital care, including both insured and uninsured costs. Most private hospital care, largely for elective treatment, is financed through voluntary health insurance. About 11 percent of the U.K. population has voluntary insurance, the majority as workrelated benefits (Nuffield Trust, 2013). In addition, just over a million people are covered through self-insuring schemes run by employers. Private providers must be registered with the Care Quality Commission and with Monitor, an economic regulator of public and private providers (described further below), but their charges to private patients are not regulated by the government, and there is no public subsidy for either voluntary insurance or provision of private care.

\section{How are health services organized and financed?}

Primary care: Primary care is delivered mainly through general practitioners (GPs). In 2012, there were 40,265 GPs in 8,088 practices, with an average of 6,891 patients per practice and 1,562 patients per GP. The number of solo practices is currently 1,480, while there are now 3,525 practices with five or more GPs (NHS Information Centre, 2013). GPs are normally patients' first point of contact, and people are required to register with a local GP. In principle, patients are allowed to choose their GP but in practice choice is limited because many GPs have a full panel and do not accept new patients. In some areas, walk-in centers offer primary care services, for which registration is not required.

Most GPs are private contractors operating under a national contract and are paid using a mixture of capitation, contract payments for specific services such as running flu clinics, and performance-related bonuses 
mostly linked to care for people with long-term conditions. The bonuses account for about one-quarter of GPs' income. Although still a minority (around 20\%), the number of GPs employed in practices as locums (e.g., standing in when GPs are unavailable because of illness, training courses, etc.) or on a salaried basis is increasing. Most GP practices employ other professionals such as nurses, who carry out monitoring measurements, e.g., blood pressure, and minor treatments such as wound dressing. Private providers of GP services set their own fee-for-service rates. GPs act as gatekeepers to specialist care.

Primary care dental services are delivered through contracts with dentists or dental practices for an agreed level of dental services per year within the framework of a nationally determined contract. Most dentists provide both NHS and private care. Eye services outside hospitals are provided almost entirely by the private sector.

Outpatient specialist care: Specialists are almost all salaried employees of NHS hospitals; payments for outpatient consultations are made to hospitals at nationally determined rates. Patients are able to choose which hospital to visit, and the government has introduced the right to choose a particular specialist within a specific hospital (not yet fully implemented). Most outpatient specialist consultations are carried out in hospitals, although consultation may take place in GP practices. Some GPs, called GPs with specialist interests, also offer specialist consultations.

After-hours care: Individual GPs are no longer required personally to provide after-hours care to their patients (a small minority still do so), but are required to ensure that adequate arrangements are in place. In practice, this means that CCGs contract for most of these services mainly with GP cooperatives and private companies, both of which usually pay GPs on a per-session basis. Serious emergencies are handled by hospital emergency departments. In some areas, less serious cases are seen in urgent care centers or minor-injury units. Telephone advice is available on a 24-hour basis through NHS111, a new service introduced in 2013 to replace NHS Direct, for those with an urgent but not life-threatening condition. Details of the care provided by these services are usually sent to the patient's GP.

Hospitals: Publicly owned hospitals are organized either as NHS trusts, which are directly accountable to the Department of Health, or as Foundation Trusts. Foundation Trusts enjoy greater freedom from central control, have easier access to capital funding, and are able to accumulate surpluses or run (temporary) deficits. The government wants all hospitals (as well as mental health and ambulance services) to become Foundation Trusts in the near future. Both types of hospitals contract with local commissioners to provide services to local populations and are reimbursed for most of those services at the same nationally determined diagnosis-related group (DRG) rates. These rates (which include the costs of medical staff) are set nationally and account for about 60 percent of hospital income. The rates are not universally applied: in some areas payments are made for a whole service, such as emergency care. Also at the local level, tariffs for "years of care," e.g., for the total cost of the care of diabetic patients over 12 months, are being developed, but are not yet in widespread use. There is no cap on hospital incomes.

Public funds have always been used to purchase some hospital care from the private sector-for example, for mental health patients-but the level has grown in recent years. From 2003 , some routine elective surgery and diagnostic services have been procured for NHS patients from freestanding treatment centers owned and staffed by private-sector providers. However, the private sector contribution remains low, at around 4 percent 
of all NHS elective operations. Specialist doctors are employed by NHS hospitals on a salaried basis, but may supplement their salary by treating private patients within specially designated wards in NHS hospitals or within private hospitals. Over 50 percent of NHS specialists work concurrently in the private sector (Office of Fair Trading, 2011).

Mental health care: Mental health care is an integral part of the NHS. Less serious illnesses, including chronic conditions such as mild depressive and anxiety disorders, are usually dealt with by GPs, but those requiring more advanced treatment, including inpatient care, are treated by mental health or hospital trusts. Some of these services are provided by community-based staff. About a quarter of mental health care hospital-based services are provided by the private sector.

Long-term care: The NHS pays for some long-term care (e.g., for those with continuing medical or skilled nursing needs), but in recent years its role has been substantially reduced. Most long-term care is referred to as adult social care, and is provided by local authorities and the private sector. State-funded residential care is means-tested and is available free only to those with less than $£ 23,250$ (US\$37,387) in assets. The level of charges for state-funded social care provided at home depends on a local council's interpretation of the national framework for eligibility, and therefore varies from area to area. In 2009, the private sector provided 78 percent of residential care places for the elderly and physically handicapped in the U.K. (including England, Northern Ireland, Scotland, and Wales), with the local authority providing 8 percent and the voluntary sector 14 percent (Laing and Buisson, 2012). End-of-life palliative care is provided by the NHS to patients at home, in hospices (usually run by charitable organizations), in care homes, or in hospitals. Separate government funding is available to people with disabilities according to national eligibility criteria.

\section{What are the key entities for health system governance?}

The Department of Health and the Secretary of State for Health are ultimately responsible for the management of the health system as a whole. However, the Health and Social Care Act 2012 transferred important functions to a new organization, the NHS Commissioning Board (now called NHS England), including overall budgetary control and, along with Monitor (described below), responsibility for setting DRG rates for provision of NHS services. NHS England also commissions some specialized low-volume services such as pediatric heart surgery, national immunization and screening programs, and primary care services including general practice, dentistry, and pharmacy. The National Institute for Health and Clinical Excellence (NICE) sets guidelines for the NHS on clinically effective treatments and appraises new health technologies for their efficacy and cost-effectiveness; all drugs or interventions that NICE evaluates as clinically effective and cost-efficient are available in the NHS. The Care Quality Commission ensures basic standards of safety and quality through a provider registration system, and also monitors the care standards actually achieved (described further below). It can require the closure of services if serious quality concerns are identified.

Monitor is responsible for authorizing NHS trusts to become Foundation Trusts and monitoring their financial performance, with powers to intervene if performance deteriorates significantly. The 2012 Act extended Monitor's role to being the economic regulator of public and private providers. In this capacity, it licenses all providers of NHS-funded care and may investigate potential breaches of the NHS cooperation and competition rules (a form of antitrust code), as well as investigating mergers involving NHS foundation trusts. Where such 
mergers are found to be prima facie undesirable, they are referred to the two national competition authorities, the Office of Fair Trading and the Competition Commission. The 2012 Act provides for the establishment of a new national body, Healthwatch England, to promote patient interests and forto establishing local Healthwatches in each locality. The local Healthwatches support people who make complaints about services, and may report quality concerns to Healthwatch England, which can then recommend that the Care Quality Commission take action.

\section{What is being done to ensure quality of care?}

Since the publication of the Department of Health report High Quality Care for All (2007), there has been an increased emphasis on improving the quality of care provided by the NHS. In 2009, the Care Quality

Commission took over responsibility for the regulation of all health and adult social care in England, including care provided by the NHS, local authorities, the private sector, and the voluntary sector; all health and social care providers must be registered with the Care Quality Commission. The Commission monitors provider performance using nationally set quality standards, and investigates individual providers where concerns have been raised (e.g., by patients). It can close down poorly performing services. NICE is charged with developing quality standards for covering the most common conditions in primary, secondary, and social care. National strategies have been published for a range of conditions including cancer, trauma, and stroke. Maximum waiting times have been set for access to cancer treatment and to elective treatments such as orthopedic procedures, and for treatment within emergency rooms. A Web site, NHS Evidence, has been established to provide professionals and patients with up-to-date clinical guidelines for a wide range of conditions. Support for quality improvement is also provided by NHS Quality Improvement, part of NHS England.

The Quality and Outcomes Framework, introduced as part of the new GP contract in 2004, provides GP practices with financial incentives to improve quality. GP practices are awarded points (the total of which determines part of their remuneration) for keeping a disease register of patients with certain diseases or conditions, managing and treating patients with those conditions, and improving the health of affected patients by, for example, helping them to control their blood pressure or cholesterol levels. These incentives make up, on average, a quarter of a GP's income. For hospitals, 2.5 percent of contract value is linked to the achievement of a limited number of quality goals through a scheme known as CQUIN (Commissioning for Quality and Innovation). In addition, DRG rates for some procedures are linked to best practice.

Since 2010, acute care and mental health care providers have had to produce annual "Quality Accounts," publicly reporting on the quality of services they provide in terms of safety, effectiveness, and patient experience; the primary aim is to provide patients with information about provider performance. These reports are not comprehensive but they must include the complete results of the national audits currently in operation as well as a statement of their current priorities for quality improvement. In the future, Quality Accounts will be extended to other care settings such as general practice.

All doctors practicing in the U.K. are required by law to have a license to practice from the General Medical Council. Similar requirements apply to all professions working in the health sector. A process of revalidation every five years is being introduced for doctors. 


\section{What is being done to improve care coordination?}

GPs increasingly work in multipartner practices employing nurses and other clinical staff, who carry out much of the routine monitoring of patients with long-term conditions. GP practices provide most of the features of a medical home: they direct patients to specialist services in hospitals or to community-based professionals such as dieticians and community nurses, and they hold all treatment records for patients registered with them. GPs are not paid a specific amount for care coordination; such activity is carried out as part of their overall contract. As noted above, GPs have financial incentives to provide continuous monitoring of patients with the most common chronic conditions such as diabetes and heart disease.

The 2012 Act introduced new responsibilities to promote integrated care, i.e., closer working links between hospital- and community-based health services, including primary care and social care. NHS England, Monitor, and CCGs are all charged by the Act with a duty to promote integration. The Health and Wellbeing Boards within local authorities are intended to promote integration between NHS and local authority services, particularly at the interface between hospital and social care. In 2013, it was announced that a number of pilot integration schemes would be established, designed to promote integration "at scale and at pace."

\section{Who is responsible for population health?}

Under the terms of the mandate set by the Department of Health, NHS England is responsible for improving the health of the English population against a set of indicators set out in the NHS Outcomes Framework relating to quality, safety, patient experience, premature death, and recovery from treatment. In practice, the main responsibility for population health rests with CCGs. They are accountable to NHS England for their degree of success (or otherwise) in improving the health of their populations.

As noted above, public health programs such as anti-smoking campaigns and the promotion of exercise programs to reduce obesity are now the responsibility of local authorities. These are also expected to use their powers in relation to housing, planning, transport, and the environment to improve the health of their residents. Immunization and vaccination programs remain the responsibility of the NHS at the national level.

\section{What is being done to reduce health disparities?}

The 2012 Act places duties on the Secretary of State, NHS England, and CCGs to "have regard" to the need to reduce health disparities, although this does not entail specific courses of action. Also, a new body, Public Health England, has been established to support the public health functions of local authorities, including reducing health disparities (Department of Health, 2011). As noted above, financing will be allocated directly to local authorities to pay for public health programs.

\section{What is the status of electronic health records?}

Every patient registered with the NHS receives an NHS number, which serves as a unique patient identifier. Most GPs' patient records are computerized. Some practices use electronic systems to allow patients to make appointments or e-mail their GP, but there is no requirement for practices to have that capability. The current aim is for all hospitals to keep patient records in electronic form. However, hospital and general practice records are not integrated into a single system. 
The previous (Labour) government attempted to introduce a patient record covering all service providers, but had to abandon it because of cost and contractor failures. The current government is introducing the Summary Care Record, which will store a limited range of data (current medication, adverse reactions, and allergies) for all patients except those who choose not to have one. By 2013, nearly 23 million people (nearly half the population of England) had a summary care record. Electronic transfers are widely used for prescriptions (from GP practices to pharmacies) and for the storage and distribution of digital images (scans, $\mathrm{x}$-rays, etc.). The Choose and Book system established under the previous government allows patients to choose online the hospital where they want to be treated. These developments were centrally led by the Department of Health. However, the national program has now been dismantled, so any new developments will be left to localities.

Interest and investment in telecare and telehealth have grown steadily over the past five years. The government announced in 2011 that 3 million people with long-term conditions will be provided with both telecare and telehealth services, but progress toward this goal remains limited.

\section{How are costs controlled?}

Budgets for the NHS are set at the national level, usually on a three-year cycle. The new commissioning organizations, CCGs, are allocated funds by NHS England, which closely monitors their financial performance to ensure that overspending is rare. They are expected to achieve financial balance each year.

The current economic situation has resulted in a largely static NHS budget, but demand continues to rise. The NHS has therefore set a target of $£ 20$ billion (US\$32 billion) in savings to be achieved over the four financial years up to 2014-2015 in order to cope with rising demand. A number of initiatives are in place to help the NHS meet this target, including strict limits on pay increases, improvements to purchasing of NHS supplies, support for increased use of generic drugs, reductions in the DRG-type payments for hospital activity, and a range of measures designed to improve operational efficiency including competition in both hospital- and communitybased services.

\section{What major innovations and reforms have been introduced?}

The structural reforms introduced by the NHS Health and Social Care Act 2012 have been set out above, including the introduction of CCGs to replace Primary Care Trusts as local health care purchasing organizations; the establishment of NHS England to take over day-to-day responsibility for running the NHS; and the expansion of the role of Monitor to being the economic regulator of public and private providers. No further structural reforms are currently envisaged; however, the government is expected to bring forward new policies in the near future in response to recent reports of poor-quality care in a number of hospitals.

The author would like to acknowledge Sarah Gregory, Claire Mundle, and Seán Boyle as contributing authors to earlier versions of this profile.

\section{References}

Department of Health (2007). High Quality Care for All.

Department of Health (2010a). Review of Access to the NHS by Foreign Nationals. London: Department of Health. 
Department of Health (2011). Healthy Lives, Healthy People.

Department Of Health (2012). The Mandate: a mandate from the Government to the NHS Commissioning Board.

Department of Health (2013). The regulation and oversight of NHS trusts and NHS foundation trusts.

NHS Information Centre (2012a). General and Personal Medical Services, England: 2001-2011.

NHS Information Centre (2012b). Prescriptions Dispensed in the Community, Statistics for England: 2000-2010.

Nuffield Trust (2013). Public payment and private provision: The changing landscape of health care in the 2000 .

Laing and Buisson (2013). Laing's Healthcare Market Review.

Office of Fair Trading (2011). Private Healthcare Market Study: Report on the Market Study and Proposed Decision to Make a Market Investigation Reference.

Office for National Statistics (2013). Expenditure on Healthcare in the UK: 2011. 


\title{
The French Health Care System, 2013
}

\author{
Isabelle Durand-Zaleski, Assistance Publique - Hôpitaux de Paris
}

\section{What is the role of government?}

The Ministry of Health regulates a large portion of healthcare expenditures. It prepares the annual Social Security Finance Act in conjunction with the Ministry of the Budget, Public Accounts and Civil Administration. The Act, subsequently passed by Parliament, sets a projected target (ceiling) for health insurance spending for the following year, provides a report on trends in policy for health and social security, and updates benefits and regulations.

The Ministry of Health is also responsible for:

- Apportioning the health budget among hospitals (including allocating funds to the regions), ambulatory care, mental health care, and the health and social sector for the disabled

- Determining the annual number of places available for medical students, as well as regulating the number of hospital beds and the amount of equipment, including expensive medical technologies

- Overseeing agreements between Statutory Health Insurance (SHI) and unions representing selfemployed health care professionals

- Setting the prices of specific medical procedures and drugs on the basis of proposals from the National Health Authority (, or HAS), and establishing safety standards in hospitals

- Defining priority areas for national programs, which currently include programs for improving cancer and rare disease treatment, health and the environment, unhealthy behavior and addiction, and quality of life for people with chronic illnesses

Since 2004, the Ministry of Health and the "statutory health insurers" (SHI, see below) have shared responsibility for defining the SHI benefit package and setting price and cost-sharing levels.

There has been a trend in the last two decades of reforms to attempt to decentralize governance and health policy decision-making, in particular in the area of planning, and apply it at the regional level. Aimed at achieving better governance of the system at the regional level, better responsiveness to population needs, and higher system efficiency, the 2009 Hospital, Patients, Health and Territories (HPST) Act created a single "one-stop shop" in each region: the Regional Health Agency (ARS), combining the roles of planner and regulator with that of hospital and ambulatory care purchaser. Cutting across the traditional boundaries of health care, public health, and the health and social care sectors, the ARS has responsibility for ensuring that health care provision meets the needs of the population by improving communication between the ambulatory and hospital care sectors, and between health and social services, while also pursuing national health expenditure objectives.

\section{Who is covered?}

Health care coverage in France is universal. All residents are entitled to receive publicly financed health care through statutory health insurance from noncompetitive SHI funds-statutory entities whose membership is 
based on occupation. SHI eligibility is granted either through employment (to salaried or self-employed working persons and their families) or as a benefit to formerly employed persons who have lost their jobs (and their families), to students, and to retired persons. Since the introduction of universal medical coverage (Couverture maladie universelle, or CMU) in 2000, the state covers the health insurance costs of residents not eligible for SHI ( $0.4 \%$ of the population, e.g., unemployed persons, and divorced women who have never worked). The state also finances health services for illegal residents who have applied for residency; the previous requirement of an annual flat fee of $€ 30$ (US\$40), established in 2011, was removed in 2012 by the newly elected socialist government. Visitors from elsewhere in the EU are covered by an EU insurance card. Non-EU visitors are covered for emergency care only; only visitors who have established a preliminary arrangement for medical cost coverage with a third-party insurance entity and the French SHI will have access to elective treatments.

SHI does not cover all expenditures; 92 percent of the population has access to complementary and supplementary voluntary health insurance (VHI) either through their employers or via means-tested vouchers (CMU complémentaire, or CMU-C). Only services that are not covered by SHI may be covered by the not-for profit supplementary VHI. Private for-profit companies are currently entering this market and offer coverage for all services..

\section{What is covered?}

Services: SHI funds cover hospital care and treatment in public or private rehabilitation or physiotherapy institutions; outpatient care provided by general practitioners (GPs), specialists, dentists, and midwives; diagnostic services prescribed by doctors and carried out by laboratories and paramedical professionals (nurses, physiotherapists, speech therapists, etc.); prescription drugs, medical appliances, and prostheses that have been approved for reimbursement; and prescribed health care-related transport. SHI also partially covers long-term and mental health care, and provides minimal coverage of outpatient vision and dental care. Health care costs account for 85 percent of SHI expenditure, while 15 percent goes toward cash benefits in the form of daily allowances for maternity, sickness, or occupational accident leave and disability pensions.

While preventive services in general receive limited coverage, there is full reimbursement for certain services for defined target populations: immunization for individuals over 65 years of age, persons suffering from chronic diseases, pregnant women, and newborns; HPV immunization for adolescent girls; and mammography and colorectal cancer screenings for individuals over the age of 50 . Other preventive services are paid for directly out of pocket by patients, or by VHI.

SHI benefits are defined differently for outpatient and inpatient care. Covered outpatient services are explicitly defined on three official positive lists-determined at the national level and applied throughout all regional authorities—of reimbursable procedures, drugs, and devices. Drug and medical device coverage is determined by the Ministry of Health, while procedures are added by SHI, following guidance from the HAS. For inpatient hospital care, selected innovative drugs and devices are paid for separately from the diagnosis-related group (DRG) tariffs; for these drugs, the hospital will claim additional reimbursement from SHI. Otherwise, there is an implicit understanding of the range of services that can be delivered to patients within the DRG reimbursement scheme. 
Cost-sharing and out-of-pocket spending: Cost-sharing takes three forms: coinsurance, copayments, and extrabilling. In 2009, total out-of-pocket (OOP) spending, largely limited by VHI coverage, made up 7 percent of total health expenditures. The rate of coinsurance and copayment varies by service (e.g., the reimbursement rate for a GP visit is $70 \%$ of the tariff). The extent of VHI coverage varies widely, but all VHI contracts cover the difference between the SHI reimbursement rate and the service tariff as set by the official fee schedule. VHI coverage of extra-billing-i.e., when a provider charges a fee higher than the SHI's reimbursement rate-is also commonly offered, and is usually described as a percentage of the SHI tariff that will be covered. Most VHI contracts will cover up to 300 percent of the official tariff, which still may not cover the provider's fee, especially for dental care. The official tariff for dental and optical services is very low, not more than a few euros for corrective lenses or hearing aids and a maximum of $€ 200$ (US\$270) for teeth prostheses, but these are commonly extra-billed at amounts over 10 times the official tariff.

Coinsurance rates are applied to all health services and drugs listed in the benefit package, and vary by:

- type of care: inpatient care (20\%), doctor visits (30\%), and dental care (30\%)

- effectiveness of prescription drugs, with highly effective drugs at o percent and all other items requiring coinsurance rates of between 40 percent and 100 percent, based on their therapeutic value

- compliance with the recently implemented gatekeeping system (): visits to the gatekeeping GP have a coinsurance charge of 30 percent, whereas visits to other GPs have a charge of up to 50 percent-the difference between the two GP rates cannot be reimbursed by VHI (see below)

In addition to coinsurance, which can be fully reimbursed by VHI (unless it applies to nongatekeeping GPs), the following nonreimbursable copayments apply, up to an annual ceiling of $€ 50$ (US\$67): €18 (US\$24) for each inpatient hospital day (€13.50 [US\$18] in psychiatric wards), €1 (US\$1.35) per doctor visit, €0.50 (US\$0.67) per prescription drug, €2 (US\$2.70) per ambulance, and €18 (US\$24) for hospital treatment above €120 (US\$162). These copayments have not changed since their initiation in 2008.

Safety net: Since 2000 , people with low incomes are entitled to free or subsidized VHI and free vision and dental care, and cannot be extra-billed by doctors. Also, exemptions from coinsurance apply to: individuals with any of 32 chronic illnesses (8.6 million people, limited to the treatments for those conditions); individuals who benefit from either complete medical coverage (CMU, 2.2 million) or means-tested vouchers for VHI (CMU-C, 4.5 million)3; and individuals receiving invalidity and work-injury benefits. Hospital coinsurance applies only to the first 31 days in hospital, and some surgical interventions are exempt. Children and people with low incomes are exempt from paying nonreimbursable copayments.

\section{How is the health system financed?}

Publicly financed health care: Public expenditure accounted for 76.8 percent of total health costs in 2011 (OECD, 2013). SHI is financed by employer and employee payroll taxes (43\%), a national earmarked income tax (33\%), revenue from taxes levied on tobacco and alcohol (8\%), state subsidies (2\%), and transfers from other branches of social security (8\%). There is no ceiling on employer and employee contributions, which are collected by the national social security agency. Funds are pooled at the national level, and the allocation of those funds to providers is determined by Parliament, which votes on a national budget for (1) public and not-for-profit hospitals,

3 http://www.cmu.fr/fichier-utilisateur/fichiers/ReferencesCMU50.pdf. 
(2) for-profit hospitals, (3) out-of-hospital care, and (4) geriatric care. Within each budget a regional allocation is determined, to be distributed by the Regional Health Agencies.

SHI funds are statutory entities, and membership is based on occupation, so there can be no competition between them. Levels of both contribution and benefits vary between funds. The three major funds cover more than 90 percent of the population: salaried employees, rural workers, and the self-employed. Each fund's managing board has equal representation from employers and employees (trade unions). Every year, Parliament sets a (soft) ceiling for the rate of SHI expenditure growth for the following year (ONDAM).

Private health insurance: Complementary VHI is provided mainly by not-for-profit, employment-based mutual associations or provident institutions, which cover around 90 percent of the population. It originally covered only those services that already were covered by SHI; however, a few VHI providers recently extended complementary coverage to well-being services that are not part of the SHI basic benefit package (including extra-billing). Reimbursement for drugs and devices by SHI and VHI is based on a reference price set by the governmental national pricing committee.

Contracts differ in regard to the percentage of coverage of the cost left to the patient after SHI reimbursement. They usually fully cover the patient's cost-sharing for nonconvenience drugs and for health professionals' procedures and tests up to the official SHI tariff. However, VHI contracts differ in the level of coverage of extra-billing, as well as the level of coverage for convenience drugs, medical devices, private amenities, and services not included in the SHI benefit package. An increasing number of VHI firms offer tailor-made contracts allowing people to choose the rate of coverage for each type of care. In 2013, legislation 4 called for new group contracts to provide VHI to employees in companies employing 50 or more who either have had no previous employer-sponsored VHI or have had more expensive individual policies. By the beginning of 2016, this group coverage is set to be fully available, with the expected population of beneficiaries at 4 million. In practice, employers have to offer VHI to their employees, but the choice of insurance plan is determined by the industry in which the employer operates.

To minimize the risk that VHI contracts will result in inequitable access, the CMU-C (described above) provides VHI to 4.3 million people at little to no cost via vouchers that can be used to obtain coverage from a variety of insurers, though most opt to obtain this additional coverage from their SHI fund. The paradoxical result is that the public provider (SHI) has become also a provider of VHI, competing with private (not-for-profit) companies.

\section{How are health services organized and financed?}

Physicians: Most physicians are self-employed (59\%), although more GPs are self-employed (68\%) than specialists (51\%) (Eco-Santé, 2010). Solo practice by both GPs and specialists is still predominant in France.

As mentioned above, the 2004 health financing reform law introduced a voluntary gatekeeping system for adults (aged 16 years and over). Although patients are not legally obligated to register, there are strong financial incentives to do so, such as higher copayments for visits and prescriptions without a referral from the

4 http://www.emploi.gouv.fr/actualites/adoption-definitive-loi-sur-securisation-lemploi. 
gatekeeper. Of the 85 percent of the population that has registered with a gatekeeper, over 90 percent chose a GP, though specialists (office- or hospital-based) can also be chosen. GPs are office-based, self-employed, and paid on a fee-for-service (FFS) basis. Outpatient specialists are office-based or in private for-profit clinics (or both). As of 2011, the cost per visit (€23 [US\$31]) is the same for specialists and for GPs. Hospital physicians are salaried.

In 2012, the newly elected socialist government made a pledge to reduce excessive extra-billing. An agreement was signed in October 2012: physicians who sign on agree to limit their extra-billing to $€ 70$ (US\$95) in exchange for reduced social insurance premiums and higher fees for procedures. By May 2013, fewer than 3,000 of the 25,000 eligible physicians had agreed to the contract.

In April 2009, SHI launched a series of individual contracts with office-based physicians that included a payper-performance mechanism - in addition to the traditional FFS, physicians could earn up to $€ 5,000$ (US $\$ 6,759$ ) per year for the achievement of targets in caring for patients with asthma, diabetes, and hypertension, as well as in immunization and breast cancer screening. The contracts also stipulate the prescription of generic drugs, particularly for cardiovascular conditions. At the end of the three-year test period, roughly 15,000 physicians (or $30 \%$ of the total eligible population) had signed these contracts, and the average additional FFS payment was $€ 3,100$ (US\$4,190). Building on the success of this program, an agreement between SHI and physicians' unions was signed in 2012 applying pay-for-performance targets to all GPs. ${ }^{5}$ In addition to target payments, GPs may receive a yearly $€ 40$ (US\$54) per patient for the care coordination of patients suffering from chronic conditions.

After-hours care: After-hours care is delivered by the emergency departments of public hospitals, private hospitals that have signed an agreement with the Regional Health Agency and receive financial compensation, selfemployed physicians who work for emergency services, and, more recently, after-hours public facilities (maisons de garde) financed by SHI funds and staffed by health professionals on a voluntary basis. Physicians are paid an hourly rate when working at maisons de garde, regardless of the number of patients seen. Emergency services can be accessed via the national emergency phone number, 15, which is staffed with trained professionals who determine the type of response needed, from GP visit to resuscitation ambulance. Some experiments are currently testing the feasibility of telephone or telemedicine advice. Publicly funded multidisciplinary health centers with self-employed health professionals (physicians and nonphysicians) allow better after-hours access to care in addition to more comprehensive care; FFS payment is the rule for these centers. 6

Hospitals: Since 2008, all hospitals and clinics are reimbursed via the DRG-like prospective payment system, which applies to all inpatient and outpatient admissions. DRG payments cover physicians' salaries. No bundled payment by episode of care exists. Two-thirds of all hospital beds are in government-owned or not-for-profit hospitals (all university hospitals are public). These hospitals are funded by SHI (80\%) and VHI or direct patient payment (20\%). Public and not-for profit hospitals also benefit from additional non-activity-based grants that compensate research and teaching (up to an additional $13 \%$ of the budget) and the provision of emergency services, organ harvesting, and transplantation (on average, an additional 10\%-11\% of a hospital's budget). The remaining third of hospitals are private, for-profit clinics owned either by individuals or, increasingly, by large

5 http://www.ameli.fr/professionnels-de-sante/medecins/votre-convention/nouvelle-convention-medicale-questionsreponses/remuneration-sur-objectifs.php.

6 http://www.irdes.fr/Publications/Qes/Qes147.pdf. 
corporations (e.g., Générale de Santé). The funding mechanism is the same as for public hospitals, but the respective shares of SHI, VHI, and OOP costs differ. Doctors' fees are billed in addition to the DRG in private clinics. DRG payments for private clinics are lower than for public or not-for-profit hospitals. This discrepancy is justified by differences in the size of facilities, the DRG mix, and the patient population (age, comorbid conditions, and socioeconomic status). 7 The previous government had planned convergence of DRG payments to different types of hospitals in 2019, but the current government stopped this initiative with the 2013 Social Security Finance Act. Hospital physicians are permitted to see private patients in public hospitals.

Rehabilitative hospitals also have a prospective payment system based on length of stay and care intensity.

Mental health care: Mental care (for the adult population) is organized through the following structures: outpatient facilities (medical-psychological centers, day clinics, or home care; 67\% of patients); full-time inpatient (25\%); inpatient, part-time either through hospitalization during the day or night or at part-time therapeutic centers $(9 \%)$.

The SHI package covers hospitalization, clinic visits, medication, and community care, but not outpatient psychologist visits, psychoanalysis, or psychoeducation. Mental health services from physicians in private practice are covered by SHI at the usual rate. Individuals presenting long-term psychiatric conditions are fully covered, and are not charged out-of-pocket fees if they receive treatment in public facilities or from office-based physicians who do not extra-bill. Public and private psychiatric hospital care is financed by SHI; patient copayment is 20 percent of a daily fee that varies across hospitals and can be fully covered by VHI. People with mental disabilities also receive care and services from the state and local government-funded health and social care sector.

Expenditures for mental health (dementia excluded) represent roughly 8 percent of total health expenditures; hospital care represents two-thirds and community care one-third of spending. Over 90 percent of inpatient expenditure is provided by SHI/state-funded public or not-for-profit institutions. Public mental health institutions use a capitated budget determined retrospectively. Private institutions charge a per diem rate in addition to the standard fees for health professionals. Out-of-hospital care is provided by self-employed GPs and specialists paid fee-for-service.

Long-term care: Coverage for long-term care was reformed in 2000. There are currently four sources of funding for long-term health and social care for frail older people (comprising mostly those over 65 with varying degree of disability, or those over 60 if they have a work disability):

- the National Solidarity Fund for Autonomy receives resources from both SHI and Solidarity Day (named for an unpaid working day introduced in 2004); it finances long-term care in nursing homes and community services for older people, as well as a share of the allowances-means-tested and varying by region - for frail older people to finance domiciliary staff or home care devices (nearly $€ 15$ billion [US\$20 billion] per year)

- total local government expenditure on 1.3 million frail elderly beneficiaries in 2011 was $€ 8$ billion (US\$10 billion), which covered payments in kind, housing, and payments for home help 8

7 http://www.irdes.fr/EspaceRecherche/DocumentsDeTravail/DT25EcartsCoutHospitaliers.pdf.

$8 \mathrm{http} / /$ www.ameli.fr/professionnels-de-sante/medecins/votre-convention/nouvelle-convention-medicale-questionsreponses/remuneration-sur-objectifs.php. 
- OOP payment for care in a nursing home currently averages $€ 1,500$ (US\$2,207) per month per individual and is steadily increasing

- VHI contracts may cover those expenses for medical care that are not fully covered by SHI, as well as part of housing expenditures (nursing homes without medical care are excluded from coverage)

\section{What are the key entities for health system governance?}

The National Authority for Health (HAS) streamlines a number of activities designed to improve the quality of patient care and guarantee equity within the health care system. Its activities range from assessing drugs, medical devices, and procedures to publishing guidelines, accrediting health care organizations, establishing requirements for patient safety, and certifying doctors, as well as conducting health technology assessments. Assessments of new technologies are based on documents provided by the manufacturer prior to market launch, and are used to determine coverage rate and market price. Old technologies are reassessed every five years using documents provided by the manufacturer and systematic reviews of the literature. The 2012 Social Security Finance Act stipulated compulsory economic evaluation of new technologies that claim a high medical benefit (and price) and that are expected to have a significant budget impact.

The French Health Products Safety Agency (ANSM) makes all safety decisions that concern health products, from manufacturing to marketing. The agency carries out three core missions: scientific evaluation; laboratory control and advertising control; and inspection of industrial sites. It also coordinates vigilance activities. In 2010-2011, a major scandal over a weight-control drug marketed by a French company (the drug Mediator remained on the French market for two years after it was withdrawn for safety reasons in other countries) resulted in a general reorganization of the market approval and safety monitoring system.

The Biomedicine Agency is a public organization under the supervision of the Ministry of Health, operating in four key areas: assisted reproductive technologies; prenatal and genetic diagnosis; embryo and stem cell research; and the procurement and transplant of organs, tissues, and cells (previously entrusted to the French Transplant Agency). It is the only such public body in Europe.

The National Support Agency for the Performance of Health and Medico-Social Facilities provides guidance to institutions in need of structural changes and performance audits, and publishes dashboard indicators such as length of stay, occupancy, patient satisfaction, and incidence of bedsores, which are classified by category and type of medical activity. The General Directorate of Health Care Supply, under the Ministry of Health, most closely fulfills the role of ensuring fair competition among health care organizations; however, its primary function is to ensure appropriate supply of and access to care, rather than to promote competition. In 2004, a new law created two new umbrella organizations-the National Union of Health Insurance Funds and the National Union of Complementary Health Insurers-incorporating all SHI funds and VHI, respectively, and charged to negotiate with providers and the government on behalf of constituents.

\section{What is being done to ensure quality of care?}

National strategies: National plans are have been developed for a number of chronic conditions (e.g., cancer, Alzheimer's disease, rare diseases, chronic conditions), prevention, and healthy aging, in addition to the 104 
targets set by the 2004 Public Health Act. These plans establish new governance (e.g., the cancer plan set up the National Cancer Institute to coordinate research and treatment in cancer) and new tools, and/or coordinate among existing organizations. All plans emphasize the importance of supporting carers and ensuring patients' quality of life in addition to enforcing compliance with guidelines and promoting evidence-based practice.

Care for people with chronic conditions: The HAS has published an evidence-based basic benefit package for 32 chronic conditions. Further guidance on recommended care pathways 9 has been published by the HAS on four conditions: COPD, heart failure, Parkinson's disease, and end-stage renal disease. Patients with chronic conditions are eligible for full coverage of their health care expenditures, conditional on a signed agreement between their physician, SHI, and themselves. In addition to the basic benefit package for chronic conditions, disease management programs exist in the form of "provider networks."

SHI and the Ministry of Health have for the past decade funded provider networks, in which participating professionals share guidelines and protocols, agree on best practice, and have access to a common patient record. However, they have been subjected to criticism because of their limited target population (less than $1 \%$ of eligible patients) and negligible effect on expenditures.

Disease and medical device registries: The 2004 Public Health Act underlined the need for larger national cohorts for disease and medical device registries, which are now being recruited. However, they are still considered too few in number and not representative enough to ensure sufficient quality of care. Medical device registries have been set up for drug-eluting stents, implantable cardiac defibrillators, and transcutaneous aortic valve implantation.

Hospitals must be accredited every four years; criteria and accreditation reports are publicly available on the HAS Web site (www.has-sante.fr). Every fifth year, physicians are required by law to undergo an external audit and assessment of their practice. For hospital physicians, these can be performed as part of the hospital accreditation process. For office-based physicians, certification and revalidation are organized by an HAS-approved independent body (usually a medical society representing a particular specialty). Accreditation results are publicly reported on the HAS Web site. Dentists and midwives will soon have to undergo a similar process. CompaqH, a national program of performance indicators, also reports results on selected indicators. Quality assurance and risk management in hospitals are monitored nationally by Plateforme d'Informations sur les Etablissements de Santé (PLATINES), under the authority of the Ministry of Health, which publishes online technical information, data on hospital activity, and data on control of hospital-acquired infections. There is also a yearly nonofficial hospital ranking by two news magazines. Currently, financial rewards or penalties are not linked to public reporting, although this issue remains contested.

\section{What is being done to improve care coordination?}

Ensuring better coordination is a priority of the Regional Health Agencies, which have been given specific budgets (e.g., €10 million [US\$13 million] in the Paris region) to deploy IT initiatives such as telehealth and

9 http://www.ameli.fr/professionnels-de-sante/medecins/votre-convention/nouvelle-convention-medicale-questionsreponses/remuneration-sur-objectifs.php. 
e-records. The government is proposing a change ${ }^{10}$ to make the providers' networks a coordination tool for GPs, by helping the GPs access specialized care; ensuring communication between the patient, caregivers, and health and social care providers; and ensuring a smooth transition between hospital and home care. ${ }^{11}$

Group practices in France most commonly consist of two or three physicians, usually of the same specialty. The share of physicians in group practice increased from 43 percent in 1998 to 54 percent in 2009-younger physicians are more likely to be in group practice. The major incentive for group practice is nonmonetary, and is instead related to a better quality of life, increased time for continuing education, and professional enhancement.

\section{What is being done to reduce health disparities?}

Despite universal coverage and access to health care, health inequities are a significant issue in France. There is a seven-year gap in life expectancy between males in the highest social category and those in the lowest (defined by type of employment, with strong correlation to income). CMU-C beneficiaries and those without VHI report poorer health than those with commercial VHI (around $38 \%$ versus $27 \%$ report bad or very bad health, respectively), a discrepancy that may be due to differences in access to care: in 2008, 14 percent of patients with commercial VHI, 21 percent of CMU-C beneficiaries, and 30 percent of patients without any commercial VHI did not seek vision or dental care. ${ }^{12}$ The 2013 SHI Finance Act has increased the income threshold for beneficiaries in order to increase eligibility for CMU-C. Also, in order to identify and eliminate discriminatory practices against CMU patients, the 2009 Hospital, Patients, Health, Territories Reform Act allows random testing of office-based physicians' practices and, if denial of care is proven, penalties are imposed by SHI.

The 2004 Public Health Act made reducing health inequalities a national priority. It set targets for reducing geographic inequities (so far, only nurses have agreed to limit new practices in over-served areas); financial inequities (OOP payments will be limited by providing free means-tested VHI); and inequities in prevention (e.g., related to obesity, screening, immunization). Provision of an adequate level of employer-sponsored voluntary health insurance for all workers was established in 2013, in order to reduce the inequities resulting from differential access to supplemental insurance and variation in the quality of their coverage.

At the regional level, Regional Health Agencies have been given a specific mandate to reduce health inequities by: ensuring access to prevention for low-income populations; including in their strategic plans health improvements for these populations; and reducing social exclusion by setting certain imperatives (not extra-billing) for health care professionals and other stakeholders. Measures also include financing health centers in low-income areas.

\section{Who is responsible for population health?}

The responsibility for population health is shared by the state (Ministry of Health, General Directorate of Health) and the Regional Health Agencies. The Ministry of Health, with the help of advisory institutions,

${ }^{10} \mathrm{http}: / / \mathrm{www} . a m e l i . f r / p r o f e s s i o n n e l s-d e-s a n t e / m e d e c i n s / v o t r e-c o n v e n t i o n / n o u v e l l e-c o n v e n t i o n-m e d i c a l e-q u e s t i o n s-$ reponses/remuneration-sur-objectifs.php.

11 http://www.irdes.fr/Publications/2010/Qes157.pdf.

12 http://www.irdes.fr/Publications/2011/Qes170.pdf. 
proposes the Public Health Acts to Parliament - the most recent act was passed in 2004. These set public health priorities, but are disconnected from funding decisions. Regional Health Agencies implement regional health policy in relation to occupational health services, maternal and childhood health services, and university and school health services; monitor the health status of the population; ensure that hygiene rules are respected; participate in prevention and patients' health education; assess health professionals' education; carry out regional SHI programs, notably in risk management; authorize the creation of new health services and social and health care services for the elderly and handicapped; and monitor water and air quality.

\section{What is the status of electronic health records?}

In 2008, the General Inspectorate for Social Affairs published a report that expanded on earlier projects and presented six principles for the success of electronic health record (EHR) technology: 1) to be useful for professionals; 2,3 ) to be modular and implemented incrementally, based on emerging requirements; 4) to be deployed according to an agreed-upon time frame; 5) to strike a balance between informational requirements and the protection of patients' privacy; and 6) to have clear governance. The report recommends the creation of a highlevel committee, chaired by the minister of health and comprising members of parliament and representatives of all stakeholders, to govern the project, and also recommends the creation of a government agency to take charge of health information technology (HIT). It estimates the total cost of developing pilot projects to be $€ 900$ million (US $\$ 1.2$ billion). In order to improve the interoperability of existing systems and to monitor the creation of a unique patient identifier, the Agency for Health Information Systems (ASIP Santé), a dedicated information systems agency, was created in 2009. In 2011, ASIP Santé launched the EHR project in four regions. The project is currently extended across the entire country and in September 2013 a total of 382,728 patients have been included by 5,176 office-based professionals and 370 hospitals.

Apart from the EHR project, there are two coexisting HIT systems: one for hospital admissions (the PMSI), used by hospitals to bill SHI, and one for patient reimbursement claims for outpatient and hospital care. The National Health

Insurance Inter-Plan Information System (SNIIR-AM) was created in 2004 to connect the two into one comprehensive system, the SHI interfund system, and the unique identifier that allows linkage of PMSI and SNIIR-AM is being pilot-tested. Currently, the PMSI system comprises information on medical diagnoses and procedures performed during an admission, while the SNIIR-AM includes claims data only, with demographic information but no medical information, although some claims can be directly connected to a medical condition.

\section{How are costs controlled?}

Cost control is a key issue, as the health insurance scheme has faced large deficits over the past 20 years. The economic downturn constitutes a further threat to the state budget in general (the public deficit for 2011 is $5.2 \%$ of GDP [INSEE 2012]) and to the health insurance scheme in particular as the revenue base shrinks. More recently, however, the health insurance scheme's deficit has fallen, from an annual €10 to €12 billion (US\$13.5 to 16.2 billion) in 2003 to $€ 7.7$ billion (US\$10 billion) in 2013 .

This drop may be partly attributable to the following changes that have taken place in the past three years: a reduction in the number of acute-care hospital beds; limits on the number of drugs reimbursed; the removal of 
600 drugs from public reimbursement in the past few years; an increase in generic prescribing and use of overthe-counter drugs; a requirement to deliver a generic drug unless specified otherwise on the prescription; the introduction of a voluntary gatekeeping system in primary care; and a basic benefit package for the management of chronic conditions. Since 2008, reimbursement by private health insurance of some copayments has been discontinued for prescription drugs, doctor visits, and ambulance transport. As of 2011, the drug reimbursement rate has been curtailed, newly diagnosed hypertension has been excluded from the list of fully covered chronic diseases, and reimbursement of transportation for chronically ill patients has been made contingent on whether it is medically justified.

The most effective cost control for drugs was the implementation in September 2012 of the 'generic versus third party' scheme. According to this scheme, patients who agree to generic substitution do not have to pay anything in exchange for their drugs. According to SHI figures, the rate of substitution jumped from $71 \%$ to $84 \%$ in one year, resulting in cost savings over $€ 200$ million (US\$270 million).

\section{What major innovations and reforms have been introduced?}

Patient empowerment and patient rights: The pivotal Patients' Rights and Quality of Care, or "Kouchner," Act was passed in 2002. The 2009 Hospital, Patients, Health, Territories Reform Act expanded the notion of patient access to information and increased the role of patient representatives in hospitals and at the National Health Authority. The Ministry of Health declared 2011 to be "the year of patients and their rights." The objectives of this "Patients' year" were to raise the awareness of patients about their rights, to promote well-treatment, and to identify and sanction professionals who denied care.

Information for patients: Information on hospitals' performance is available on the HAS Web site, although it concerns only accreditation outcomes. Physicians who successfully complete an appraisal can publicly advertise it, but no standardized process is currently in place to disseminate the information.

\section{References}

Ameli (2012) (http://www.ameli.fr/professionnels-de-sante/medecins/exercer-au-quotidien/le-capi/qu-est-ceque-le-capi.php).

Chevreul, K., Durand-Zaleski, I., Bahrami, S., Hernández-Quevedo, C., and Mladovsky, P. (2010). “France: Health System Review," Health Systems in Transition 12(6):1- 291.

CMU (2012) (http://www.cmu.fr/cmu-complementaire.php).

INSEE (2012). “General Government National Accounts - First Results - Year 2011” (http://www.insee.fr/fr/ themes/info-rapide.asp?id=37).

IRDES Eco-Santé (http://www.ecosante.fr/). http://www.irdes.fr/Publications/Qes/Qes147.pdf

Le Garrec, M., Bouvet, M., Koubi, M. (2012). Comptes nationaux de la santé 2011. 
OECD Health Data (2013) (http://www.oecd.org/els/health-systems/oecdhealthdata2013-frequentlyrequesteddata.htm).

ONDAM (2010) (http://www.irdes.fr/Publications/2010/Qes157.pdf). 


\title{
The German Health Care System, 2013
}

\author{
Miriam Blümel, Berlin University of Technology
}

\section{What is the role of government?}

Since 2009, health insurance has been mandatory for all citizens and permanent residents of Germany (previously, certain populations could choose not to have insurance, though few did so). It is provided by competing, not-for-profit, nongovernmental health insurance funds (called "sickness funds"; there were 134 as of January 2013) in the statutory health insurance scheme (SHI), or by voluntary substitutive private health insurance (PHI). States own most university hospitals, while municipalities play a role in public health activities and own about half of hospital beds. However, the various levels of government have virtually no role in the direct delivery of health care. A large degree of regulation is delegated to self-governing associations of the sickness funds and the provider associations. The most important body is the Federal Joint Committee, created in 2004 (see below).

\section{Who is covered?}

Coverage is universal for all legal residents. All employed citizens (and other groups such as pensioners) earning less than $€ 4,350$ (US $\$ 4,874$ ) per month ( $€ 52,200$ [US\$70,489] per year) as of 2013 are mandatorily covered by SHI, and their dependents are covered free of charge. Individuals whose gross wages exceed the threshold, civil servants, and the self-employed can choose either to remain in the publicly financed scheme on a voluntary basis (and 75\% of them do) or to purchase substitutive PHI. Especially for young people with a good income, $\mathrm{PHI}$ is attractive, as the insurance may offer contracts with more extensive ranges of services and lower premiums. PHI also plays a mixed complementary and supplementary role, covering minor benefits not covered by SHI, access to better amenities, and some copayments (e.g., for dental care). About 86 percent of the population receives their primary coverage through SHI and 11 percent through substitutive PHI. The remainder (e.g., soldiers and policemen) are covered under special programs. Undocumented immigrants are covered by social security in case of acute illness and pain, as well as pregnancy and childbirth. Services are provided by the responsible authorities or physicians and hospitals.

\section{What is covered?}

Services: SHI covers preventive services, inpatient and outpatient hospital care, physician services, mental health care, dental care, optometry, physical therapy, prescription drugs, medical aids, rehabilitation, hospice and palliative care, and sick leave compensation. SHI preventive services include regular dental checkups, wellchild checkups, basic immunizations, checkups for chronic diseases, and cancer screening at certain ages. All prescription drugs-including newly licensed ones-are covered unless explicitly excluded by law (mainly socalled lifestyle drugs) or pending evaluation. While the broad contents of the benefits package are legally defined, specifics are decided upon by the Federal Joint Committee (see below).

Since 1995, long-term care has been covered by a separate insurance scheme (LTCI), which is mandatory for the whole population. Unlike SHI benefits, however, LTCI benefits are 1) dependent on an evaluation of individual care needs by the SHI Medical Review Board (leading either to a denial or to a grouping into one of three levels 
of care), and 2) limited to certain maximum amounts, depending on the level of care. LTCI covers home and institutional care. Beneficiaries can choose to receive either a cash amount or benefits in kind. As benefits are usually not sufficient to cover institutional care completely, people are advised to buy supplementary private LTCI.

Cost-sharing: Within SHI, there were only a few cost-sharing provisions (mainly for pharmaceuticals and dental care) until 2004, when copayments were introduced for ambulatory care office visits (to general practitioners, specialists, and dentists) for adults age 18 years and older (€10 [US\$13.50] for the first visit per quarter or subsequent visits without referral). These copayments were subsequently removed in January 2013 , but other remaining copayments include $€ 5$ (US\$6.75) to €10 per outpatient prescription (unless the price is at least $30 \%$ below the reference price, meaning that over 5,000 drugs are effectively free of charge), €10 per inpatient day for hospital and rehabilitation stays (for the first 28 days per year), and $€ 5$ to $€ 10$ for prescribed medical aids. Sickness funds can offer a range of deductibles and no-claims bonuses. Preventive services do not count toward the deductible. SHI-contracted physicians are not allowed to charge above the fee schedule for services in the SHI benefit catalogue. However, a list of "individual health services" outside the comprehensive range of SHI coverage may be offered to patients paying out-of-pocket (OOP). OOP spending accounted for 13.2 percent of total health spending in 2011, mostly on pharmaceuticals, nursing homes, and medical aids (OECD 2013).

Safety net: Children under 18 years of age are exempt from cost-sharing. For adults, there is an annual cap on cost-sharing equal to 2 percent of household income; part of a household's income is excluded from this calculation for additional family members. The cap is lowered to 1 percent of annual gross income for qualifying chronically ill people; to qualify, these people have to demonstrate that they attended recommended counseling or screening procedures prior to becoming ill. Unemployed people contribute to SHI in proportion to their unemployment entitlements. For the long-term unemployed, the government contributes on their behalf.

\section{How is the health system financed?}

Publicly financed health care: In 2011, SHI spending accounted for 57.3 percent of total health expenditure (total public spending on health, including statutory LTCI, statutory retirement insurance, statutory accident insurance, and taxes, constituted 72.6\%). Sickness funds are autonomous, not-for-profit, nongovernmental bodies funded by compulsory contributions levied as a percentage of gross wages up to a ceiling. Since 2009, a uniform contribution rate has been set by the government (and has been set in federal law since 2011). As of 2011, insured employees or pensioners contribute 8.2 percent of their gross wages, while the employer, or the pension fund, adds another 7.3 percent, so the combined maximum contribution is around $€ 610$ (US\$824) per month. This contribution also covers dependents (nonearning spouses and children). Earnings above €47,250 (US $\$ 63,805$ ) per year (as of 2013) are exempt from contribution. Sickness funds' contributions are centrally pooled and then reallocated to each sickness fund based on a risk-adjusted capitation formula, taking into account age, sex, and morbidity from 80 chronic and/or serious illnesses. Since 2009, sickness funds have been able to charge the insured person an additional nominal premium if a sickness fund's revenue is insufficient (or to reimburse patients in the case of surplus revenue). In March 2011, 13 of the then 156 sickness funds charged an additional premium, which fluctuated between $€ 8$ (US\$11) and $€ 15$ (US\$20) per month. All insurance companies that had to raise additional contributions in the past have now abolished this. Since 2004 , there is an amount of (general) tax-financed federal spending on "insurance-extraneous" benefits provided by SHI (e.g. 
coverage for children), which amounted to $€ 15.7$ billion (US $\$ 21.2$ billion) in 2010 and fell to $€ 14$ billion (US\$19 billion) (about 7 percent of total SHI revenue) in 2012. In 2013, it was lowered because of the consolidation of the federal budget to $€ 11.5$ billion (US $\$ 15.5$ billion).

Privately financed health care: There were 43 substitutive PHI companies in 2011, of which 24 were for-profit and 19 were nonprofit organizations. Substitutive PHI covers the two groups that are exempt from SHI (civil servants, whose health care costs are partly refunded by their employer, and the self-employed) and those who have chosen to opt out of the SHI scheme. All PHI insured pay a risk-related premium, with separate premiums for dependents; risk is assessed only upon entry, and contracts are based on lifetime underwriting. The employer's contribution is based on the maximum contribution to SHI ( $€ 287.44$ [US\$388] per month in 2013), but the maximum contribution is 50 percent of the employee's premium. PHI is regulated by the government to ensure that the insured do not face large premium increases as they age and are not overburdened by premiums if their income decreases. Since January 2009, private insurers offering substitutive PHI coverage have been required to take part in a risk-adjustment scheme (separate from SHI) to be able to offer basic insurance for people with ill health who are not eligible to return to SHI (e.g., because of their status as being either a pensioner or self-employed) and who cannot afford a risk-related premium. Recent legislation also has aimed to intensify competition between insurers. In order to slow the increase of premiums with age, private insurers are forced by law to set aside savings (aging reserves) from when the insured are young for use when those insured grow older. Previously, these aging reserves remained with the insurer if a person cancelled a policy or changed to another insurer. Since January 2009, however, individual aging reserves have been transferable.

PHI also plays a mixed complementary and supplementary role, covering minor benefits not covered by SHI, access to better amenities, and some copayments (e.g., for dental care). The federal government determines provider fees in substitutive, complementary, and supplementary PHI through a specific fee schedule. There are no government subsidies for complementary and supplementary PHI. In 2011, all forms of PHI accounted for 9.4 percent of total health expenditure.

\section{How are health care services organized and financed?}

Physicians: General practitioners (GPs) and specialists in ambulatory care who get reimbursed by SHI are by law mandatory members of regional associations that negotiate contracts with the sickness funds. Regional Physicians' Associations are responsible for coordinating care requirements within their region, and act as financial intermediaries to the sickness funds and the physicians in ambulatory care. However, ambulatory physicians typically work in their own private practices-around 60 percent in solo practice and 25 percent in dual practices. Most physicians employ doctors' assistants, while other nonphysicians (e.g., physiotherapists) have their own premises. In 2012, of the 141,038 practicing SHI-accredited physicians in ambulatory care, 49 percent were practicing as family physicians and 51 percent as specialists. Since 2004, specialized medical care provided by hospital specialists in outpatient care has been introduced. It includes treatment of severe progressive forms of disease and of rare diseases, as well as highly specialized procedures. Details of this and qualifications requirements are defined by the Federal Joint Committee.

Individuals have free choice among GPs, specialists, and, if referred to inpatient care, hospitals. Registration with a primary care physician is not required and GPs have no formal gatekeeping function. However, since 
2004, sickness funds have been required to offer their members the option to enroll in a "family physician care model," which has been shown to provide better services and often also provides incentives for complying with gatekeeping rules. In January 2007 , about 24.6 million SHI insured had the option of subscribing to such a model; about 4.6 million subscribed. About 1.8 million other insured took part in the nationwide model of the "Barmer Ersatzkasse," a sickness fund that allows for exemptions from copayments for prescriptions if prescribed by their family physician.

SHI-accredited physicians in ambulatory care (GPs and specialists) and in outpatient care are generally reimbursed on a fee-for-service (FFS) basis with a uniform fee schedule negotiated between sickness funds and physicians (see below). Payments are limited to predefined maximum numbers of patients per practice and reimbursement points per patient, setting thresholds on the number of patients and treatments per patient for which a physician can be reimbursed. Pay-for-performance has not been established yet.

GPs receive a financial bonus for patients enrolled in a Disease Management Program (DMP), in which sickness funds pay the physician an annual lump-sum; in return the physician provides patient training and documents patient data. Bundled payments are not the common way of remuneration in primary care, but a regional initiative, "Healthy Kinzigtal" (Gesundes Kinzigtal), provides an example of an integrated care model offering primary care doctors and other providers financial incentives for bundling payments across providers and services. The remuneration of the health care providers in Kinzigtal is based on a four-stage model: 1) regular payment through SHI; 2) FFS (e.g., for a regular health check-up); 3) performance-based remuneration according to specific structural and quality characteristics; and 4) profit distribution for the network of health care providers.

After-hours care: After-hours care is organized by the regional physician associations to ensure access to ambulatory care around the clock. Physicians are obliged to provide after-hours care, with differing regional regulations. In a few areas (e.g., Berlin), after-hours care has been delegated to hospitals. The patient is given an overview of the visit afterwards to hand to his or her GP. There is also a tight network of emergency care providers (the responsibility of the municipalities). After-hours care assistance is also available via a nationwide telephone hotline. Payment of ambulatory after-hours care is based on the above-mentioned fee schedule, again with differences in the amount of reimbursement for SHI and PHI.

Hospitals: Not-for-profit public hospitals make up about half of all beds, while private not-for-profits account for about a third. The number of private, for-profit hospitals has been growing in recent years (around onesixth of all beds). Regardless of ownership, hospitals are staffed principally by salaried doctors. Doctors in hospitals are typically not allowed to treat outpatients (similar to hospitalists in the U.S.), but exceptions are made if necessary care cannot be provided by office-based specialists. Senior doctors can treat privately insured patients on an FFS basis. Since 2004, hospitals can also provide certain highly specialized services on an outpatient basis.

The 16 state governments determine hospital capacity, while ambulatory care capacity is subject to rules set by the Federal Joint Committee. Inpatient care is paid per admission through a system of diagnosis-related groups (DRGs), made obligatory in 2004, currently based on 1,187 DRG categories. The system is revised annually to 
account for new technologies, changes in treatment patterns, and associated costs. Other payment systems like pay-for-performance or bundled payments have yet to be implemented in hospitals.

Long-term care: LTCI is mandatory and usually provided by the same insurer as health insurance, and therefore is composed of a similar public-private insurance mix. The contribution rate of 1.95 percent of gross salary is shared between employers and employees; people without children pay an additional 0.25 percent. Everybody with a physical or mental illness or disability (who has contributed for at least two years) can apply for benefits. Eligible beneficiaries are stratified into three groups of care needs dependent on illness or disability severity. As stated above, beneficiaries can choose between in-kind benefits and cash payments (around a quarter of LTCI expenditure goes to these cash payments). Both home care and institutional care are provided almost exclusively by private not-for-profit and for-profit providers. LTCI covers approximately 50 percent of institutionalized care, and hospices and ambulatory palliative care are fully covered.

Mental health care: During the process of dehospitalization in the 1990s, acute psychiatric inpatient care was largely shifted to psychiatric wards in general (acute) hospitals and the number of hospitals providing care only for patients with psychiatric and/or neurological illness fell, while the number of office-based psychiatrists, neurologists, and psychotherapists working in the ambulatory care sector (all funded by both SHI and VHI, and paid FFS) increased. To further promote outpatient care for psychiatric patients (particularly in rural areas with a low density of psychiatrists in ambulatory care), hospitals can be authorized to offer outpatient treatment. Since 2000, ambulatory psychiatrists have been made coordinators of a new set of SHI-financed benefits called "sociotherapeutic care" (which requires referral by a GP), to encourage the chronically mentally ill to use necessary care and to avoid unnecessary hospitalizations.

\section{What are the key entities for health system governance?}

Within the legal framework, the Federal Joint Committee has wide-ranging regulatory power to determine the services to be covered by sickness funds and to set quality measures for providers (see below). To the extent possible, their coverage decisions are based on evidence from health technology assessments and comparativeeffectiveness reviews. The Federal Joint Committee is supported by the Institute for Quality and Efficiency (IQWiG), a foundation legally charged with evaluating the cost-effectiveness of drugs with added therapeutic benefits, and the Institute for Applied Quality Improvement and Research in Health Care (the AQUA Institute). Since 2008, the Federal Joint Committee has had 13 voting members: five from the Federal Association of Sickness Funds, two each from the Federal Association of Statutory Health Insurance Physicians and the German Hospital Federation, one from the Federal Association of SHI Dentists, and three who are unaffiliated. Five patient representatives have an advisory role but no vote in the committee.

The Federal Association of Sickness Funds works with the Federal Association of Statutory Health Insurance Physicians and the German Hospital Federation to develop the ambulatory care fee schedule and the DRG catalogue, respectively, which are then adopted by bilateral joint committees. To extend competition beyond these jointly regulated issues, some purchasing powers have been handed over to the sickness funds, e.g., to contract providers selectively within an integrated care contract or to negotiate rebates with pharmaceutical companies. 


\section{What is being done to ensure quality of care?}

Quality of care is addressed through a range of measures broadly defined by law, and in more detail by the Federal Joint Committee. Since January 2010, the AQUA Institute has been charged with developing quality assurance across ambulatory and inpatient care. Although there are several approaches and associations to ensure quality of care and patient safety, a national safety agency does not yet exist. Structural quality is assured by the requirement that providers have a quality management system, by the stipulation that all physicians continue their medical education, and by health technology assessments for drugs and procedures. All new diagnostic and therapeutic procedures applied in ambulatory care must be positively evaluated in terms of benefits and efficiency before they can be reimbursed by sickness funds. Hospital accreditation is voluntary. Volume thresholds have been introduced for a number of complex procedures (e.g., transplantations), requiring a minimum number of such procedures for hospitals to be reimbursed. Process and (partly) outcome quality is addressed through the mandatory quality reporting system for about 2,000 acute-care hospitals. Under this system, more than 150 indicators are measured for 30 diagnoses and procedures covering about one-sixth of all inpatients.

Since 2007, all hospitals have been required to publish results on 27 selected indicators defined by the Federal Office for Quality Assurance, enabling a comparison of hospitals. Many institutions and health service providers include complaint management systems as part of their quality management programs, which, in 2013, were made obligatory for hospitals. At the state level, professional providers' organizations are urged to establish complaint systems and arbitration boards for the extrajudicial resolution of medical malpractice claims.

Since 1998, the Robert Koch Institute, an agency subordinate to the Federal Ministry of Health and responsible for the control of infectious diseases and health reporting, has conducted national patient surveys and published epidemiological, public health, and health care data. Disease registries for specific diseases, such as certain cancers, are usually organized regionally. In August 2012, as part of the National Cancer Plan, the federal government introduced a draft bill that proposes the implementation of a nationwide standardized cancer registry in 2018 to improve the quality of cancer care; every hospital will be obliged to document the incidence, treatment, and course of the disease.

\section{What is being done to improve care coordination?}

Many efforts to improve care coordination are being implemented. Since the introduction of multispecialty clinics in ambulatory care in 2004, their number had grown from 70 clinics and 251 working physicians to 1,814 clinics and 10,020 working physicians (6.8\% of ambulatory care physicians) by 2011 . SHI funds also offer integrated-care contracts: GPs receive an average flat rate of approximately $€ 100$ (US\$135) per year for each patient enrolled in such a contract. Legislation in 2002 introduced SHI disease management programs for chronic illnesses to improve the provision of care for chronically ill patients and to improve care coordination between providers in the ambulatory sector. Disease management programs for diabetes types 1 and 2, breast cancer, coronary heart disease, asthma, and chronic obstructive pulmonary disease are modeled on evidence-based treatment recommendations, with mandatory documentation and quality assurance. Physicians receive an extra payment for their efforts in documentation. Nonbinding clinical guidelines are produced by the Physicians' Agency for Quality in Medicine and by professional societies. In January 2012, 10,618 registered regional disease management programs had enrolled almost 6 million patients (about $8 \%$ of all SHI-insured). 
Participating in such a program is voluntary for patients and can be done through GPs as well as specialists. Sickness funds are free to give patients incentives to enroll, such as exemptions from copayments for pharmaceuticals. Until 2009, participation in disease management programs was a separate category in the risk adjustment scheme, giving sickness funds a strong incentive to implement them. Since the risk adjustment scheme was strengthened in 2009, sickness funds receive only a per-capita administration compensation of $€ 168$ (US\$227) per year for each insured enrolled in a program.

\section{What is being done to reduce health disparities?}

Strategies to reduce health disparities are mainly delegated to public health services, and the levels at which they are carried out differ from state to state. Health disparities are implicitly mentioned in the national health targets. In 2001, the Federal Center for Health Education initiated a network of 53 health-related institutions (e.g., sickness funds and their associations) to promote the health of the socially deprived. The law $\$ 20$ SGB V makes primary prevention mandatory for sickness funds; detailed regulations are delegated to the Federal Association of Sickness Funds, which has developed guidelines regarding need, target groups, and access, as well as content and methods. Sickness funds support 22,000 health-related programs according to law $\$ 20$ SGB V, e.g., in nurseries and schools.

\section{Who is responsible for population health?}

The Federal Institute for Infectious and Non-Communicable Diseases, otherwise known as the Robert Koch Institute, is responsible for the surveillance, detection, prevention, and control of diseases. Since 2000 the Institute's role in the areas of prevention and surveillance has been strengthened with regard to monitoring, the coordination of interventions, risk communication, international cooperation, and microbiological and epidemiological research. While the specific tasks of the public health services and the levels at which they are carried out differ from state to state, they generally include activities linked both to the states' sovereign rights and the care provided for selected groups, such as: surveillance of communicable diseases; health reporting; supervision of hygiene in hospitals and among hospital staff, and, since 2000 , of office-based physicians and nonphysician health professionals; supervision of commercial activities involving food, pharmaceuticals, and drugs; overseeing certain areas of environmental hygiene; physical examinations of school children and certain other groups; diagnostic and-in exceptional circumstances-therapeutic services for persons with specific communicable diseases, including sexually transmittable diseases and tuberculosis; provision of community-oriented psychiatric services; health education and promotion; and cooperation with and advice to other public agencies. These services are provided by roughly 350 public health offices across Germany, which vary widely in size, structure, and tasks.

\section{What is the status of electronic health records?}

About 90 percent of physicians in private practice use electronic health records (EHRs) to help with billing, documentation, tracking of laboratory data, and quality assurance. In some regions, about 60 percent of physicians use online services to transmit billing information and documentation from disease management programs. A unique patient identifier does not exist, as data safety concerns represent a significant obstacle. Nevertheless, many hospitals have implemented EHRs, to varying degrees. The greatest problem with implementing a systemwide EHR is the incompatibility of the different programs within and between hospitals, and between hospitals and ambulatory care. A national strategy to create an electronic medical chip card was implemented in 
October 2011 and by January 2013 about 70 percent of SHI enrollees had received the new card. Owing to difficulties of data security, the electronic medical chip card contains the same data as the card before (the insured person's name, address, date of birth and health insurance fund, along with details of insurance coverage and the person's status regarding supplementary charges).

\section{How are costs controlled?}

A central element of the 2007 health reform legislation aimed to enhance competition in health care services with the introduction of various elective insurance schemes (such as disease management programs, family physician care models, and optional deductible schemes). Enrolling in an elective insurance scheme is voluntarily and the contract lasts for at least three years. Sickness funds are obliged by law to report regularly on the results of these insurance schemes, especially regarding efficiency and savings.

All drugs, both patented and generic, have been subject to reference prices since 2004, unless they can demonstrate added medical benefit. Since 2008, IQWiG has been legally charged with evaluating the cost-effectiveness of drugs with added therapeutic benefits, leading to either inclusion in the reference group in case of no added benefit, or price negotiations between the manufacturer and the Federal Association of Sickness Funds. Since 2011, drug companies have been required to produce a scientific dossier demonstrating a drug's added medical benefit, to be evaluated by the Federal Joint Committee and IQWiG within a three-month period. In addition, rebates by sickness funds to pharmaceutical manufacturers have been negotiated as incentives to lower prices below the reference price.

Recently, reliance on overall budgets for ambulatory physicians and hospitals and collective regional prescription caps for physicians has been replaced by emphasis on quality and efficiency. However, physicians are still financially liable if they exceed regular volumes for their patient mix above the prescription cap.

\section{What major innovations and reforms have been introduced?}

During what is known as the 2011 health reform, four acts were introduced between 2010 and 2012. In 2010, the SHI Financing Act was enacted into law; although conversion to a new model of financing for SHI has not yet happened, this act is a step toward per-capita flat-rate financing of SHI. It legislated 1) the setting of a uniform contribution rate by law, rather than by the federal government; 2) the supplementary insurance premium, which individual sickness funds can impose if necessary, and which is no longer limited to 1 percent of the income of a member; and 3) the introduction of socioeconomic adjustment, paid into the health care fund as a federal subsidy, to protect members with lower incomes from excessive financial burdens.

The 2011 health care reform also involved extensive changes for the pharmaceutical sector. The SHI Reform Act of 2010 and the Pharmaceuticals Market Reform Act of 2011 both provide structural changes and anticipated savings over a defined period of time. The SHI Reform Act has obliged pharmaceutical manufacturers to give a discount of 16 percent (previously 6\%) on all drugs that are not subject to a reference price; prices have been frozen at the August 2009 level until the end of 2013.

The final major piece of legislation for health care reform was passed in December 2011: the SHI Care Structure Act consists of a number of measures with the common objective of improving provision of services 
nationwide. Structural changes particularly relate to ambulatory SHI care and are intended to counteract the problem of under- and oversupply.

The “General Law on Patients' Rights" came into force into 2013. It includes several measures designed to strengthen patients' rights. The most important one is the incorporation of the treatment agreement into the Civil Code, in which the rights, duties, and forms of etiquette emerging from the relationship between provider and patient are established, as well as a statutory duty to provide information and documentation to patients upon their request.

The author would like to acknowledge Reinhard Busse and Stephanie Stock as contributing authors to earlier versions of this profile.

\section{References}

Busse, R., Blümel, M., and Ognyanova, D. (2013). "Das deutsche Gesundheitssystem: Akteure, Daten, Analysen”, Medizinische Wissenschaftliche Verlagsgesellschaft, European Observatory on Health Systems and Policies.

Federal Ministry of Health (Bundesministerium für Gesundheit) (2012). Daten des Gesundheitswesens 2012, http://www.bmg.bund.de (accessed Aug. 24, 2013).

Federal Association of Sickness Funds (GKV Spitzenverband) (2013). Kennzahlen der gesetzlichen Krankenversicherung, http://www.gkv-spitzenverband.de (accessed Aug. 24, 2013).

Federal Association of SHI Physicians (Kassenärztliche Bundesvereinigung) (2013). Statistische Informationen aus dem Bundesarztregister 2012, http://www.kbv.de (accessed Aug. 24, 2013).

Federal Statistical Office (Statistisches Bundesamt) (2012). Gesundheitsberichterstattung des Bundes, http:// www.gbe-bund.de (accessed Aug. 24, 2013). 


\title{
The Italian Health Care System, 2013
}

\author{
Andrea Donatini, Emilia-Romagna Regional Health Authority
}

\section{What is the role of government?}

The central government controls the distribution of tax revenue for publicly financed health care (Servizio Sanitario Nazionale, or SSN) and defines a national minimum statutory benefits package to be offered to all residents in every region - the "essential levels of care" (livelli essenziali di assistenza, or LEAs; see below). The 19 regions and two autonomous provinces have responsibility for the organization and delivery of health services through local health units (LHUs). The regions enjoy significant autonomy in determining the macro structure of their health systems. LHUs are managed by a CEO appointed by the governor of the region, and deliver primary care, hospital care, public health, occupational health, and health care related to social care.

\section{Who is covered?}

The SSN covers all citizens and legal foreign residents. Coverage is automatic and universal. Since 1998, illegal immigrants have been granted access to basic services. Temporary visitors can receive health services by paying for the costs of treatment. Modeled after the British National Health Service, the SSN replaced a Bismarckian system of health insurance funds in 1978. Complementary and supplementary private health insurance is also available.

\section{What is covered?}

Services: Primary and inpatient care are free at the point of use. Positive and negative lists are defined using criteria related to medical necessity, effectiveness, human dignity, appropriateness, and efficiency in delivery. Positive lists identify services that are to be offered to all residents (e.g., pharmaceuticals, inpatient care, preventive medicine, ambulatory care, home care, primary care). Negative lists, on the other hand, identify services that are not offered to patients (e.g., cosmetic surgery), services which are covered only on a case-by-case basis (e.g., orthodontics and laser eye surgery) and services for which hospital admissions are likely to be inappropriate (e.g., cataract surgery). Payment rates for hospital and outpatient care are determined by each region, with national rates (determined by the Ministry of Health) as a reference, while the National Drugs Agency sets the reference price for drugs. Regions can choose to offer non-LEA services, but must finance them themselves.

LEAs do not include a specific list of mental health services. Rather, national legislation creates an organizational framework for mental health services, and local health authorities are obliged to define the diagnostic, curative, and rehabilitative services available at each level of care. Nor do LEAs explicitly define the preventive, public health, or long-term care services that are covered by the SSN. Instead, they outline general community and individual levels of preventive services to be covered, including hygiene and public health, immunization, and early diagnosis tools. In addition, they broadly state that rehabilitative and long-term inpatient care is to be delivered as part of a standard, inpatient curative care program.

Prescription drugs are divided into three tiers according to clinical effectiveness and, in part, cost-effectiveness. The SSN covers the first tier in all cases, but covers the second tier only in hospitals, and does not cover the 
third. For some categories of drugs, therapeutic plans are mandated, and prescriptions must follow clinical guidelines.

Dental health care is included in the LEAs for specific populations such as children (0-16 years old), vulnerable people (the disabled, people with HIV, people with rare diseases), and individuals who need dental health care in some urgent/emergency cases. For other people, dental care is generally not covered and is paid for out of pocket (OOP).

Cost-sharing: Procedures and specialist visits can be prescribed either by a GP or by a specialist. Since 1993, patients have paid for the total cost per prescription up to a ceiling determined by law-currently, the ceiling stands at $€ 36.15$. Therefore, a patient who receives two separate prescriptions (e.g., a magnetic resonance imaging scan and a laboratory test) after a visit has to pay the first $€ 36.15$ for each prescription. To address rising public debt, in July 2011, the government introduced, along with other economic initiatives, an additional €10 copayment for each prescription. Copayments have also been applied to outpatient drugs at the regional level and, since 2007, a $€ 25$ copayment has been introduced for the "unwarranted" use of emergency services-that is, instances deemed to be noncritical and nonurgent (although some regions have not enforced this copayment). Public providers, and private providers under a contractual agreement with the SSN, are not allowed to charge above the scheduled fees.

Safety net: All individuals with OOP payments over $€ 129$ in a given year are eligible for a tax credit equal to roughly one-fifth of their spending, but there are no caps on OOP spending. Exemptions from cost-sharing are applied to people age 65 and over or age 6 and under who live in households with a gross income below a nationally defined threshold (approximately $€ 36,000$ ); people with severe disabilities, as well as prisoners, are exempt from any cost-sharing. People with chronic or rare diseases, people who are HIV-positive, and pregnant women are exempt from cost-sharing for treatment related to their condition. Most screening services are provided free of charge.

\section{Who is responsible for population health?}

Local health units (LHUs) are responsible for protecting and promoting public health and are responsible for achieving the health objectives and targets established by national and regional planning. Each LHU has a health promotion division in charge of hygiene and public health (infectious and parasitic disease, prophylaxis, health promotion and education), food control (prevention of food-related disease and nutritional surveillance), occupational diseases and accidents, and veterinary medicine.

In 2004, the National Centre for Disease Prevention and Control (CCM) was established by the Ministry of Health $(\mathrm{MoH})$. The CCM's main objective is active prevention, which it pursues through the promotion of healthy lifestyles and screening and by addressing a variety of health emergencies.

\section{How is the health system financed?}

Publicly financed health care: Public financing accounted for 78.2 percent of total health spending in 2012 (Organisation for Economic Co-operation and Development, 2013). The public system is financed primarily through a corporate tax pooled nationally and allocated back to the regions, typically the source region (there 
are large interregional gaps in the corporate tax base, leading to financing inequalities), and a fixed proportion of national value-added tax (VAT) revenue collected by the central government and redistributed to regions unable to raise sufficient resources to provide LEAs (see section on health disparities). Regions are allowed to generate their own additional revenue, leading to further interregional financing differences. Every year the Standing Conference on Relations between the State, the Regions and the Autonomous Provinces (set up in 1988, with the presidents of the regions and representatives from the central government as its members) sets the criteria (population size and age demographics) used to allocate the funding for delivering the LEAs among the regions. LHUs are funded mainly through capitated budgets.

The 2008 financial law established that regions would be financed through standard rates set on the basis of actual costs in the regions considered to be the most efficient. Established in legislation, this policy is not operating yet

Privately funded health care: In 2011, 18 percent of total health spending was paid out of pocket, mainly for drugs not covered by the public system (over-the-counter drugs) and for dental care (OECD, 2013). OOP payments can be used to access specialist care and, to a lesser extent, inpatient care delivered in private and public facilities to paying patients.

Private health insurance (PHI) plays a limited role in the health system, accounting for roughly 1 percent of total health spending in 2009. Approximately 15 percent of the population has some form of PHI, generally to cover services excluded under the SSN, to benefit from a higher standard of comfort and privacy in hospital facilities, and to have wider choice among public and private providers. Some PHI policies also cover copayments for privately provided services, or provide compensation during hospitalization, with patients receiving a fixed sum per day. Since the Italian SSN does not allow members to opt out of the system and seek only private care, substitutive insurance does not exist. PHI is provided both by mutual associations (distinguished by their nonprofit status) and by commercial (for-profit) companies, with very few $(0.8 \%)$ specializing in health care insurance only. Approximately 74 percent of policies are purchased by individuals, while the remaining 26 percent are purchased by groups. In 1999, increased tax relief was established for PHI contributions.

\section{How are health services organized and financed?}

Primary/ambulatory care: General practitioners and pediatricians (GPs) are paid on a capitation basis. LHUs can also pay additional allowances for the delivery of planned care to specific patients (e.g., home care for chronically ill patients), for reaching performance targets, or for delivering additional treatments (e.g., medications, flu vaccinations), sometimes related to performance, and are regulated under national and regional contracts. Capitation is adjusted for age and accounts for approximately 70 percent of the overall payment. The variable portion comprises fee-for-service (FFS) payment for specific treatments, including minor surgery, home care, preventive activities, and taking care of chronically ill patients. It also may include a portion related to performance in order to reward effective cost containment on pharmaceuticals, laboratory tests, and therapeutic treatments prescribed by the GP.

The payment levels, duties, and responsibilities of GPs are determined in a collective agreement signed every three years by consultation between the central government and the GPs' trade unions. 
The majority of GPs operate in solo practices, although the central government and the regions have offered economic incentives to encourage group practice and greater integration between GPs and social care, home care, health education, and environmental health services (see below). In 2010, there were approximately 53,500 general practitioners and pediatricians (33.3\%) and 107,000 hospital clinicians (66.7\%). Patients are required to register with a gatekeeping GP, who has incentives to prescribe and refer only as appropriate. People may choose any physician whose list has not reached the maximum number of patients allowed (1,500 for GPs and 800 for pediatricians) and may switch at any time.

Outpatient specialist care: Outpatient specialist care is generally provided by LHUs or by public and private accredited hospitals under contractual agreement with an LHU. Once referred, patients are given free choice of any public or private accredited hospital. Ambulatory specialists are generally paid on a per-hour basis, while hospital-based physicians are salaried employees.

After-hours care: To promote coordination among health care professionals and improve the accessibility of primary care, government and GP associations have agreed to implement a model where GPs, specialists, and nurses coordinate to ensure 24-hour access and avoid unnecessary use of hospital emergency departments. The general structure of the model has been outlined in the collective agreement; there is no additional payment for the provision of this care, and regions have been given the responsibility of developing the model. Implementation is uneven across regions. After-hours centers are generally located in LHU-owned premises. Following examination and initial treatment, the doctor can prescribe medication, issue employees' medical certificates, and recommend hospital admission. Guardia medica is a free telephone health service for emergency cases. It normally operates at night and on weekends, and the doctor on duty usually provides advice, in addition to home visits if needed. Information on a patient's visit is not routinely sent to the patient's GP.

Hospitals: Depending on the region, public funds are allocated by the LHU to public and accredited private hospitals (private hospitals must be accredited by the region in which they operate in order to contract with the SSN; public hospitals must also undergo the accreditation process). In 2010 there were approximately 200,000 hospital beds in public hospitals and 48,000 beds in private accredited hospitals. Public hospitals either are managed directly by the LHUs or operate as semi-independent public enterprises, similar to the traditional British trust hospitals. A diagnosis-related group-based prospective payment system operates across the country, although it is generally not applied to hospitals run directly by LHUs. There are considerable interregional variables in the prospective payment system, such as how the fees are set, which services are excluded, and what tools are employed to influence patterns of care. Regions even use different coding and classification systems. Moreover, in all regions, a portion of funding is administered outside the prospective payment system (e.g., funding of specific functions such as emergency departments and teaching programs). All regions have mechanisms for cutting tariffs once a spending threshold for the hospital sector is reached, to contain costs and offset incentives to increase admissions. Hospital-based physicians are salaried employees. Before 1999, all physicians could earn additional income by treating patients privately on an FFS basis, but since then public-hospital physicians have been prohibited from treating patients in private hospitals; all public physicians who see private patients in public hospitals must now pay a portion of their extra income to the hospital.

Mental health care: Mental health care is provided by the SSN in a variety of community-based, publicly funded settings, including community mental health centers, community psychiatric diagnostic centers, general 
hospital inpatient wards, and residential facilities. At present, promotion and coordination of mental health prevention, care, and rehabilitation are the responsibility of specific mental health departments in LHUs. These are based on a multidisciplinary team, including psychiatrists, psychologists, nurses, social workers, educators, occupational therapists, people with training in psychosocial rehabilitation, and secretarial staff. Flat copayments apply to diagnostic procedures, pharmaceuticals, and specialist visits. Physicians or specialists providing mental health services are reimbursed on a capitation basis.

Long-term care: Patients are generally treated in residential (approximately 213,000 beds in 2010) or semi-residential (approximately 48,000 beds) facilities, or in community home care (approximately 600,000 cases). Residential and semi-residential services provide nurse, physician, and specialist care; rehabilitation services; and medical therapies and devices. Patients must be referred in order to receive residential care. Cost-sharing for residential services varies widely according to region, but is generally determined by patient income. Community home care is funded publicly, whereas residential facilities are managed by a mixture of public and private, for-profit and nonprofit organizations. Unlike residential and semi-residential care, community home care is not designed to provide physical or mental care services but rather to enhance a patient's autonomy by providing additional assistance throughout a course of treatment or therapy. In spite of government provision of residential and home care services, long-term care in Italy has traditionally been characterized by a low degree of public financing and provision ass compared with other European countries.

Until 1999, palliative care was very limited and was concentrated mainly in northern Italy. Much was left to the efforts of voluntary organizations, which still play a crucial role in the delivery of these services. Although much still needs to be done to ensure the diffusion of homogeneous palliative care services, a national policy on palliative care has been in place since the end of the 1990 and has contributed to an increase in palliative care services such as hospices, day-care centers, and palliative care units within hospitals.

\section{What are the key entities for health system governance?}

The $\mathrm{MoH}$ draws on the expertise of various institutions for technical support. Key nongovernmental entities include the National Health Council (which provides support for national health planning, hygiene and public health, pharmacology and pharmaco-epidemiology, continuing medical education for health care professionals, and information systems) and the National Institute of Health (which provides recommendations and control in the area of public health). The National Committee for Medical Devices (created in 2003) develops cost-benefit analyses and determines reference prices. The Agency for Regional Health Services, the main institution responsible for conducting comparative effectiveness analysis, is accountable to the regions and the Ministry of Labor. The National Drugs Agency (Agenzia Italiana del Farmaco), founded in 2003, is responsible for all matters related to the pharmaceutical industry, focusing on quality, production, distribution, scientific research, and prescription drug pricing and reimbursement policies. It is accountable to the $\mathrm{MoH}$ and the Ministry of Economy and Finance.

The national government defines the benefits package, or LEAs, at the annual Standing Conference on Relations between the State, the Regions and the Autonomous Provinces. Decisions are based mainly on clinical effectiveness and appropriateness rather than cost-effectiveness. At the regional level, some governments have established agencies to evaluate and monitor local health care quality and provide technical 
comparative effectiveness assessments and scientific support to regional health departments (see below). Regional governments underwrite annual "Pacts for Health" that link additional resources to the achievement of health care planning and expenditure goals.

\section{What is being done to ensure quality of care?}

The national and regional ministries, which are responsible for upholding quality, ensure that LEA services are provided and waiting times are monitored. Several regions have introduced effective programs for prioritizing the delivery of care on the basis of clinical appropriateness of services prescribed and patient severity (France et al., 2005). All doctors under contract with the SSN must be certified, and all SSN staff participate in a compulsory continuing education program. The National Commission for Accreditation and Quality of Care is responsible for outlining the criteria used to select providers and for evaluating the accreditation models (including that of private hospitals), which are regionally determined and vary considerably across the system.

The National Health Plan for 1994-1996 led to the establishment of the National Oncology Commission; it was tasked with developing an intervention program to monitor and prevent cancer. Screening guidelines were then produced with the aim of reducing the heterogeneity of interventions and enhancing evidence-based program planning.

In 1995, national legislation stated that all public health care providers should issue a "health service chart" that provides the public with information on service performance, highlighting quality indicators, waiting times, and a strategy for quality assurance, while also outlining the process by which patients can make complaints in the system. These charts have been adopted by the private sector for its accreditation process, and must be published annually, although dissemination methods are decided regionally. Most providers issue performance data through leaflets and the Internet, while nurses and other medical staff are offered financial incentives for performance (linked to manager evaluations but not to publicly reported data). The National Plan for Clinical Guidelines has been implemented in recent years and has produced guidelines on topics ranging from cardiology to cancer prevention and from appropriate use of antibiotics to cesarean delivery.

In 2003, the National Technical Committee on Clinical Risk was established, and a year later the Working Group for the Assessment of Methodological Approaches for the Evaluation of Clinical Risk was formed. In February 2006, the two groups merged into the Working Group on Patient Safety (WGPS), and in 2007 the Ministry of Health initiated the National System for Patient Safety as a two-year pilot project, which also functions as the National Observatory for Patient Safety in collaboration with the WGPS.

\section{What is being done to improve care coordination?}

In the past few years general practice has witnessed a transformation, with the solo practice model being progressively modified by new organizational forms (networks, groups, etc.), particularly in the northern part of the country. Specifically, recent legislation encourages multidisciplinary teams to work in three ways: base group practice, where GPs from different offices share clinical experiences, develop guidelines, and participate in workshops that assess performance; network group practice, which functions like base group practice but allows GPs to access the same patient electronic health record system; and advanced group practice, where GPs 
share the same office and patient health record system, and are able to provide care to patients beyond individual catchment areas.

Also in recent years, significant inroads have been made into better integration of health and social care services, with the vision being to shift long-term care from institutional services to community care with an emphasis on the home. The community home care scheme was founded as part of the National Health Plan for 1998-2000, and establishes a home care network that integrates the competencies of nurse, GP, and specialist physician with the needs and involvement of the family. GPs oversee the home care network, liaise with social workers and other sectors of care, and take responsibility for patient outcomes.

Some regions are promoting care coordination by asking their GPs to work in multi-specialty groups involving specialists, nurses, and social workers. The aim is for each group to be in charge of all the health needs of its assigned population. Shifting to this new organizational arrangement nevertheless requires considerable efforts, given that, traditionally, Italian GPs have been used to working in solo practices. To further promote integration and adoption of multidisciplinary teams, Medical Homes are being encouraged in some regions. Tuscany and Emilia-Romagna have invested considerable resources in activating and promoting Medical Homes. In Emilia-Romagna, for example, there are currently 51 medical homes providing multi-specialty care to approximately 700,000 people.

\section{What is being done to reduce health disparities?}

Interregional inequity is a long-standing concern. The less affluent southern regions trail the northern regions in the number of beds and availability of advanced medical equipment, have more private facilities, and have less-developed community care services. Data show a rise in interregional mobility in the 1990s, with movement particularly from southern to central and northern regions (France, 1997). Income-related disparities in selfreported health status are significant, though relatively low and similar to those observed in the Netherlands, Germany, and other European countries (Van Doorslaer and Koolman, 2004).

The National Health Plan for 2006-2008 cites overcoming large regional discrepancies in care quality as a key objective for future reform. The Ministry of Health and the Ministry of Economics and Finance signed an agreement in April 2007 to direct EU resources toward health services in eight regions in the south, as a first step in reducing this persistent variation. Regions receive a proportion of funding from an equalization fund (the National Solidarity Fund), which aims to reduce inequalities between northern and southern regions. Aggregate funding for the regions is set by the Ministry of the Economy and Finance, and the resource allocation mechanism is based on capitation adjusted for demographic characteristics and use of health services by age and sex.

\section{What is the status of electronic health records?}

In 2001, the New Health Information System (NSIS) was developed to establish a universal system of electronic health records that connects every level of care and provides information on the services delivered, resources used, and associated costs. The NSIS has been implemented incrementally since 2002, but is not yet universal. A core component of the NSIS is the nationwide clinical coding program known as the "bricks" program, aimed at defining a common language to classify and codify concepts in a uniform manner; at sharing methodologies 
for measuring quality, efficiency, and appropriateness of care; and at allowing an efficient exchange of information between the national level and regional authorities. The "bricks" program has been the focus of considerable effort and is one of the most mature elements of Italy's developing electronic health program. Some regions have developed computerized networks connecting physicians, pediatricians, hospitals, and territorial services to facilitate communication among health care professionals and to improve continuity of care. These networks allow automatic transfer of patient registers, services supplied to patients, prescriptions for specialist visits and diagnostics, and laboratory and radiology test outcomes.

\section{How are costs contained?}

Containing health costs is a core concern of the central government, as public debt in Italy is among the highest in industrialized nations. Fiscal capacity varies greatly across regions. Recently, the central government imposed specific recovery plans on those regions that have generated financial deficits in health care expenditure. The plans identify tools and measures needed to achieve economic balance, which include revising hospital and diagnostic tariffs, reducing the number of hospital beds, increasing copayments for pharmaceuticals, and reducing human resources through limits on staff turnover.

In 2007, the Agency for Regional Health Services, in collaboration with the Ministry of Health, was given authority to conduct health technology assessments (HTAs) and disseminate the implementation of its findings at the regional level, but these are not yet formalized or undertaken systematically. There are very few regional health technology assessment agencies currently in place, but those that are have as their primary function to evaluate individual technologies, and the assessments are not mandatory for new or referred procedures and devices. However, reference prices for medical devices and pharmaceutical prices are set according to costeffectiveness studies carried out by the National Committee for Medical Devices and the National Drugs Agency, respectively. Furthermore, the National Pharmaceutical Formulary bases coverage decisions in part on clinical effectiveness and cost-effectiveness. Prices for reimbursable drugs are set in negotiations between the government and the manufacturer according to the following criteria: cost-effectiveness for pharmaceuticals where no effective alternative therapies exist; comparison of the prices of alternative therapies for the same condition; costs per day compared with those of products of the same effectiveness; the financial impact on the health system; the estimated market share of the new drug; and average prices and consumption data from other European countries. Prices for nonreimbursable drugs are set by the market.

\section{What major innovations and reforms have been introduced?}

Because of the regionalization of the health system, most innovations in the delivery of care take place at the regional rather than the national level, with some regions viewed as leaders in innovation. Significant innovations can be found in:

- pharmaceutical care: both the National Drugs Agency and the regions are particularly active in coordinating guidelines and rules to promote appropriate and cost-effective prescribing; and

- hospital care: various innovations have been introduced concerning the overall organization, management of operations (e.g., planning of surgical theaters and delivery of drugs), and health information technology (e.g., electronic medical records, automation of administrative and clinical activities). 
Regarding the organization and delivery of care, the 1992 reform was aimed toward a quasi-market for health care services, with LHUs and regions able to contract with competing public and private accredited providers. This new model of competition has emerged to varying degrees across regions, and has gradually changed. In some regions, the model has been fully implemented (e.g., Lombardia in the late 1990s), while in others the actual allocation of resources to hospitals has never followed competitive mechanisms (as in southern Italy). In addition, market mechanisms have increasingly evolved to balance financial incentives for quality and efficiency with clear safeguards for the financial viability of the system. Regions have used the hospital accreditation system and introduced caps on spending to create barriers to entry and to maintain control over expenditure.

With regard to cost containment, in August 2012 the national parliament passed a law aimed at curbing and rationalizing public expenditure (so called "spending review"). The law further promoted the prescription of generic drugs, cut the hospital bed ratio from four per 1,000 people to 3.7, and reduced the public financing of the SSN by $€ 900$ million in 2012, $€ 1.8$ billion in 2013 , $€ 2$ billion in 2014 , and $€ 2.1$ billion in 2015 . In 2012 , the government approved a decree (named after the then Minister of Health, Renato Balduzzi) to reorganize health care at the regional level, with the introduction of teams of primary health care professionals to ensure 24-hour coverage; to update health care tariffs; to restructure governance of hospitals and LHUs; to revise the list of reimbursable pharmaceuticals; and to introduce health technology assessment as a tool for renegotiating the price of less effective medicines. An evaluation of the decree's outcomes is not yet available as its implementation is still in its early stages.

The author would like to acknowledge Sarah Jane Reed and David Squires as contributing authors to earlier versions of this profile.

\section{References}

Dona Sofio, A., et al. (eds.) (2006). CEIS Health Report: Management of the Italian National Health System: Complexity and Perspectives of the New Institutional Set-Up (Rome: Health Communication, 2006).

France, G. (1997). "Cross-Border Flows of Italian Patients Within the European Union: an International Trade Approach," European Journal of Public Health, 7(3 Suppl.):18-25.

France, G., Taroni, F., and Donatini, A. (2005). “The Italian Health-Care System,” Health Economics, 14:S187-S202.

Lo Scalzo, A., Donatini, A., Orzella, L., Cicchetti, A., Profili, S., Maresso, A. (2009). "Italy: Health System Review," Health Systems in Transition, 11(6):1-216.

OECD Health Data, 2013

Van Doorslaer, E., Koolman, X. (2004). "Explaining the Differences in Income Related Health Inequalities Across European Countries," Health Economics, 13(7):609-28. 


\title{
The Japanese Health Care System, 2013
}

\author{
Ryozo Matsuda, College of Social Sciences, Ritsumeikan University, Kyoto
}

\section{What is the role of government?}

The government regulates almost all aspects of the universal public health insurance system (PHIS). The national government sets the fee schedule by developing consensus among stakeholders; gives subsidies to local governments, insurers, and providers to implement its policies; and establishes and enforces detailed regulations for insurers and providers. Japan's 47 prefectures (regions) implement regulations for health care providers and insurers and develop regional "visions" for health care delivery. More than 1,700 municipalities operate parts of the public health insurance and long-term care insurance systems and organize health promotion activities for their residents.

\section{Who is covered?}

About 3,500 insurers constitute the universal PHIS. Employees and their dependents under age 75 are required to enroll in the coverage offered either by their employers (if employed by large companies) or the Japan Health Insurance Association (if employed by small or medium-sized companies). The remaining population under age 75 (unemployed, self-employed, retired, and others) is covered by municipal-run "Citizens Health Insurance" plans. Those age 75 and over are covered by health insurance plans operated by insurers established in each prefecture ("Health Insurance for the Old-Old"). Individuals cannot choose their plan. Resident noncitizens and long-term visitors also are required to obtain coverage; undocumented immigrants are not covered. Those who neglect to enroll must pay back up to two years of premiums when they reenter the system. Means-tested public assistance covers health care for its recipients, since they are considered to be unable to pay premiums. Voluntary supplementary private health insurance (described further below) is held by the majority of the adult population to provide additional income in case of sickness, mainly in the form of lump-sum payments, such as daily amounts during hospitalization.

\section{What is covered?}

Services: All plans provide the same national benefits package, which covers hospital care, ambulatory care, mental health care, approved prescription drugs, home care, physiotherapy, and most dental care; it does not cover corrective lenses unless recommended by physicians for children under nine years old. A number of preventive measures are publicly provided to those age 40 and older, including screening, health education, and counseling. Since 2000 , long-term care has been covered under its own insurance system, administered by municipalities. Long-term care insurance provides personal budgets for patients to arrange their own services or have them organized by care managers.

Cost-sharing: All enrollees have to pay coinsurance (copayment) of 30 percent for services and goods covered, except for children under three years old (20\%) and people age 70 and over with lower incomes (10\%). In 2009, out-of-pocket payments, most of which were spent in the form of coinsurance, accounted for 16 percent of total health expenditures (OECD 2012). Some employer-based health insurance funds offer reduced cost-sharing. Providers are prohibited from charging extra fees except for some services specified by the Ministry of Health, 
Labour and Welfare, including amenity beds, "experimental" treatments, the outpatient services of large multispecialty hospitals, after-hours services, and hospitalizations of 180 days or more.

Safety net: Catastrophic coverage stipulates a monthly out-of-pocket threshold that varies according to enrollee age and income (for example, 80,100 yen for people under age 75 with an average income); above this threshold, a 1 percent copayment is applied. Alternatively, the threshold works as a ceiling for low-income people, who do not pay more than 35,400 yen a month. Subsidies (mostly restricted to low-income households) reduce the burden of cost-sharing for people with disabilities, mental illness, and specified chronic conditions. Annual expenditure on health services and goods, including copayments and payments for extra billing and over-the-counter drugs, of between 100,000 yen and 2 million yen can be deducted from taxable income. There is an annual household threshold for health and long-term care out-of-pocket payments, which varies between 310,000 yen and 670,000 yen according to income and age, above which such payments can be reimbursed. Enrollees with employer-based insurance who are on parental leave are exempt from payment of premiums. Enrollees with Citizens Health Insurance (for unemployed, self-employed, retired, and others under 75) with already low income and those with moderate income who face sharp, unexpected income reductions are eligible for reduced premium payments.

\section{How is the health system financed?}

Publicly financed health care: In 2009, 80.5 percent of total health expenditure was financed through the PHIS (OECD, 2012). Premiums accounted for approximately half of total health expenditure. Citizens Health Insurance insurers levy premiums on a per capita, per-household, income-related, and asset-related basis, and employer-based insurers levy premiums on wages. Employers pay half of these premiums for their employees. The premium rates of employer-based plans vary between 3 percent and 10 percent of payrolls. On the other hand, rates for employees of small and medium-sized employers, insured by the Japan Health Insurance Association, are around 10 percent of income. Rates also vary among municipalities, albeit to a smaller degree. Government employees are covered by their own system of insurers (known as Mutual Aid Societies), as are some groups of professionals (e.g., doctors in private practice). Government subsidies, funded from the general budget, are provided mainly to Citizens Health Insurance insurers, Health Insurance for the Old-Old insurers, and, to a lesser extent, small-business employer-based insurers. There are also cross-subsidies from Citizens Health Insurance and employer-based insurance to Health Insurance for the Old-Old, and between Citizens Health Insurance and employer-based insurance.

Privately funded health care: Provision of privately funded health care has been limited to such dental services as orthodontics and expensive artificial teeth, and treatments of traffic accident injuries. These treatments, however, are usually paid by compulsory and/or voluntary automobile insurance.

Private health insurance developed, historically, as a supplement to life insurance. It usually pays a lump sum when insured persons are hospitalized over a defined period and/or diagnosed with cancer or any of a number of other specified chronic diseases. More than 70 percent of adults hold this kind of insurance. In the past decade, however, complementary private health insurance policies sold separately from life insurance have been on the rise. More than 23 million policies were active in 2010, and most are issued on an individual basis (Life Insurance Association of Japan, 2012). Part of an individual's life insurance premium (up to 40,000 yen) 
can be deducted from taxable income. Small discounts also can be applied to the employees whose employers have collective contracts with insurance companies.

\section{How are health services organized and financed?}

Primary care: Primary care and specialist care are not regarded as distinct disciplines, although it has been argued that they should be. Traditionally, most physicians are trained as specialists, then choose to work in clinics and hospitals. Clinics are often owned by physicians or by medical corporations (special legal entities for health care management, usually controlled by physicians, that own hospitals as well as clinics), but sometimes by local governments or public agencies. Primary and specialist care are provided at clinics, although specialist care requiring hospitalization and the use of expensive medical devices is usually provided at hospitals. Primary care practices typically include teams with physicians and nurses. Clinics can dispense medication (which doctors can provide directly to patients). The use of pharmacists, however, has been growing; more than 60 percent of prescriptions were filled at pharmacies in 2009. There is no gatekeeping: a patient does not need to register with a physician to use health services and can choose to drop in at any clinic, but the government asks patients to choose their family physician. Extra-billing is prohibited in principle.

Payments for primary care are based principally on a complex national fee-for-service (FFS) schedule, which includes financial incentives for taking better care of those with chronic diseases, and for team ambulatory and home care. Per-case payments can be chosen by providers in selected cases: daily payments for pediatric care and monthly payments for treating patients with diabetes, hyperlipidemia, and hypertension. Most clinic-based physicians are self-employed; the rest are salaried. Clinics receive fees from insurers and accompanying copayments from patients. The PHIS fee schedule includes both primary care and specialist services, which have common prices for common services. It is a sum of fees for consultations, examinations, laboratory tests, imaging tests, defined chronic disease management, and certain other services. Bundled payments are not used.

Outpatient specialist care: Outpatient specialist care is provided at hospital outpatient departments as well as at clinics, where patients can visit without referral. Some hospitals, particularly educational hospitals, bill patients extra fees for visits without referrals from primary care physicians.

After-hours care: After-hours care is provided by hospital outpatient departments, where on-call physicians are available, and by regular clinics and after-hours care clinics. Hospitals and clinics are paid "top-up" fees for after-hours care, including telephone consultations. Usually, after-hours care clinics are staffed by physicians and nurses, and are owned by local governments, to which local medical societies provide human resources. The national government grants subsidies to local governments for these clinics. Information on the patient is provided by after-hours clinics to family physicians if necessary (often, that information is handed to patients to show to family physicians). There is a national pediatric medical advice telephone line called Telephone Advice on Children's Medical Emergencies for after-hours care for children.

Hospitals: More than 55 percent of hospital beds are in private nonprofit hospitals; the rest are in public hospitals, which tend to be larger than private hospitals. Entry by private for-profit companies into the hospital sector is virtually prohibited, while existing hospitals owned by for-profit companies established for 
their employees (e.g., Toyota) are allowed to continue. Payments to hospitals from the PHIS include costs for physicians, who are usually employed by the hospital on a salary basis. Public-hospital physicians can practice privately with the approval of their hospitals, but in such cases they usually provide services covered by the public system.

While patients in general are free to self-refer, some large hospitals and academic medical centers charge extra fees to patients not referred by a physician. Roughly half of all acute-care hospital beds are paid for solely on an FFS basis, and the other half are partially paid for using the Diagnosis Procedure Combination (DPC) modification, a case-mix classification similar to that of DRGs (Matsuda et. al., 2008). Hospitals voluntarily elect to receive the DPC payments or remain under FFS. The DPC payment consists of a DPC component and a fee-for-service component. A per diem payment determined by the DPC grouping is used for the DPC component, which includes basic hospital services and less-expensive treatments; the fee-for-service component includes surgical procedures, rehabilitative services, and other specified expensive services (OECD, 2009). DPC rates are multiplied by a hospital-specific coefficient, so as to keep them relatively in line with FFS payments. Episode-based payments are not used.

Mental health: Mental health care is covered under the PHIS, along with the standard 30 percent copayment, although financial protections exist that include reduced cost-sharing for patients recently discharged from psychiatric institutions. Japan has the largest number of psychiatric beds per capita in the world, but has been taking some steps in the past decade to move mental health care into the community. Approximately 80 percent of psychiatric beds are private and nonprofit, and providers are generally paid on an FFS basis. Outpatient and home mental health services, including psychological therapies, are also covered.

Long-term care: Long-term care has traditionally been provided by hospitals far more routinely in Japan than in other countries, although there is a policy focus on directing more patients to nursing home equivalents. Since 2000, the national Long-Term Care Insurance scheme, administered by the municipalities, has covered those age 65 and older and some disabled people age 40 to 64. It covers home help, home nursing, respite care, and domiciliary care, but not medical services. Palliative care in hospitals and medical services under home palliative care are covered by public health insurance, while nursing services are covered by long-term care insurance. Roughly half of the financing comes through taxation, and half through premiums. Premiums for those age 65 and older are decided by municipalities based on estimated expenditures and are linked to the income (including pensions) of the insured.

Premiums for those age 40 to 64 are decided by enrolled insurers and are collected along with premiums for health insurance. A 10 percent copayment applies to all covered services, up to an income-related ceiling. There is additional copayment for bed and board in institutional care, but it is waived or reduced for those with low income (all costs for those with means-tested social assistance are paid from local and national tax revenue). Most home care providers are for-profit and nonprofit; the remained is public. For-profits are not allowed in institutional care. 


\section{What are the key entities for health system governance?}

The Social Security Council, a statutory body within the Ministry of Health, Labour and Welfare, is in charge of national strategies on quality and safety, cost control, and the setting of provider fees in health care. The national government and prefectures make cost-control plans (described further below). The Japan Council for Quality Health Care, a nonprofit organization, works to improve quality throughout the health system and to develop clinical guidelines, although it does not have any regulatory power to punish poorly performing providers. Specialist societies themselves also produce clinical guidelines. Technology assessment of pharmaceuticals and medical devices is conducted by the Pharmaceutical and Medical Devices Agency, a regulatory agency of the government. Assessments are conducted using only medical, social, and ethical criteria, not economic ones. The Central Social Insurance Medical Council decides coverage of and fees for health care services and sets the Public Health Insurance Drug Price List, which is a list of pharmaceuticals and their prices covered by the PHIS (English Regulatory Information Task Force Japan Pharmaceutical Manufacturers Association, 2012). The criteria for coverage include clinical effectiveness and social acceptability but not economic appraisal. Since 2012, the council has been discussing possible application of comparative cost-effectiveness studies in its decisionmaking. Nonprofit organizations work for public engagement and patient advocacy, and every prefecture establishes a health care council to discuss the local health care plan. Under the Medical Care Law, these councils must have members representing patients. The Japan Fair Trade Commission is tasked with promoting fair competition among providers and medical device companies.

\section{What is being done to ensure quality of care?}

Under law, prefectures are responsible for conceiving health care delivery "visions," which include detailed visions for delivering care of cancer, stroke, acute myocardial infarction, diabetes mellitus, and psychiatric disease, as well as emergency medicine, pediatrics, prenatal medicine, rural medicine, disaster medicine, and home care. These visions include structural, process, and outcome indicators, as well as strategies for effective and high-quality delivery. Prefectures promote collaboration between providers to achieve them, with or without subsidies. Waiting times, in general, are not monitored by the government, although there is cause for concern in some clinical areas, such as palliative care. There are structural health care delivery regulations, including those concerning workforce, infrastructure, and medical devices, but relatively few apply to process and outcomes. Prefectures are in charge of annual inspection of hospitals. Hospitals can be sanctioned through reduced reimbursement rates if staffing per bed falls below a certain ratio. Hospital accreditation, on the other hand, is voluntary and is undertaken largely as an improvement exercise; roughly one-third of hospitals are accredited by the Japan Council for Quality Health Care. It does not, however, disclose names of hospitals that have failed the accreditation process. Since 2010, the Ministry of Health, Labour and Welfare has organized and financially supported a benchmarking project in which hospitals have voluntarily participated and publicly reported their quality indicators on their Web sites. The government has developed cancer registries in cooperation with local governments and has recently supported medical societies in developing them. Medical device registries are relatively underdeveloped, although the Pharmaceutical and Medical Devices Agency has started a registry for Mechanically Assisted Circulatory Support.

A physician needs a national license obtained through national examination in order to practice. No revalidation of licenses is required so far. However, specialist societies have introduced revalidation for 
qualified specialists. Clinical audits are voluntary. Public reporting on performance has been discussed, but is not yet available.

Every prefecture has a medical safety support center for handling complaints and promoting safety. Since 2004, advanced academic and public hospitals have been required to report adverse events to the Japan Council for Quality Health Care.

\section{What is being done to improve care coordination?}

Care coordination has developed differently in different areas, with different utilizations of information technology. Clinics are mostly physician-led, with nurses playing less of a role in caring for patients. Multispecialty groups or clinics are not common. Rather, physicians refer patients to each other if necessary. Although little information has been available on communication between physicians, the amount of organized coordination involving multi-providers seems to have been increasing in the last five years (Ueno, 2013).

In 2008, financial incentives were introduced to improve care coordination, particularly in cancer care, stroke care, cardiac care, and palliative care. Hospitals admitting stroke victims or patients with hip fractures can receive additional fees if they use post-discharge protocols and make contracts with clinic physicians (for which those physicians also receive additional fees) to provide effective follow-up care after discharge. The government has developed other subsidies for leading providers in the community to facilitate care coordination.

\section{What is being done to reduce health disparities?}

In 2012, the government revised its health promotion objectives, known as Health Japan 21, and made reduction of health disparities a general goal. Its objectives include a target for reducing disparities in healthy life expectancies and cancer treatment delivery between prefectures; the government gives subsidies to prefectures to develop cancer care centers.

\section{What is the status of electronic health records?}

In 2013, almost all hospitals used electronic billing, compared with 85.6 percent of medical clinics, 47.2 percent of dental clinics, and 94.8 percent of pharmacies (National Insurance Claims Review \& Reimbursement Services, 2013). The government has made electronic billing obligatory in the PHIS for all providers except those without the necessary staffing and instruments. Despite a number of initiatives over the past decade, electronic health record networks have developed only as experiments in selected areas. Interoperability between providers has not been generally established. Online appointment systems are available at fewer than half of all hospitals. Currently, experiments are being carried out to make personal health information available to patients and providers via cloud computing. Under the National Identification Number Act, passed in 2013, the PHIS is planning to use unique identifiers for financial transfers starting in 2016 . Whether the identifiers will be used for medical records, however, remains unclear.

The government has declared a goal of establishing a countrywide health information network by FY 2018 . The New Strategy in Information and Communications Technology, released in 2010, outlines the following goals: (1) to develop patient electronic medical records that are accessible by all providers; (2) to develop health 
information technology and telehealth platforms that help link patients with doctors and nurses in underserved areas; (3) to create a platform that can monitor pharmaceutical prescriptions and adverse events in real time, in order to improve patient safety and monitoring; and (4) to create a claims database of all conditions and interventions to facilitate assessment of community needs and development of interventions.

\section{How are costs contained?}

Price regulation for all health care services included in the national benefits package is a critical costcontainment mechanism (Ikegami and Anderson, 2012). All health insurers in the PHIS pay providers according to a national fee schedule that is revised every two years as follows: after informal stakeholder negotiations, the national government determines the overall rate of estimated change in public health care expenditures, and subsequently the rates of change in expenditures for medical services, dental services, pharmacy services, and pharmaceuticals and devices.

For medical, dental, and pharmacy services, the Central Social Insurance Medical Council revises fees on an item-by-item basis in order to meet overall spending targets set by the cabinet. Highly profitable categories see larger reductions in the fee schedule. The revisions of prices of drugs and devices in the PHIS are then determined based on a market survey of their actual current prices (which are often lower than the listed prices). Furthermore, drug prices can be revised downward for new drugs selling in greater volume than expected and for brand-name drugs when generic equivalents hit the market. Prices of medical devices in other countries are now also considered in the revision.

Another cost-containment strategy is to limit services, such as MRIs or certain expensive drugs, deemed to be inflating costs. Peer review committees in each prefecture also monitor claims and may deny payment for services deemed inappropriate. There have also been constraints on the number of hospital beds and physicians; the number of hospital beds is regulated by prefectures in accordance with national guidelines. Hospital mergers and acquisitions have been facilitated by the government. The number of physicians was strictly restricted in the past but the national medical student capacity has been increasing since 2007 owing to increased demand (physician shortages).

The government's Cost-Containment Plan for Health Care focuses on health behavior change and on shortening hospital stays through care coordination and home care development. Each prefecture is required to make its own cost-control plan for appropriate health care. Substitution of generics has been promoted with financial incentives in the fee schedule and with measures to improve the reliability of generic drugs.

\section{What major innovations and reforms have been introduced?}

One emerging trend has been to promote evidence-based policymaking. For example, the current process through which the Central Social Insurance Medical Council revises the national fee schedule has been criticized for a lack of transparency and for vulnerability to potential abuses and conflicts of interest. The DPC hospital payment system may offer one opportunity to create a more robust and transparent policymaking infrastructure. Introduction of economic evaluation into health technology assessments has been increasingly discussed, although highly controversial. Policymakers have also stressed the importance of prevention and wellness in reducing health care costs. Current priorities in prevention include reducing smoking and reducing 
the incidence of cardiovascular disease, diabetes mellitus, and hyperlipidemia. Since 2008 , statutory health insurers have been responsible for delivering annual health checks to beneficiaries between the ages of 40 and 74 (Matsuda, 2007). Policy tools for improving quality and efficiency, such as comparable quality indicators, are being developed.

The devastating earthquake, tsunami, and nuclear emergency that occurred in March 2011 created a health crisis while also destroying a significant part of the health care infrastructure, particularly in the Tohoku region. Restoring needed health services to the affected areas has been a national priority, and rebuilding is a primary focus of the current government.

\section{Who is responsible for population health?}

It is not clear who is responsible for population health in Japan. The national and local governments have an obligation to organize activities for promoting population health, while individuals have an obligation to be health-conscious. Employers have an obligation to endeavor to ensure the safety and health of workers in the workplace.

In practice, the national government published a national strategy for health promotion, Health Japan 21 (the second edition was published in 2012). The strategy set two broad objectives: prolonging healthy life and reducing health inequalities. The document includes targets for incidence of diseases and suicides, prevalence of healthy behaviors, and other indicators. The national government conducts national surveys, in cooperation with prefectures, on health status, nutrition, and healthy behaviors. Prefectures use the results of the surveys to develop their strategies for health promotion, in accordance with the national strategy and the guidelines set by the national government, and support municipalities in organizing health promotion activities. Those strategies are evaluated usually every five years.

The author would like to acknowledge David Squires as a contributing author to earlier versions of this profile.

\section{References}

English Regulatory Information Task Force Japan Pharmaceutical Manufacturers Association (2012).

"Pharmaceutical Administration and Regulations in Japan" (http://www.jpma.or.jp/english/parj/pdf/2012.pdf, accessed 20 August 2013). "top-up"

Life Insurance Association of Japan (2012). Life Insurance Business, 2011 Edition.

Ikegami, N., and Anderson, G.F. (2012). "In Japan, All-Payer Rate Setting Under Tight Government Control Has Proved to Be an Effective Approach to Containing Costs." Health Affairs 31(5):1049-1056.

Matsuda, R. (2007). "Reorganization of regular health check-ups." Health Policy Monitor, October 2007. Available at http://www.hpm.org/survey/jp/a1o/4.

Matsuda, S., Ishikawa, K.B., Kuwabara, K., Fujimori, K., Fushimi, K., and Hashimoto, H. (2008). "Development and use of the Japanese case-mix system." Eurohealth 14(3):25-30. 
National Institute of Population and Social Security Research (2011). Social Security in Japan.

National Insurance Claims Review \& Reimbursement Services (2013). "Utilization of electronic billing as of May, 2013” (in Japanese) (http://www.ssk.or.jp/rezept/files/hukyuo2.pdf, accessed 20 June 2013).

OECD (2009). "Health-care reform in Japan: controlling costs, improving quality and ensuring equity." Economic Survey of Japan 2009. OECD Publishing.

OECD (2012). OECD Health Data 2012.

Tatara, K., and Okamoto, E. (2009). "Japan: Health system review." Health systems in Transition 11(5).

Ueno, T. (2013). A countrywide survey on local health care coordination using IT, 2012 edition. Japan Medical Association Research Institute (in Japanese) (http://www.jmari.med.or.jp/research/dl.php?no=514, accessed 19 August 2013). 


\title{
The Dutch Health Care System, 2013
}

\author{
Gert Westert and Joost Wammes, Radboud University Medical Centre
}

\section{What is the role of government?}

The national government monitors access, quality, and costs, and provides most preventive care. The 2006 reforms introduced a prominent role for health insurers. Under the Health Insurance Act (Zorgverzekeringswet, or ZVW), statutory coverage is provided by private insurers and regulated under public law. Health insurers are given the task of increasing health system efficiency through prudent purchasing of health services on behalf of their enrollees.

\section{Who is covered?}

Since 2006, all residents (and nonresidents who pay Dutch income tax) are mandated to purchase statutory health insurance (SHI) from private insurers. People who conscientiously object to insurance and active members of the armed forces (who are covered by the Ministry of Defense) are exempt. Insurers are required to accept all applicants, and enrollees have the right to change insurer each year. In $2013,30,000^{13}$ persons $(<0.2 \%$ of the Dutch population) were uninsured and more than $300,000^{14}(2 \%)$ defaulted on or failed to pay their premium for at least six months. Defaulters remain covered for the statutory benefits package, but health insurers have the right to discontinue voluntary benefits. ${ }^{15}$ The number of people defaulting on payment increased slightly for several years, leading up to 319,000 in 2013. In 2009, additional policy measures were taken to enforce insurance premium payment. Since then, health insurers enlist defaulters with the Health Care Insurance Board (CVZ), which levies a premium (automatically deducted from income) equal to 130 percent of the standard premium. Only once the defaulter has paid off the debt to the health insurance company does the premium return to the standard amount.3,16 Asylum-seekers are covered by the government, and several mechanisms, including a government fund implemented in 2008, are in place to reimburse the health care costs of illegal immigrants unable to pay for care.

Most people also purchase complementary voluntary private health insurance ( $\mathrm{PHI}$ ) for services not covered by the statutory benefits package, such as adult dental care. Insurers are allowed to screen applicants for voluntary health insurance based on risk factors. Many people purchase complementary coverage because they (often wrongly) believe they are at risk of incurring high health care costs. ${ }^{17}$

13 http://www.cjib.nl/Actueel/nieuwsberichten_2011/boetevoornietverzekerdzijntegenziektekosten.aspx.

14 http://www.volkskrant.nl/vk/nl/2686/Binnenland/article/detail/3344079/2012/11/07/Aantal-wanbetalers-in-de-zorgdaalt-licht.dhtml (verschillende media melden dit, op de CVZ-site niet kunnen bevestigen).

15 http://www.rijksoverheid.nl/onderwerpen/zorgverzekering/vraag-en-antwoord/wat-gebeurt-er-als-ik-de-premievan-mijn-zorgverzekering-niet-betaal.html.

16 http://www.cvz.nl/hetcvz/actualiteit/121206-regeling-wanbetalers-onverzekerden-2013.html Of: http://www.cvz.nl/binaries/content/documents/cvzinternet/nl/documenten/rubriek+verzekeringen/wanbetalers-onverzekerden-broninhouding-gemeenten-2013-v3.pdf.

17 http://www.gezondheidsnet.nl/zorgverzekering/artikelen/9741/nederlanders-vaak-onnodig-aanvullend-verzekerd. 


\section{What is covered?}

Services: The government defines the statutory benefits package on the basis of advice from the Health Care Insurance Board (CVZ). Health insurers are legally required to provide a standard benefits package covering the following: medical care, including care provided by general practitioners (GPs), hospitals, specialists, and midwives; dental care through age 18 (coverage after age 18 is confined to specialist dental care and dentures); medical aids and devices; prescription drugs; maternity care; ambulance and patient transport services; paramedical care (limited physical/remedial therapy, speech therapy, occupational therapy, and dietary advice); ambulatory mental health care maximum of five sessions with a primary care psychologist); and outpatient and inpatient mental care for up to a year. If the latter takes more than 365 days the AWBZ (see further on) takes over and the care is considered as long term care.

Some treatments are only partially covered or are excluded, e.g.: since January 2012, the first 20 sessions of physiotherapy in a year are no longer covered, except those for people with specific chronic conditions; some elective procedures are excluded (e.g., cosmetic plastic surgery without a medical indication); only the first three attempts are included for in vitro fertilization; sleep medication and antacids were excluded in 2012 for most patients; walkers and other simple mobility aids are no longer covered; and a limited number of effective health improvement programs (e.g., smoking cessation) are covered, and weight management advice is limited to three hours per year.

Long-term disability protection is organized separately from health insurance. People residing legally in the Netherlands and nonresidents who pay Dutch payroll tax are compulsorily insured for long-term care under the Exceptional Medical Expenses Act (AWBZ), a statutory social insurance scheme for those whose chronic conditions require continuous care and have considerable financial consequences (Schäfer et al., 2010). People can choose to receive a personal care budget with which to purchase care themselves (personal care, nursing, support with daily activities and intramural care). Between 1998 and 2011, the number of personal budget recipients of AWBZ care rose from 10,000 to almost $139,000 .{ }^{18}$ In 2012 , eligibility criteria for a personal care budget were restricted to those who would otherwise need institutional care (i.e., 10\% of those who were previously eligible), but the restriction was mitigated later that year, widening the array of personal nursing and other care services (with or without support) for clients needing at least 10 hours support per week and for new clients with longterm care needs. ${ }^{19,20}$

Cost-sharing: In addition to income-based contributions and community-rated premiums (see below), every insured person over age 18 must pay a deductible of $€ 350$ (US\$467) (as of 2013) for any health care costs in a given year (with some services, such as GP visits, excluded from this general rule).

Safety net: GP care and children's health care are exempt from cost-sharing. The government also pays for children's coverage up to the age of 18 and provides subsidies (known as "health care allowances") to cover community-rated premiums for low-income families (annual income of less than $€ 30,939$ [US\$41,825] for singles and

18 Budgettair kader zorg.

19 http://www.rijksoverheid.nl/onderwerpen/persoonsgebonden-budget-pgb/vraag-en-antwoord/kan-ik-een-persoonsgebonden-budget-pgb-uit-de-awbz-krijgen.html.

20 http://www.rijksoverheid.nl/onderwerpen/persoonsgebonden-budget-pgb/veranderingen-persoonsgebonden-budget. 
less than $€ 42,438$ [ US $\$ 57,370$ ] for households); approximately 5 million people receive the allowance.21 Since 2013, the health care allowances are subject to asset testing. The actual allowance is on a sliding scale ranging from $€ 2$ (US\$2.70) to €115 (US\$155) per month, depending on income.

\section{How is the health system financed?}

The statutory health insurance system under the Health Insurance Act is financed through a nationally defined, income-related contribution and through community-rated premiums set by each insurer (everyone with the same insurer pays the same premium, regardless of age or health status). In 2012, the average annual community-rated premium for adults was $€ 1,253 .{ }^{22}$ (US\$1693) The income-related contribution is set at 7.75 percent of up to $€ 50,853$ (US\$68,747) of annual taxable income (as of 2013). ${ }^{23}$ Employers must reimburse their employees for this contribution, and employees must pay tax on the reimbursement. For those who do not have an employer and do not receive unemployment benefits, such as the self-employed, the income-related contribution is 5.65 percent. Contributions are collected centrally and distributed among insurers in accordance with a sophisticated risk-adjusted capitation formula that considers age, gender, labor force status, region, and health risk (based on past drug and hospital utilization).

Insurers or payers are supposed to engage in strategic purchasing, and contract providers are supposed to provide their enrollees selectively with the best value, with regard to both quality and cost. The insurance market is dominated by the five largest insurer conglomerates, which account for more than 80 percent of all enrollees. In 2012, total spending on health care and social care was $€ 92.7$ billion, (US $\$ 125$ billion) a 3.7 percent increase over 2011.24

In addition to purchasing statutory health insurance, most of the population purchases a mixture of complementary and supplementary voluntary PHI covering benefits such as dental care, alternative medicine, physiotherapy, spectacles and lenses, contraceptives, and full-cost coverage of copayments for medicines. Voluntary health insurance premiums and products are not regulated. Insurers can offer both statutory and voluntary benefits. People with voluntary health insurance do not receive faster access to any type of care, nor do they have increased choice of specialist or hospital. PHI typically accounts for 3 percent to 5 percent of total annual health spending.

\section{How are health care services organized and financed?}

Primary care: The GP is the central figure in primary care; other primary care providers include dentists, midwives, and physiotherapists. Hospital care and specialist care (except emergency care) are accessible only upon GP referral; only 4 percent of appointments with a GP result in a referral to secondary care. All citizens are registered with a GP of their choice, usually in their own neighborhood. On average, patients contact their GP five times per year; a full-time GP has a practice list of approximately 2,350 patients. ${ }^{25}$ At present, the role of district

${ }^{21}$ http://www.rijksoverheid.nl/onderwerpen/zorgtoeslag/veranderingen-zorgtoeslag-2013.

22 Budgettair kader zorg.

$23 \mathrm{http} / /$ www.belastingdienst.nl/wps/wcm/connect/bldcontentnl/belastingdienst/prive/werk_en_inkomen/zorgverzekeringswet/veranderingen_bijdrage_zvw_2013/veranderingen_inkomensafhankelijke_bijdrage_zvw_2013.

24 http://www.cbs.nl/nl-NL/menu/themas/gezondheid-welzijn/publicaties/artikelen/archief/2013/2013-037-pb.htm.

25 http://medischcontact.artsennet.nl/nieuws-26/archief-6/tijdschriftartikel/91056/de-huisarts-heeft-te-veel-patienten. htm. 
nurses is being strengthened, as their activities will be financed under the Health Insurance Act via spending arrangements similar to those in the curative sector.

Patients can switch GP without formal restriction. In 2012, there were 8,831 practicing GPs: 36.4 percent worked in group practices of three to seven, 37.9 percent worked in two-person practices, and 25.7 percent worked solo. Most GPs are independent entrepreneurs or work in a partnership; only a small number (11.1\%) are employed in a practice that is owned by another GP.

Since the 2006 reform, GP remuneration combines elements of the pre-2006 payment systems for social insurance (capitation fee per registered patient) and private insurance (fee-for-service). As a result, the system consists of several components:

- Capitation fee per registered patient

- Consultation fee for GPs, including phone consultation

- Consultation fee for practice nurses (if practice includes any), including phone consultation

- Fee-for-service for activities that either increase efficiency (e.g., task delegation) or substitute GP care for secondary care

- Compensation (mostly hourly rates) for providing after-hours care

In addition, there are bundled payments for a few chronic diseases (diabetes, cardiovascular risk management, and COPD), and efforts are under way to implement them for heart failure and depression (described below). Many GPs employ nurses on salary, and the reimbursement for the nurse is received by the GP, so any productivity gains that result from substituting a nurse for a GP's work accrue to the GP. Each GP practice can negotiate additional budgets with the insurer for extra services, practice nurses, additional staff, nature of location (e.g., a socially deprived area), etc. There are ongoing experiments with pay-for-performance and population management to improve quality in primary and hospital care. The Dutch Health Care Authority (NZa) determines national provider fees for some of the services in primary care (others are freely negotiable).

Outpatient specialist care: Almost all specialists are hospital-based and are either in group practice (65\%-70\%) or on salary (most but not all in university clinics). There is a nascent trend among specialists of working outside hospitals-for example, in the growing numbers of ambulatory surgery centers-but this shift is rather marginal, and most ambulatory surgery centers are tied to hospitals. These ambulatory surgery center specialists are paid fee-for-service (FFS) and the fee schedule is negotiated with insurers. Patients are free to choose their provider (following referral), but insurers may vary restrictions on choice within their policies (Schäfer, et al., 2012).

After-hours care: After-hours primary care is organized at the municipal level in GP "posts"-centralized services typically run by a nearby hospital that provide GP care between 5:00 p.m. and 8:00 a.m. Specially trained assistants answer the phone and perform triage. GPs decide whether or not patients need to be referred to the hospital. The GP post sends the information regarding a patient's visit to his or her GP. 
Emergency care is provided by GPs, emergency departments, and trauma centers, and is covered under SHI. Depending on the urgency of the situation, patients or their representatives can contact their GP or a GP post (for after-hours care), call an ambulance, or go directly to the emergency department at the nearest hospital (Schäfer, et al., 2012). The great majority of hospitals have emergency departments, and all have a GP post. ${ }^{26}$

Hospitals: In 2012, the Netherlands had 132 hospital sites and 97 outpatient specialty clinics spread among 92 organizations, including eight university medical centres. Practically all the organizations were private and nonprofit. There were also more than 150 independent private and nonprofit treatment centers whose services were limited to same-day admissions for nonacute, elective care (e.g., eye clinics, orthopedic surgery centers). ${ }^{27}$

Hospital budgets were previously developed using a formula that paid a fixed amount per number of beds, patient volume, number of licensed specialists, and other factors; additional funds were provided for capital investment. Since 2006, budgets have been determined through negotiations between insurers and hospitals over price and volume; capital investment has been funded through a prospective payment mechanism. Payment takes place through the case-based Diagnosis Treatment Combinations (DTC) system (a DRG-like system) and the prices of approximately 70 percent of hospital services are freely negotiable: each hospital negotiates with each insurer to set the DTC rate. For the remaining 30 percent of services, DTC rates are nationally determined. In 2012, the DTC system was fundamentally reformed and the number of DTCs was reduced from 30,000 to $4,400 .{ }^{28}$ DTCs cover both outpatient and inpatient hospital costs as well as specialist costs, thereby strengthening the integration of specialist care in the hospital organization. Bundled payments have been introduced for select chronic conditions (e.g., diabetes) (see section on coordination).

Hospital specialists practice under FFS contracts negotiated by the management with insurers. ${ }^{29}$ Two-thirds of hospital-based specialists are self-employed or work in partnership with other physicians, and are paid on an FFS basis; the remaining third are salaried.

Mental health care: Mental health care is provided in both primary and secondary care. Primary health care professionals in mental health care include GPs, psychologists, and psychotherapists. When more specialized care is required, the

GP refers the patient to a psychologist, an independent psychotherapist, or a specialized mental health care institution. In 2009, around 859,000 people were treated in specialized mental health care organizations. ${ }^{30}$ Around 90 percent of them received ambulatory treatment; 3 percent received part-time inpatient care (i.e., one

26 Sluiting SEH Zevenaar, Spijkenisse, Amsterdam.

27 http://www.zorgatlas.nl/zorg/ziekenhuiszorg/algemene-en-academische-ziekenhuizen/aanbod/ locaties-algemene-en-academische-ziekenhuizen/.

${ }^{28}$ http://www.nza.nl/zorgonderwerpen/zorgonderwerpen/ziekenhuiszorg/veelgesteldevragen/ veelgestelde-vragen-dbc-dot/.

29 http://www.nza.nl/publicaties/nieuws/ Conceptadvies-NZa-zorg-dat-verzekeraar-vrij-kan-contracteren-in-ziekenhuiszorg/.

30 http://www.ggznederland.nl/de-ggz-sector/feiten-en-cijfers.html. 
or more daily periods of care per week in an institution); and 9 percent were hospitalized in a closed institution. ${ }^{31}$

Prior to 2008, most mental health care was financed under the AWBZ; in 2008 the financing structure was fundamentally reformed. The first 365 days of mental health treatment and up to five primary care psychologist sessions became coverable under statutory health insurance, financed under the Health Insurance Act via similar spending arrangements as in the hospital sector. Further support for integrating GP and mental health center services was agreed to by the Ministry of Health (MOH), insurers, and providers in 2012.32

Long-term care: Long-term care, financed by the AWBZ, accounts for 41.5 percent of the government's total health care budget and is provided both in institutions (residential care) and in communities (home care). 33 Health insurers are formally responsible for implementing the AWBZ, but this task is delegated to regional care offices (Zorgkantoren). The Center for Needs Assessment (CIZ) has been commissioned by the government to carry out assessments of AWBZ eligibility. Patients, their relatives, or their health care providers can file a request with the $\mathrm{CIZ}$, which then sends its decision to a care office (Zorgkantoor). Recipients of intramural long-term care share some of the costs of their stay depending on length of stay, number of people within the family, annual income, indication, and assets. 34

Home care is provided by home care organizations, residential homes, and nursing homes. In 2009, the Netherlands had 479 nursing homes, 1,131 residential homes, and 290 combined institutions. 35 Most palliative care is integrated into the regular health system and is delivered by GPs, home care providers, nursing homes, specialists, and voluntary workers. Health care providers, palliative units, and hospices currently participate in regional networks in order to promote integration and coordination of care. The number of hospices and palliative units is growing throughout the country: in 2013 there were 123 hospices, 143 nursing or residential homes, and 15 hospitals with special departments for symptom control and stabilization. Still, less than 5 percent of the population currently dies in a hospice.

\section{What are the key entities for health system governance?}

A number of arm's-length agencies are responsible for setting operational priorities. At the national level, the Health Council advises the government on evidence-based medicine, health care, public health, and environmental protection; the Health Care Insurance Board (CVZ) advises the government on the components of the statutory health insurance benefits package; and the Medicines Evaluation Board (CBG) oversees the efficacy, safety, and quality of medicinal products. Health technology assessments (HTAs) are carried out by the Health Council and the CVZ. The Dutch Health Care Authority (NZa) has primary responsibility for ensuring that the

31 http://www.venvn.nl/Dossiers/GGZ/Detail/tabid/5248/ArticleID/8508/mod/14775/Terugdringen-vrijheidsbeperking-inggz.aspx of http://www.ggznederland.nl/feiten-en-cijfers/sectorrapport-2010.pdf.

32 http://www.rijksoverheid.nl/documenten-en-publicaties/rapporten/2012/06/18/bestuurlijk-akkoord-toekomstggz-2013-2014.html.

33 http://www.rijksbegroting.nl/2013/voorbereiding/begroting,kst173930_24.html.

34 http://www.rijksoverheid.nl/onderwerpen/algemene-wet-bijzondere-ziektekosten-awbz/vraag-en-antwoord/betaal-ikeen-eigen-bijdrage-als-ik-in-een-awbz-instelling-verblijf-zorg-met-verblijf.html.

$35 \mathrm{http} / /$ www.zorgatlas.nl/zorg/langdurige-zorg/verpleging-en-verzorging/ verpleeg-en-verzorgingshuizen-per-gemeente-2009/\#breadcrumb. 
health insurance market, the health care purchasing market, and the health care delivery market function appropriately (e.g., they set prices for 30 percent of DTCs), while the Dutch Competition Authority (NMa) enforces fair competition among both insurers and providers, subject to the Dutch Competition Act. DBCOnderhoud (Diagnosis Treatment Combination Maintenance) is an independent organization responsible for the design, construction, and maintenance of the DTC system.

\section{What is being done to ensure quality of care?}

The Dutch Health Care Performance Report 2010 provided indisputable evidence that the quality and price of Dutch health services vary substantially among providers, and that more needs to be done to address the variation in quality (Westert, et al., 2010).

At the health system level, quality of care is ensured through legislation governing professional performance, quality in health care institutions, patient rights, and health technologies. The Dutch Health Care Inspectorate (IGZ) is responsible for monitoring quality and safety. Most quality assurance is carried out by health care providers, sometimes in close cooperation with patient and consumer organizations and insurers. Mechanisms to ensure quality of care provided by individual professionals include reregistration/revalidation of specialists based on compulsory continuous medical education; regular on-site peer assessments organized by professional bodies; and profession-owned clinical guidelines, indicators, and peer review. The main methods used to ensure quality in institutions include accreditation and certification; compulsory and voluntary performance assessment based on indicators; and national quality improvement programs based on the breakthrough method sneller beter ("faster, better"). Patient experiences are also systematically assessed and, since 2007, a national center has been working with validated measurement instruments in an approach comparable to that of the Consumer Assessment of Healthcare Providers and Systems (CAHPS) in the United States. The center also generates publicly available information for consumer choice on waiting lists, patient satisfaction, and a few quality indicators.

The $\mathrm{MOH}$ recently issued a directive to the Dutch parliament stating that, from 2014, a central body (the National Institute for Health Care Quality) needs to be established to further accelerate the process of quality improvement and to encourage evidence-based practice.

\section{What is being done to improve care coordination?}

In 2007, the $\mathrm{MOH}$ approved the introduction of a bundled-payment approach to integrated chronic care, initially on an experimental basis with a focus on diabetes. In 2010, the bundled-payment concept was approved for nationwide implementation for diabetes, COPD, and vascular risk management. Under this system, insurers pay a single fee to a principal contracting entity-the "care group" - to cover a full range of chronic disease (diabetes, COPD, and vascular disease) care services for a fixed period. The care group is a newly created participant in the health care system, consisting of a legal entity formed by multiple health care providers, who are often exclusively GPs. The care group assumes both clinical and financial responsibility for all assigned patients in the diabetes care program. For the various components of diabetes care, the care group either delivers services itself or subcontracts with other care providers. The bundled-payment approach supersedes traditional health care purchasing for the condition and divides the market into two segments-one in which health insurers contract care from care groups, the other in which care groups contract services from individual providers. 
The price for the bundle of services is freely negotiated by insurers and care groups, and the fees for the subcontracted care providers are similarly freely negotiated by the care group and the providers (Struijs, 2011). An initial evaluation of the new payments system indicated that it improved the organization and coordination of care, but no improvement of the outcomes of care were reported (de Bakker, 2012).

\section{What is being done to reduce disparities?}

Smoking is still a leading cause of death, followed by obesity. For many determinants, lower socioeconomic groups do worse on all fronts. However, the current government does not have a specific policy to overcome health disparities, as the cornerstone of present policy is an emphasis on people's personal responsibility for healthy lifestyles. In 2013, the government decided to include diet advice and smoking cessation programs in the statutory benefits package.

\section{Who is responsible for population health?}

At present, most population health activities and monitoring are executed by municipal health services. However, there are a considerable number of pilot projects testing the assumptions supporting population management. These pilots are in most cases initiated by GP care groups. These groups consist of a number of GP practices (up to 50) and explore the possibility of taking responsibility for population health in a specific geographic area. Although the pilot projects are rather varied, they have in common that they aim to strengthen care and support at the local level. The $\mathrm{MOH}$ has loosened regulation to support pilots that aim to substitute primary care for hospital care and projects that aim to stimulate quality of care. ${ }^{36}$ The good thing about this development is that population management shifts the focus from delivery of services to the ultimate goal of health care: improving health and quality of life.

\section{What is the status of electronic health records?}

Dutch authorities are working to establish a central health information technology network to enable information exchange across sites of care. All Dutch patients have a unique identification number (BSN). Virtually all GPs have a degree of electronic information capacity-for example, they use an electronic health record, and can order prescriptions and receive lab results electronically. At present, all hospitals have an electronic health record. 37

EHRs for the most part are not nationally standardized or interoperable between domains of care, reflecting their historic development as regional initiatives. In 2011, the organizations representing GPs (LHV), afterhours, GP cooperatives (VHN), hospitals (NVZ), and pharmacies (KNMP) set up the Union of Providers for Health Care Communication (VZVZ). The Union is responsible for the exchange of data via an IT infrastructure named AORTA; data are not stored centrally. Patients must give their approval before being registered in this exchange, and have the right to withdraw from participation. ${ }^{38}$ In 2012, the previously mentioned four parties, organizations representing insurers and patients (NPCF), and several others signed an agreement to promote further development of the national health care IT infrastructure. 39

\footnotetext{
36 Kamerbrief. Proeftuinen en pilots 'betere zorg met minder kosten'.

37 http://www.zorgvisie.nl/PageFiles/81591/001_1363085284562.pdf.

38 http://www.vZvZ.nl/page/Over-VZVZ.

39 http://www.knmp.nl/organisatie-regelgeving/lsp.
} 


\section{How are costs controlled?}

One of the most significant themes in the public debate surrounding the most recent elections (September 2012) was that of how to bend the cost curve. Recent figures from Statistics Netherlands indicate that health expenditures have risen substantially-the most recent annual expenditure growth was approximately 3.6 percent-not least as a result of increases in doctors' incomes and volume of services delivered.

When the 2006 reforms were first introduced, the government aimed to take a back seat and allow market forces to operate. The main approach to controlling costs in the Dutch health system rests on regulating competition between insurers and improving efficiency of care through the use of performance indicators. In addition, provider payment reforms, including a general shift from a budget-oriented reimbursement system to a performance- and outcome-driven approach, have been implemented; costs are increasingly expected to be controlled by the new DTC system, in which hospitals must compete for the prices of specific services; and various local and national programs aim to improve health care logistics.

In 2013, a new agreement was signed between the $\mathrm{MOH}$, all health care providers, and insurers that effectively sets a ceiling for the annual growth of hospital and mental care volume at 1.5 percent in 2014 and 1 percent per year between 2015 and 2017. When macro-costs exceed this limit, the government has the ability to control spending via the imposition of generic budget cuts. However, part of this agreement included an extra 1 percent spending growth allowance for primary care practices in 2014 and 1.5 percent in 2015-2017, provided that they demonstrate that primary care services are a substitute for hospital care. These extra growth allowances and rising costs elsewhere in the system (AWBZ), combined with the economic crisis, may force the government to intervene further.

\section{What major innovations and reforms have been introduced?}

The biggest reform of the past decade involved the 2006 introduction of a universal compulsory insurance scheme executed by private insurers. Previously, people with earnings above approximately $€ 30,000$ (US\$40,559) per year and their dependents (around 35\% of the population) had been excluded from statutory coverage provided by public sickness funds and could purchase coverage only from private health insurers; the government had regulated this form of substitutive private health insurance to ensure that older persons and people in poor health had adequate access to health care and that the publicly financed health insurance scheme was properly compensated for covering a disproportionate number of high-risk individuals. However, growing dissatisfaction with the dual system of public and private coverage eventually led to the 2006 reform (substitutive private health insurance was also abolished in 2006), creating a level playing field. The underlying logic is that consumers who have the right to exercise choice induce competition among insurers, and insurers will therefore push health care providers to increase the quality and efficiency of their services. However, further research will be required to determine whether this policy has led to optimal performance for all actors involved.

Additionally, there is an ongoing review of the coverage provided by the statutory health insurance scheme and the AWBZ scheme for long-term care. Progress has been made on producing indicator information, although there is a continuing focus on improving transparency. 
The present government is working on a long-term care reform to bring back the AWBZ to its original purpose: covering uninsurable risks. Other care activities will be delegated to municipalities and the curative care sector. According to the most recent plan, these changes will come into effect in 2015.

\section{References}

Schäfer, W., Kroneman, M., Boerma, W., et al. (2012). “The Netherlands: Health System Review,” Health Systems in Transition 12(1):1-229.

Struijs, J.N., and Baan, C.A. "Integrating Care through Bundled Payments—Lessons from the Netherlands." $N$ Engl J Med 2011 364:990-991, March 17, 2011.

Westert, G.P., van den Berg, M.J., Zwakhals, S.L.N., et al. (2010). Dutch Health Care Performance Report 2010 (http://www.gezondheidszorgbalans.nl/object_binary/010298_dhCPR2010.pdf).

Westert, G.P., Burgers, J.S, Verkleij, H. (2009). “The Netherlands: Regulated Competition Behind the Dykes?” BMJ 339:b3397, Sept. 7, 2009.

De Bakker, D.H., Struijs, J.N., et al. (2012). "Early results from adoption of bundled payment for diabetes care in the Netherlands show improvement in care coordination." Health Aff (Millwood) 31(2):426-433. 


\title{
The New Zealand Health Care System, 2013
}

\author{
Robin Gauld, University of Otago, New Zealand
}

\section{What is the role of government?}

The government plays a central role in setting the health policy agenda and service requirements for the health system, and in setting the annual publicly funded health budget. Responsibility for planning, purchasing, and providing health and disability support services lies with 20 geographically defined District Health Boards (DHBs). DHBs comprise seven members elected by the people in their area and up to four members appointed by the Minister of Health. They pursue government objectives, targets, and service requirements while operating government-owned hospitals and health centers, providing community services, and purchasing services from nongovernment and private providers.

\section{Who is covered?}

All permanent residents have access to a broad range of health and disability services that are largely publicly financed through general taxes. As of October 2013, nearly 4.5 million New Zealand residents were eligible for publicly funded health services. Nonresidents, such as tourists and illegal immigrants, are charged the full cost for services provided by public hospitals or primary medical care providers, unless their health needs are the result of an accident, in which case they are covered by New Zealand's no-fault accident compensation scheme.

Complementary and supplementary private voluntary health insurance is mostly used to cover cost-sharing requirements, elective surgery in private hospitals, and private outpatient specialist consultations. Private payment tends to secure faster access to treatment for nonurgent care in the private sector. In March 2013, just over 1.3 million New Zealanders had some private health insurance (PHI, covering approximately $30 \%$ of the New Zealand population).

\section{What is covered?}

Services: The publicly funded system covers preventive care, inpatient and outpatient hospital care, primary care services (excluding some services such as optometry care, adult dental services, orthodontics, and physiotherapy), inpatient and outpatient prescription drugs included in the national formulary (described further below), mental health care, dental care for schoolchildren, long-term care, home help, and disability support services. The government sets an annual global budget for most publicly funded health services and sets national requirements for those services, to be implemented by the 20 DHBs. Rationing and prioritization are applied largely to nonurgent services, and vary by DHB.

Safety net: Primary care is mostly free for children age 6 and under, and is subsidized for the 98 percent of the population enrolled in networks of self-employed providers (mainly GPs), known as Primary Health Organizations (PHOs). PHOs include GPs, practice nurses, and allied practitioners. Additional PHO funding and services are available for treating people with chronic conditions and for improving access for groups with high health needs. Around 30 percent of all primary care practices, those usually found in poorer communities with high health needs, operate in a "very low cost access" environment where a higher per annum, per patient 
capitation rate is paid, and in return patient fees are capped. A "high use health card" is also available upon application to patients who have had more than $12 \mathrm{GP}$ visits in a year. Subsequent capitation payments to the GP for those patients are then set at a higher level to reflect this high-utilization pattern, although patients continue to pay their usual GP copayments, albeit at a lower rate. Public hospital services are predominantly free, although there are some user charges, e.g., for aids and appliances.

Cost-sharing: Copayments exist for GP services and many nursing services provided in GP settings, as capitation funding covers only a portion of costs; copayments for after-hours consultations are generally higher. The median fee for an adult's GP consultation is NZ\$30-\$35 (US\$25-29), but fees vary significantly as GPs set their own fees-the exception being for the one-third of New Zealanders in the aforementioned low-cost areas, where the maximum adult fee is NZ\$17 (US\$14) per visit. GP copayments fell during a period (2002-2008) of significant increases in government funding for primary care, but have been increasing since then.

Copayments are also required for community-prescribed drugs (NZ\$5.00 [US\$4] per item, following an increase from NZ\$3.00 [US\$2.50] on January 1, 2013); after copayments are made for 20 items per family per year, items are free. There are no charges for children under 6 years of age.

Long-term care subsidies for older people are means-tested; only those with limited financial means or assets are eligible. Residents with assets over a given national threshold pay the cost of their care up to a maximum contribution. Residents with assets under the allowable threshold contribute all their income. In cases where this income is exhausted, the person is eligible for a new means test. Household management, which accounts for one-third of home support funding, is means-tested.

\section{How is the health system financed?}

Publicly financed health care: Public health spending accounted for 82.7 percent of total health spending in 2011 (OECD, 2013) and was distributed as follows.

- 87.1 percent to the New Zealand Ministry of Health, which in turn distributed around 80 percent of that amount to DHBs using a weighted, population-based funding formula, and the remaining 20 percent directly to services providers.

- 10.1 percent to the Accident Compensation Corporation, which provides funding for accident and injury care. The ACC is funded from levies on people's earnings, businesses' payrolls, petrol, and fees from vehicle licensing, as well as from government funding.

- 2.8 percent to other central, regional, and local government services.

Privately financed health care: Out-of-pocket payments, including both cost-sharing and other costs paid directly by private households, accounted for approximately 10.9 percent of total health expenditure in 2011 (OECD, 2013). Private health insurance is offered by a variety of organizations, from nonprofits and "Friendly Societies" to companies listed on the stock market. It accounts for about 5 percent of total health expenditure and is used mostly to cover cost-sharing requirements, elective surgery in private hospitals, and private outpatient specialist consultations, as well as often offering faster access to nonurgent treatment. About one-third of the 
population has some form of private health insurance, which is predominantly purchased by individuals. Insurers reimburse providers up to company-specific maximums.

\section{How are health services organized and financed?}

Primary care: GPs act as gatekeepers to specialist care and are usually independent, self-employed providers, compensated predominantly by a capitated government subsidy paid through PHOs in addition to patient copayments. GPs work together with practice nurses in general practice teams-these nurses have a significant role in the management of long-term conditions (e.g., diabetes). Patient registration is not mandatory, but GPs and PHOs must have a formally registered patient list to be eligible for government subsidies. Patients enroll with a GP of their choice; in smaller communities choice is often limited.

Over recent years, there has been substantial funding to subsidize primary care and improve access to care. PHOs receive additional per capita funding for promoting health, coordinating care, reducing barriers to care for patients with difficulties of access, and providing additional services for people with chronic conditions. They also receive funding if GPs collectively reach quality and service delivery targets for cancer, diabetes, and cardiovascular disease screening and follow-up, as well as for vaccinations.

Outpatient specialist care: New Zealand has "dual practice" in specialist care, meaning that most specialists are employed by DHBs and paid a salary for working in a public hospital, but are also able to work privately in their own private clinics or treat patients in private hospitals, where they are paid on a fee-for-service (FFS) basis. These private specialists are concentrated mostly in larger urban centers, and set their own fees, which vary considerably; insurance companies have little, if any, control over those fees, although insurers will pay only up to a maximum level, meaning that patients will pay any difference. In public hospitals, patients generally have limited choice of specialist.

After-hours care: GPs are expected to provide or arrange for the provision of after-hours care, and they receive government subsidies for doing so. In rural areas and small towns, GPs work on call but, in cities, GPs tend to provide after-hours service on a roster at purpose-built, privately owned clinics in which they are shareholders. Patient charges at these clinics are higher than for services during the day (although over 90 percent of children under 6 years can access free GP after-hours services). Consequently, some patients will visit the hospital emergency department instead, or avoid after-hours service altogether. A patient's usual GP routinely receives information on after-hours encounters. The public also has access to the 24-hour, seven-day-a-week phone-based Healthline, staffed by nurses who provide advice for general health questions. Plunketline provides a similar service for child and parenting problems.

Hospitals: New Zealand has a mix of public and private hospitals, but public hospitals make up the majority, providing all emergency and intensive care. Public hospitals receive a budget from their owners, DHBs, based on historic utilization patterns, population needs projections, and government goals in areas such as elective surgery. A DHB hospital's budget tends to be allocated to the various inpatient services using a case-mix funding system. A proportion of DHBs' funding for elective surgery is held by the Ministry of Health, and payments are made upon delivery of surgery. Certain areas of funding, such as mental health, are ring-fenced, meaning the DHB must spend the money on a specified range of inputs. 
Private hospital patients with complications are often admitted to public hospitals, in which case the costs are absorbed by the public sector. Specialists who receive salaries in public hospitals can maintain their own private clinics or treat patients in private hospitals where income is on an FFS basis. Public hospital services are largely provided by consultant specialists, specialist registrars, and house surgeons. Health Workforce New Zealand (HWNZ) is currently conducting pilot programs for the usage of physician assistants at five sites. If the demonstration proves successful, HWNZ will explore options for regulating the profession and training New Zealand physician assistants.

Mental health care: DHBs own and run a range of mental health facilities, from acute inpatient to outpatient community services. They fund mental health care provided in the community and in institutional settings for those with the most severe mental health needs. Those with long-term care needs are cared for in community settings, usually by nongovernmental agencies that provide various support services on contract to DHBs. Patients with mild to moderate mental health needs are treated in primary care. New Zealand has only one private psychiatric hospital, and it does not receive government funding.

Long-term care: DHBs fund long-term care for patients on the basis of needs assessments, age requirements, and a means test. They fund these services both for those over age 65 and for those "close in age and interest" (e.g., people with early-onset dementia or a severe physical disability requiring long-term care). Those eligible receive comprehensive, fully funded services, including medical care; many older or disabled people receive inhome care. Residential facilities, mostly private, provide some long-term care. DHBs also provide hospital-and community-based palliative care. A network of hospices provides end-of-life care, and approximately 70 percent of hospice funding is through $\mathrm{DHBs}$, with the remainder coming through fundraising.

\section{What are the key entities for health system governance?}

As the health system is controlled and financed primarily through the public sector, government-funded and -appointed entities dominate governance structures. Some, like the Health and Disability Commissioner (whose function is to champion consumers' rights in the health sector), sit at arm's length from central government. Others are "Crown Entities" with their own boards, and are required to meet annually reviewed government expectations. Key national arrangements are:

- The National Health Board (NHB): Established by the government in November 2009, the NHB is a Ministry of Health business unit that aims to improve the quality, safety, and sustainability of health care for New Zealanders by actively engaging with clinicians and the wider health sector. The NHB also provides advice to the Minister and the Director-General of Health on these matters. The NHB has two subcommittees: Health Workforce New Zealand, created in 2009 to plan for future health workforce needs, and the Health IT Board, also created in 2009, charged with ensuring that health sector policy is supported by appropriate health information and IT solutions across the health and disability sector.

- Health Benefits Limited (HBL), established in July 2010, supports DHBs in delivering shared services and reducing costs by identifying savings in administrative, support, and procurement services for the health sector. It also leads initiatives that reduce duplication and result in savings and efficiencies for DHBs in their nonclinical and back-office functions. 
- The Pharmaceutical Management Agency of New Zealand (PHARMAC) assesses the effectiveness of drugs; distributes prescribing guidelines; determines the inclusion of drugs on the national formulary, with relative cost-effectiveness being one of nine criteria for inclusion; and, since 2010, has also focused on assessing medical devices.

- The Health Quality and Safety Commission was established in 2010 to ensure that all New Zealanders receive the best health and disability care within available resources. It is also working toward what is known as the New Zealand Triple Aim-improved quality, safety, and experience of care; improved health and equity for all populations; and better value for public health system resources.

- The National Health Committee advises the government on the priorities for new and existing health technologies. All new diagnostic and (nonpharmaceutical) treatment services and significant expansions of existing services are referred to the NHC for evaluation and advice. The Committee also provides advice on what technologies are obsolete or are no longer providing value for money.

\section{What is being done to ensure quality of care?}

The publicly funded but independent Health and Disability Commissioner investigates and reports on patient complaints. The Commissioner reports directly to Parliament and has been important in promoting quality and patient-safety improvements.

DHBs are held formally accountable to the government for delivering efficient, high-quality care in hospitals, as measured by the achievement of targets across a range of indicators. In addition, DHB performance with regard to waiting times, access to primary care, and mental health outcomes is publicly disclosed. Data comparing performance of PHOs are also publicly reported, but data on individual doctors' performance are not routinely available. As noted above, PHOs and GPs receive performance payments for achieving various targets.

Certification by the Ministry of Health is mandatory for hospitals, nursing homes, and assisted-living facilities, which must meet published and defined health and disability standards. Certification audits are often performed, in conjunction with accreditation, by third parties.

The Health Quality and Safety Commission (HQSC) replaced the government's Quality Improvement Committee in 2010. It is intended to increase the focus on quality while better coordinating the varied approaches to quality improvement across DHBs. It will continue to oversee existing public hospital programs, which are focused on such issues as optimizing the patient journey, ensuring safer medication management, reducing rates of health care-acquired infection, and standardizing national incident reporting. Recent initiatives include the launch of initial components of the Atlas of Healthcare Variation (aimed at highlighting variations in the provision and use of services by geographic area), development of a series of standard quality and safety indicators for DHBs based on routinely collected data, development of a program for consumer involvement in service design, and advice for DHBs on how to prepare annual Quality Accounts, required of DHBs in 2012-2013. Much like a "financial account," the Quality Accounts are intended to report on how the DHB has approached quality improvement, including descriptions of key initiatives and their impact. In 2013, HQSC launched a national patient safety campaign, Open for Better Care, focused on reducing harms associated with falls, surgery, health care-associated infections, and medications. 
The National Health Board is also working on quality improvement in DHBs, with a particular focus on management systems, clinical services, and patient pathways. "Clinical governance" has been implemented in most DHBs, meaning that management and health professionals are assuming joint accountability for quality, patient safety, and financial performance.

\section{How is care coordinated?}

Since 2008, some PHOs have decided to merge to improve their performance and reduce administrative duplication. The government has also started to develop larger Integrated Family Health Centers (IFHCs), in line with its "Better, Sooner, More Convenient" policy, which aims to improve access to integrated care provided by DHBs and PHOs by establishing more convenient locations for patients (outside of hospital settings), and also focuses on chronic disease management. These IFHCs will provide comprehensive primary care and care coordination, after-hours services, and some minor elective procedures for an enrolled population. The new facilities will see services and providers colocated, or coordination of services improved, with funding from both primary care budgets and DHBs.

Patients enrolled in PHOs have a medical home, but PHOs vary widely in their size, performance, and activities. The highest-performing provide a model that, if nationally emulated, would result in all enrollees having a fully functional, multidisciplinary medical home, although institutional barriers to integrating primary and hospital care remain.

Government is accelerating the drive for clinical integration to create a more patient-centered health system. It is delivering change in four priority areas: urgent and unplanned care, long-term conditions, wraparound services for older people, and maternity and child services. It is also ensuring that all DHBs' Annual Plans include integration proposals to drive change at a local level. These directions will be propelled by a new PHO contract in place from mid-2013 that requires a "whole of system" approach, with DHBs and PHOs working as partners in alliance-governance arrangements modeled after IFHC pilot programs.

\section{What is being done to reduce health disparities?}

Since the late 1990s, governments have made reducing disparities a policy priority. Disparities in health are a central concern in New Zealand, as Maori and people of Pacific Island origin have shorter life expectancies than the overall population of New Zealanders (Maori by seven years in 2005-2007, Pacific Islanders by four years). ${ }^{40}$ Maori and Pacific people are also known to experience greater difficulty in accessing health services. The formula by which DHBs are funded assigns specific categories and weights to recognize the additional resources required to provide services for Maori and other underserved populations.

Through much of the 2000s, a multi-sector policy approach saw investments in housing, education, and health, as DHBs and PHOs were required to develop strategies for reducing disparities. Many PHOs were created especially to serve Maori or Pacific populations.

40 Based on the most recently available census information, from 2006. The 2011 census, from which life expectancy data were to be finalized, was postponed until March 2013 following the February 2011 earthquake in Christchurch. Results will be released as of December 2013. 
The post-2008 government has been more focused on specific initiatives such as Whanau Ora, a policy designed to integrate the various providers of social services, including health, for disadvantaged Maori, who often fall between the boundaries of different agencies. The aim here has been to develop multiagency approaches to service provision and joint responsibility for outcomes.

\section{Who is responsible for population health?}

Population health is the responsibility of 12 regional Public Health Units (PHUs), owned by the 20 DHBs, and a range of local and nongovernmental organizations. PHUs are focused largely on communicable disease control, environmental health, tobacco control, and health promotion. Medical Officers of Health and Health Protection Officers, employed by PHUs, have various statutory powers. Policy priorities for population health, such as targets for increased immunization, cardiovascular screening, and smoking cessation advice, are set by the government and pursued by a mix of DHBs, PHOs, and PHUs.

\section{What is the status of electronic health records?}

New Zealand has one of the world's highest rates of information technology (IT) use among primary care physicians. The government's goal is that all New Zealanders have electronic access to a core set of personal health information by 2014. Since the National Health IT Plan was launched in September 2010, there has been good progress toward that goal. Clinicians and vendors are working together on a number of projects: there is a larger focus on supporting and enabling integrated care, and a shift toward regional investment decisions and the development of regional solutions. However, challenges with legacy systems remain.

Increasingly, primary care IT systems provide services such as the capability for structured electronic transfer of patient health records, electronic referrals, decision support tools with patient safety features, and patient access to health information in a secure environment.

More generally, the focus for the future is on facilitating secure sharing of patient health information between community, hospital, and specialist settings, including common clinical information; providing all consumers with an online view of their information; and supporting the development of shared care plans (where a number of health professionals are involved in a person's care).

The National Health IT Board works with a number of sector groups and receives advice from others, including clinicians, consumers, and vendors. The Health Information Standards Organisation (HISO) supports and promotes the development and use of health information standards to ensure interoperability between systems. Every person who uses health and disability support services in New Zealand has a national health index number as a unique identifier.

\section{How are costs controlled?}

The financial sustainability of publicly funded health care is a top governmental priority. To support this goal, the government has implemented a range of measures to manage key pressures, including four-year planning to align expenditure with priorities over a longer period and improving regional collaboration to drive efficiencies. All new proposals must be integral to a four-year plan and need to demonstrate their fit with the strategic direction of the health sector over the next four years. 
Cost control in DHBs has been closely monitored by the Ministry of Health, with a significant reduction in deficits over the last five years, from NZ\$104.8 million (US\$88 million) in 2008-2009 to NZ\$21 million (US\$18 million) in 2012-2013.

In its shared services role, Health Benefits Limited has been charged with finding cost-savings for DHBs, with a target of NZ\$700 million (US\$587 million) over five years across procurement, financial management, and information systems.

The National Health Committee has been established to prioritize health technologies and provide advice as to which technologies no longer offer value for money. It will increasingly use comparative-effectiveness research methods to evaluate existing and new interventions and technologies.

PHARMAC uses a range of tactics, such as reference pricing and competitive tendering, to set prices for publicly subsidized drugs dispensed through community pharmacies and hospitals. If patients prefer unsubsidized medicines (there are no clinical indications that these would be more effective), they pay the full cost. Such strategies have helped drive down pharmaceutical costs and, as a result, New Zealand's drug expenditure per capita was the third-lowest in the OECD in 2010 (OECD, 2012).

\section{What major innovations and reforms have been introduced?}

Following the advice of the 2009 Ministerial Review Group report, the government has announced a series of initiatives, most of which have been outlined above, designed to improve service efficiency, access, and quality while shifting expenditure away from administration and toward patient services. The National Health Board aims to enhance administrative and clinical service efficiency, coordination, and national procurement; the Health Quality and Safety Commission targets improved quality of care; and all policy activities emphasize the notion of comparative effectiveness. Projects to reduce emergency department waiting times have demonstrated the value of "lean" methods designed to improve patient flow. PHOs have been involved in many provider-driven primary care delivery programs focused on population health and service integration. In disability support care, there have been promising experiments with personal budgets, allowing recipients to purchase home help, although these are voluntary and only available in a few localities. The quarterly publication of DHB performance against six government targets has inspired much of the increased focus on such innovations.

To retain New Zealand-trained health professionals and direct them to hard-to-staff communities and specialties, a voluntary bonding scheme was introduced in February 2009 for medical, midwifery, and nursing graduates. The government has also increased the number of places available in medical and nursing schools, with greater numbers of doctors and nurses expected to join the workforce in coming years. DHBs are increasingly working collaboratively to ensure the sustainability of and access to specialist services in smaller towns and regions.

The author would like to acknowledge the New Zealand Ministry of Health for its comments and for providing updated information for the profile. 


\section{References}

Gauld, R. (2012). "New Zealand's Post-2008 Health System Reforms: Toward Recentralization of Organizational Arrangements," Health Policy 106:110-13.

Ministerial Review Group (2009). Meeting the Challenge: Enhancing Sustainability and the Patient and Consumer Experience within the Current Legislative Framework for Health and Disability Services in New Zealand (Wellington: Ministry of Health).

Ministry of Health (2013). Annual Report for the year ended 30 June 2013 including the Director-General of Health's Annual Report on the State of Public Health

(Wellington: Ministry of Health).

OECD Health Data 2013.

Ryall, T. (2008). Better, Sooner, More Convenient: Health Discussion Paper by Hon. Tony Ryall MP (Wellington: National Party). 


\title{
The Norwegian Health Care System, 2013
}

\author{
Anne Karin Lindahl and Ånen Ringard, Norwegian Knowledge Centre for Health Services
}

\section{What is the role of government?}

The role of government differs according to the level of health care. The Ministry of Health and Care Services has a direct role in secondary care, legislating and funding health services, owning hospitals, and providing directives to the boards of the four regional health authorities (RHAs), which are state-owned corporations. Since the 2002 Hospital Reform, the RHAs have been responsible for supervising inpatient and specialist somatic and psychiatric care, and alcohol and substance abuse treatment. The ministry provides the RHAs' budgets, and issues a yearly document instructing the RHAs as to aims and priorities. RHAs report to the ministry on their activities.

Primary health care is the responsibility of Norway's 428 municipalities. The municipalities are independently governed, so the Ministry plays a more indirect role, mainly through legislation and funding mechanisms. Municipalities are responsible for organizing and delivering services like health promotion, preventive medicine, rehabilitative services, emergency care, and long-term (LTC) and home-based nursing care. Funding comes from municipal taxes, general contributions from the government, and earmarked government grants. General practitioners (GPs) also receive part of their funding from the Norwegian Health Economics Administration (HELFO), an institution subordinate to the Norwegian Directorate of Health and responsible for, among other areas, direct payments to various health service providers, individuals' reimbursement for certain medicines, dental services, and health services abroad. The municipality provides care in accordance with current legislation and written directives based on national priorities from the Directorate of Health. Public dental care and public health tasks are the responsibility of the 19 counties.

\section{Who is covered?}

Coverage is universal. The nationally managed and financed health system is built on the principle of equal access for all citizens regardless of socioeconomic status, ethnicity, and area of residence. European Union (EU) residents have, through common agreements, the same access to health services as Norwegians. For undocumented immigrants, access is limited to emergency acute care. Private voluntary health insurance (VHI), although expanding, covers less than 1 percent of total health care expenditures. It is bought mostly by employers in order to procure quicker specialist health services for their employees (please see below).

\section{What is covered?}

Services: Parliament determines coverage, and also establishes the cost ceiling (see below) and criteria for costsharing. In practice, statutory national health insurance covers primary care, including home care, hospital care, inpatient drugs, ambulatory care, and outpatient prescription drugs on the "blue list" formulary. It also covers dental care and prescribed physiotherapy for children and other prioritized groups. It does not cover nonmedical eye care. A physician must consider certain treatments, such as plastic surgery, to be medically essential in order for them to qualify for public coverage. Complementary medicine is not covered. 
Primary care (services by GPs, physiotherapists, and chiropractors), preventive care (checkups, screening, and immunization of infants and schoolchildren), and nursing care are organized by the municipalities.

Municipalities also create public health initiatives to promote healthy lifestyles and to reduce social health disparities. Long-term care is provided, based on need, either at home, in institutions, or in nursing homes. The health budgets for municipal services are decided locally. A number of services are, however, mandatory, particularly within pediatric care.

Cost-sharing: GP and specialist visits, including outpatient hospital care and same-day surgery, require copayments (NOK140 [US\$23] and NOK315 [US\$52] per visit in 2013, respectively), as do physiotherapy visits (in varying amounts), covered prescription drugs (up to NOK520 [US\$87] per prescription; see below for further detail), and radiology and laboratory tests (NOK224 [US\$37] and NOK48 [US\$8], respectively). As long as they are part of the public system, providers are not allowed to charge a higher price than the national insurance will pay. Institution-based long-term care for older or disabled people may require substantial cost-sharing (up to $85 \%$ of personal income), but is means-tested.

Prescription drug prices are linked to reference prices set as the average of the three lowest market prices for the drug in a group comparison of prices in Scandinavian and Western European countries. The drug pricing scheme aims to encourage use of generic drugs.

Safety net: There is an annual limit for many cost-sharing requirements, above which out-of-pocket (OOP) costs are waived; for 2013, the cost-sharing ceiling, set by the Parliament, is NOK2,040 (US\$340). A second ceiling is set at NOK2,620 (US\$436) for services such as physiotherapy and certain dental services. Long-term care and prescription drugs outside the "blue list" do not qualify toward these ceilings. Certain groups are exempt from cost-sharing: children under the age of 16 receive free physician treatment and access to essential drugs on the blue list, children under the age of 18 receive free psychological and dental care, pregnant women receive free medical examinations during and after pregnancy, and residents eligible for minimum retirement pensions or disability pensions receive free essential drugs and nursing care. Individuals suffering from specified communicable diseases, e.g., HIV/AIDS, and patients with work-related injuries receive free medical treatment and medication. All inpatient care in a public hospital, including use of pharmaceuticals, is free of charge.

\section{How is the health system financed?}

In 2011, Norway had the second-highest per capita spending on health care among Organisation for Economic Co-operation and Development (OECD) countries; as a percentage of GDP, it spent close to the OECD median (9.4\%).

Publicly financed health care: Public spending on health accounted for 85 percent of total health expenditure in 2012, and is financed through general taxation collected by the central government, counties, and municipalities (taxpayers with high expenses as a result of permanent illness are entitled to a tax deduction). The government proposes an annual health budget in October, which the Parliament debates and passes in December. After that, the government's General Purpose Grant Scheme allocates funds to municipalities according to population size and other characteristics. Hospital care funds are allocated to the RHAs through a combination of block grants (60\%) and activity-based funding (40\%). 
Privately funded health care: In 2012, OOP payments accounted for approximately 15 percent of total health care expenditure, mainly reflecting cost-sharing arrangements for medicines and GP services (37\% of the total costs of GP services), as well as outpatient specialist services and transportation. Supplementary voluntary health insurance, operated by for-profit companies and offering shorter waiting times for publicly covered elective services, does not play a significant role in health care financing (less than 1 percent of total health care costs) and covers above 5 percent of the population. Of these, 88 percent receive coverage through their employer (employees are taxed for these benefits).

\section{How are health services organized and financed?}

Primary care: Although the number of physicians has increased in both the primary and the hospital sector, the proportion of physicians working as GPs has fallen dramatically in the past 10 years, indicating higher growth in specialist care. According to the health personnel registry, there are 2.09 specialists in hospitals or ambulatory care for every GP. Financial incentives have, however, been put in place both to encourage more GPs to become specialists in primary care medicine (which involves several years of education and service, as well as recertification every five years) and to encourage individual GPs to see more patients per day.

Since 2001, patients have been encouraged to register with a particular GP, and virtually all residents are now registered. Those not included in the GP scheme pay an additional NOK115 (US\$15) for GP consultations. Patients have a legal right to seek a second medical opinion, and may change their GP up to twice a year. However, in many places there are too few GPs with availability on their list, leaving patients without a real choice of provider.

GP financing is determined through negotiations at the national level. The 2001 reform established the current payment model: municipalities contract with GPs, who in turn receive a combination of capitation from municipalities, fee-for-service (FFS) from the Norwegian Health Economics Administration (Helfo), and OOP from patients. Some incentives (e.g., for GPs to take part in meetings about individual care plans with and for patients with chronic diseases, or to meet with employers to get people on sick leave back to work) are instituted through the FFS system. GPs are mainly self-employed, but a few are salaried municipal employees. GP practices typically comprise two to six physicians as well as nurses, lab technicians, and secretaries. GPs and ambulance services are the main referrers of patients to emergency hospital consultations or admittance to hospitals for specialty care.

Outpatient specialist care: Hospital-based specialists are salaried. Privately practicing specialists are selfemployed and paid through a combination of annual lump sums from the RHAs (according to type of practice and number of patients), in addition to FFS (from Helfo) and OOP (from patients). There are incentives in the form of higher reimbursement rates for some services, such as secondary prevention of cardiovascular diseases and promoting smoking cessation.

After-hours care: After-hours emergency services are the responsibility of the municipalities and are provided by GPs on contract. Municipalities provide offices, equipment, and assistance, and pay the GPs a small fee. In many places, after-hours emergency services are located close to or at a hospital, providing easy access to $\mathrm{X}$-rays, laboratory services, and hospital care. Patient cost-sharing and provider fees are slightly higher for 
after-hours emergency services. In urban areas, after-hours care is provided by the municipality in special wards operated 24 hours a day, seven days a week.

Hospitals: Most hospitals are state-owned, but are formally registered as legal entities with an executive board (approved by the Ministry of Health and Care Services) and governed as publicly owned corporations. All hospitals offer ambulatory services, and ambulatory care consultations take place in hospitals or through privately practicing specialists. Patients are free to choose the hospital they want to go to for elective services, but not for emergency care (set with regards to proximity). Hospitals are financed by the government through the RHAs. There is no particular funding for entire episodes of care from diagnosis through rehabilitation-rather, hospitals are funded through an annual budget. The Coordination Reform (2012) introduced a cofinancing requirement for municipalities of approximately 20 percent of hospital costs for their residents (excluding surgical procedures, obstetric services, children's care, and psychiatric care).

Mental health care: Mental health care is provided by GPs and other providers (e.g., nurses and psychologists) by the municipalities. For specialized care, GPs can refer patients to a private psychologist or psychiatrist, or to a low-threshold outpatient hospital (district psychiatric center), some of which also have inpatient wards. Such centers are located in residential areas so as to facilitate further treatment and follow-up by community health and social care workers. They often have psychiatric outreach teams that treat patients in their homes. More advanced treatment is organized in the inpatient psychiatric wards of mental health and general hospitals. Hospital treatment is provided free of charge, and outpatient services are subject to the same cost-sharing as described above. Private mental hospitals play a limited role, and include services for eating disorders, nursing homes for older psychiatric patients, and psychiatrist/psychologist outpatient practices. Psychiatric care and addiction treatment are financed through block grants.

Preventive services for mental health, organized by the municipalities, are mostly directed toward children and adolescents and are provided through the school systems.

Long-term care: The municipalities are responsible for providing long-term care. Cost-sharing for institutionalized care is means-tested, but can reach 85 percent of patients' income. Institutions include nursing homes, long-term psychiatric homes, and homes for the severely disabled. More and more long-term care is being provided as home-based care. A few nursing homes are privately operated under contract with the municipalities. Municipalities may provide end-of-life care for terminal patients, but many nursing homes do not have palliative units.

\section{What are the key entities for health system governance?}

The Ministry of Health and Care Services is, as described above, the key organization for health system governance in Norway. The Directorate of Health is the main actor responsible for implementing national health policies on behalf of the Ministry of Health and Care Services. It is also in charge of national emergency health preparedness for crises like tsunamis, swine flu emergencies, and the national catastrophe of July 22, 2011. It issues national guidelines and approves national quality registries and Centers of Competence. The responsibilities of the Directorate's eHealth unit include overseeing electronic prescriptions and health records and the dissemination of hospital quality information to authorities and patients. It governs the Norwegian Health Economics 
Administration (Helfo), the Norwegian Knowledge Centre for the Health Service (NOKC; see below), and the Registration Authority for Health Personnel (SAK; see below).

The Norwegian Board of Health Supervision is a national institution organized under the ministry. Public supervision in Norway is intended to ensure that health and social services are provided in accordance with national acts and regulations. The Board carries out three types of supervision: area surveillance, planned supervision of services, and incident-related supervision. Area surveillance is supervision with the purpose, among others, of evaluating whether needs are met (are people offered the services they require?) and whether the quality of services is adequate (do the services that are provided meet the requirements laid down in the legislation?). On the other hand, planned supervision of services entails systemwide audits determining whether guidelines are being followed and whether current practices are safe. Incident-related supervision examines individual cases to see whether there has been a breach of acts or regulations (exposing approximately 200 per year).

The Norwegian Institute of Public Health (NIPH), also organized under the Ministry of Health and Care Services, is a driving force in improving the population's health and quality of life and preventing illness and injury. It bases its advice and services on research and health surveillance. The Institute also assists in resolving criminal and civil cases (e.g., through forensic work).

The Norwegian Medicines Agency (NoMA) determines which medications qualify for reimbursement. For new drugs, the agency determines whether a prescription drug should be covered (i.e., put on the "blue list") by evaluating its cost-effectiveness in comparison with existing treatments; new drugs expected to have a significant impact on the public budget must receive ministerial and parliamentary approval before being covered. It also administers the "green" scheme, which encourages providers to prescribe lifestyle and nutrition programs as a first alternative to more expensive preventive medicine.

The Norwegian Knowledge Centre for the Health Services (NOKC), financed by the government, focuses on comparative effectiveness, patient safety, and publication of quality indicators and national patient experience surveys. It often includes economic analyses in its systematic reviews and health technology assessments, which are actively used by the National Council for Priority Setting in Health Care, a body providing advice to the Ministry of Health and Care Services and others on controversial issues of priority-setting. The Knowledge Centre also includes the National Agency for Patient Safety, which oversees the Secretariat for the Patient Safety Campaign, initiated in 2011. Since July 2012, the Knowledge Centre has run the National Reporting and Learning System, which addresses adverse events in health care.

\section{What is being done to ensure quality of care?}

The Directorate of Health has developed a national strategy (2005-2015) for quality improvement in health and social services. It focuses on safety and efficiency, patient-centered care, care coordination, and continuity of care. Eliminating socioeconomic inequalities is also a priority. In support of these efforts, the Norwegian Knowledge Centre for the Health Services gathers and disseminates information on the effectiveness and quality of health services. The Registration Authority for Health Personnel licenses and authorizes all health care professionals and can grant full and permanent approval to those meeting educational and professional 
criteria. Audits of all levels of the health system, including the health care workforce, are carried out by the Norwegian Board of Health Supervision.

RHAs, hospitals, and municipal health care providers are responsible for ensuring service quality. National performance measurements and quality indicators are continuously being developed. Previously, only process indicators, such as hospital waiting times and number of performed procedures, were available. Since 2010 , outcome indicators, like 30-day survival rates after admission for heart attack, stroke, and hip fracture, and overall rates, have been developed by the Norwegian Knowledge Centre for the Health Services. The Knowledge Centre also conducts national patient experience surveys. All these indicators are approved by the Directorate of Health and are made publicly available on a Web page (www.helsenorge.no).

There are currently 15 national health registries (e.g., the Birth and the Cancer Registries). In addition there are a number of clinical quality registries; 30 are national (i.e., covering all hospitals), while others are aiming at becoming national through national funding and technical support from the National Centre for Clinical Documentation and Evaluation (SKDE). Registries are based mainly on data submitted by hospitals with patient consent, and hospitals are given feedback on their performance in relation to average national hospital performance. Most registries are not linked to electronic medical records, but efforts are being made to achieve more integrated solutions.

The Norwegian Institute of Public Health uses the Norwegian Prescription Database to produce annual reports on prescribing trends, giving national health authorities a statistical base for planning and monitoring drug prescription and use; personal information held by the registry is anonymized.

\section{What is being done to improve care coordination?}

Within primary care, the number of multi-specialty practices is growing, with GPs establishing common practices with physiotherapists and specialists within orthopedics, ophthalmology, dentistry, and pediatrics.

Practices share nurses (some having specialized nurses for ailments such as diabetes and lung disease), secretaries, and lab personnel.

For hospitals, incentives for care coordination are provided by mandatory agreements between hospitals and the municipalities, and through the recently introduced cofinancing of hospital care by municipalities. After elective and emergency hospitalization, a discharge letter is sent to a patient's GP, in most cases. If patients need home-based nursing care, there are routines for alerting the home municipality, and in most instances the municipality makes a needs-based evaluation before the patient leaves the hospital.

New models for integrated care are currently being tested, with joint wards (financed jointly by hospitals and municipalities) for patients with intermediate needs for institutionalized care. In some instances these include wards for palliative end-of-life care (mostly cancer patients); in other areas, hospice-type wards are operated by and within nursing homes. All patients with chronic diseases, including patients with mental health diagnoses, have a legal right to an individual plan for their care and treatment. 


\section{What is being done to address health disparities?}

There is ever-increasing awareness of health disparities with regard to socioeconomic and immigrant status. Studies show that some immigrant groups, on average, have poorer health, while others show that they have better health than the average native Norwegian. Research on pregnancy has been informative, as there are significantly more complications for newborns and mothers among immigrant women than among Norwegians. The need for provision of adequate health-related information in immigrants' native languages has also been emphasized. Geography plays a significant role in differences in health outcomes, as recruitment of health personnel, notably doctors and specialized nurses, is difficult in rural areas, particularly in the north.

It has been a long-standing political goal of the health care system to grant equal access to services for all inhabitants, regardless of their social or economic status and geographical location. This aim has also been included in health care legislation (e.g., the 1999 Specialist Care Act), and in 2007 a national strategy for addressing inequalities in health and health care was issued. However, there have been no accurate measures to determine whether access goals have been achieved.

\section{Who is responsible for population health?}

Traditionally, population health has been about infection control; now, it is focusing more on preventing chronic noncommunicable diseases and mental health problems. The Norwegian Directorate of Health initiates campaigns to promote physical activity and reduce smoking and alcohol intake, and sets goals for municipalities in an annual steering document. Municipalities are responsible for using available resources and establishing political priorities to promote the health of their populations. Counties also have a separate responsibility to engage in preventive population health initiatives, such as mental health programs for high school students.

\section{What is the status of electronic health records?}

The Ministry of Health and Care Services has decided upon a national strategy for information technology, and the implementation is being overseen by a governmental steering committee. The National Health Network, a centralized company owned by the state, is currently establishing a single information exchange platform for health providers and authorities. The resulting network will facilitate communication for GPs, hospitals, nursing homes, pharmacists, and others.

IT in primary care is fragmented, and some areas of service lack resources and equipment for implementation. Currently, all GPs use electronic patient records, and most receive discharge letters electronically from hospitals, whereas electronic referral from GPs to the hospitals is less widespread. GPs often communicate electronically with laboratories, and most send electronic prescriptions to pharmacies. Many GPs can also order X-rays and outpatient specialist services directly through the electronic network. Uptake by municipality home care and nursing homes has been slower, owing to more complex and integrated information system requirements.

All hospitals use electronic patient records. The lack of structured patient records in both primary and secondary care precludes automatic data extraction; hence there is still a need for quality improvement or national activity registration at both the local and the national level. After-hours emergency care is often (but not always) organized within the same patient record network, so that patient data remain available after hours, and primary care providers are able to access information regarding emergency visits. 


\section{How are costs contained?}

A balanced national budget gives Norway flexibility in addressing rising health costs. The Parliament sets an overall health budget in December every year, although it may also approve additional funds throughout the year. Municipalities and RHAs are then given the responsibility for maintaining their budgets. The Norwegian Medicines Agency, as described earlier, uses cost-effectiveness evaluations to determine which drugs will be reimbursed, and there are incentives for the use of generics. Further efforts at cost containment are described in the following section.

\section{What major innovations and reforms have been introduced?}

As described above, there have been several major changes in Norwegian health care, with relatively recent reforms in primary care (GP reform, 2001), in hospital care (2002), and at the national authority level (2002).

In 2009, the Ministry of Health and Care Services proposed the Coordination Reform, focusing on prevention, care integration, and the strengthening of municipal health care. There has been growth in annual health expenditure in the past 10 years, most of it experienced by hospitals; the Coordination Reform, which came into effect in January 2012, also aims to curb that growth and direct more funding toward primary care. It has introduced an economic incentive for municipalities to work toward fewer patient hospitalizations: the municipalities now must pay 20 percent of their residents' hospitalization costs. In addition, municipalities are obliged (from 2012 to 2015) to establish primary emergency 24-hour care for patients who do not need specialized hospitalization, but nevertheless have health care needs that cannot be met at home. The Coordination Reform will also strengthen information systems: the Norwegian Health Network will be developed further and will operate information technology infrastructure for the health care sector.

In recent years there has been greater focus on quality and priority-setting. As described earlier, the current government has established the National Council for Priority Setting in Health Care, and a set of priority-setting guidelines has been created to guide referrals to secondary care. Starting in 2013, a system for regulating the introduction of new and costly treatments in hospitals is being implemented.

In July 2012, the national reporting system for adverse events in hospitals was replaced by the nonpunitive, electronic Reporting and Learning System. Whereas the previous reporting system could be used as the basis for punitive action relating to health personnel's authorization to practice, or for litigation, the new system is geared only toward preventing future harm to patients, and therefore focuses only on learning from the incidents.

The authors would like to acknowledge David Squires as a contributing author to earlier versions of this profile.

\section{References}

Ahlberg, N., and Vangen, S. (2005). "Pregnancy and Birth in Multicultural Norway," Tidskr Nor Legefor 125(5):586-88.

Johnsen, J.R. (2006). Health Systems in Transition: Norway. Copenhagen: WHO Regional Office for Europe on behalf of the European Observatory on Health Systems and Policies. 
Ministry of Health and Care Services (2009). "The Coordination Reform: Proper Treatment at the Right Place and Time," report no. 47. Oslo: Ministry of Health and Care Services.

Ministry of Health and Care Services (2007). National Strategy to Reduce Social Inequalities in Health, report no. 20. Oslo: Ministry of Health and Care Services.

Ministry of Health and Care Services (2011). "Helse-og omsorgstjenesteloven" ("The new law for health and care services”), http://www.l ovdata.no/all/hl-20110624-030.html.

National Health Network (Norsk Helsenett): http://www.nhn.no/.

OECD (2012). Health at a Glance 2011: http://www.oecd.org/health/healthpoliciesanddata/healthataglance2011. htm.

National Strategy for Quality Improvement for the Health and Care Services, 2005-2015, report no. IS 1162. Directorate of Health, 2005.

Ringard, Å., Sagan, A., Saunes, I.S., and Lindahl, A.K. “Norway: Health System review.” Health Systems in Transition, 15(8). Copenhagen: The European Observatory on Health Systems and Policies on behalf of WHO Regional Office for Europe.

Ringard, Å., Sagan, A., Saunes, I.S., and Lindahl, A.K. (2013). "Norway: Health System review." Health Systems in Transition, 15(8). Copenhagen: The European Observatory on Health Systems and Policies on behalf of WHO Regional Office for Europe. 


\title{
The Swedish Health Care System, 2013
}

\author{
AnNa H. GlenngÅRd, Lund University School of Economics and Management
}

\section{What is the role of government?}

The three independent levels of Swedish government are all involved in the health system. At the state level, the Ministry of Health and Social Affairs is responsible for overall health and health care policy while working in concert with eight national government agencies directly involved in the areas of health, health care, and public health. Sweden has had a long history of strong local self-government. Responsibility for the organization and provision of health care services lies mainly with the 21 county councils (including four regional bodies), which also are responsible for operating regional transportation and cultural activities. At the local level, 290 municipalities are responsible for matters relating to the immediate environment of their citizens, including care of older people and disabled people. The regional and local authorities are represented by the Swedish Association of Local Authorities and Regions (SALAR).

\section{Who is covered?}

Coverage is universal. The 1982 Health and Medical Services Act states that the health system must cover all legal residents. Emergency coverage is provided to all patients from EU/European Economic Area countries. It is also provided to patients from nine other countries with which Sweden has bilateral agreements. Asylumseeking and undocumented children have the right to health care services, as do permanently resident children, and adult asylum seekers have the right to receive care that cannot be deferred (e.g., maternity care). Undocumented adults have the right to receive nonsubsidized immediate care. About 4 percent of the population has supplementary private voluntary health insurance (PHI).

\section{What is covered?}

Services: There is no defined benefits package. The publicly financed health system covers public health and preventive services; primary care; inpatient and outpatient specialized care; emergency care; inpatient and outpatient prescription drugs; mental health care; rehabilitation services; disability support services; patient transport support services; home care and long-term care, including nursing home care; dental care for children and young people; and, with limited subsidies, adult dental care. Responsibility for the organization and financing of health care is decentralized and rests with the 21 county councils, and responsibility for the care of older people and the disabled rests with the 290 municipalities. Services may therefore vary throughout the country. However, three basic principles apply to all health care in Sweden: human dignity (all human beings have an equal entitlement to dignity and have the same rights regardless of their status in the community), need and solidarity (those in greatest need take precedence in being treated), and cost-effectiveness (when a choice has to be made, there should be a reasonable relationship between health care costs and benefits measured in terms of improved health and quality of life).

Cost-sharing: Cost-sharing per health care visit and per bed-day is determined by individual county councils and municipalities. In 2013, consultation with a physician in primary care cost between SEK120 (US\$18) and SEK200 (US\$31). The fee for consulting a specialist at a hospital was between SEK200 and SEK350 (US\$54), and 
patients were charged SEK80 (US\$12) per day for hospitalization (SALAR, 2013). In almost all county councils, people under 20 years of age are exempt from user charges for health care visits. Older and/or disabled people incur a separate maximum copayment for services commissioned by the municipalities (SEK1,780 [US\$274] per month in 2013).

Dental and pharmaceutical benefits are determined at the national level. People under 20 have free access to all dental care. People 20 or older receive a fixed annual subsidy of between SEK150 (US\$23) and SEK300 (US\$46), depending on age, for preventive dental care. For other dental services, in a 12-month period, patients 20 or older pay the full cost of services up to SEK3,000 (US\$462), 50 percent for services between SEK3,000 and SEK15,000 (US\$2,308), and 85 percent for services above SEK15,000. Individuals pay the full cost of prescribed drugs up to SEK1,100 (US\$169) annually, after which the subsidy gradually increases to 100 percent.

Safety net: There is a national ceiling for out-of-pocket payments that ensures that an individual will never pay more than SEK1,100 (US\$169) annually for health care visits. The ceiling for prescribed drugs is SEK2,200 (US\$339) annually for adults. A separate annual maximum of SEK2,200 for pharmaceuticals applies collectively to all children belonging to the same family. Some over-the-counter drugs and prescription drugs are not subject to reimbursement; patients must pay the full price. There is no cap on user charges for dental care.

\section{How is the health system financed?}

Publicly financed health care: In 2011, about 82 percent of all expenditures on health in Sweden were publicly financed, with county councils' expenditures amounting to about 72 percent, municipalities' to about 8 percent, and the central government's to about 2 percent (Statistics Sweden, 2013). The county councils and the municipalities levy proportional income taxes on the population to help cover health care services. In 2011, 70 percent of county councils' total revenues were derived from local taxes and 22 percent from subsidies and state grants financed by national income taxes and indirect taxes (SALAR, 2012). General state grants are based on a capitation formula that partly reallocates resources among municipalities and county councils. Targeted state grants must be used to finance specific initiatives, e.g., reducing waiting times, sometimes over a specific period. In 2011, about 92 percent of county councils' total spending was on health care (SALAR, 2012).

Privately financed health care: In 2011, about 18 percent of all expenditures on health were private, whereof outof-pocket spending accounted for about 16 percent (Statistics Sweden, 2013). The primary reason for having private individual insurance is to get quick access to a specialist in ambulatory care and to avoid waiting lists for elective treatment. Voluntary health insurance in Sweden is, however, mainly linked to occupational health services, and most voluntary health insurance plans are paid for by employers (Swedish Insurance Federation, 2013). Some 500,000 individuals had private health care insurance in 2012 , including about 10 percent of all employed individuals.

\section{How are health services organized and financed?}

The health system is highly integrated. An important policy initiative driving structural changes since the 1990 s has been to shift from inpatient care to outpatient or community-based care. Patient choice of provider has also been gradually rolled out since then, and now is available for both primary care and specialist services. Provider payment varies by county council. 
Primary care: Primary care has no formal gatekeeping function. Team-based primary care is the main form of practice, where GPs, nurses, midwives, physiotherapists, psychologists, and gynecologists provide treatment, advice, and prevention. The GP is often the first point of contact for adults, including older people. For children, this function is shared between GPs, outpatient pediatricians, and district nurses. District nurses employed by municipalities participate in home care and regularly make home visits, especially to older people; they have limited prescribing authority.

Since 2010 , it is stipulated by law that citizens may register with any public or private provider accredited by the local county council and that payment to providers should follow individual's choices. Freedom of establishment applies to all providers fulfilling the conditions for accreditation determined by the county councils. Such conditions primarily focus on opening hours and minimum number of clinical competences available at the practice. There are more than 1,100 primary care practices throughout the country, of which about one-third are privately owned. The same requirements for accreditation apply to both public and private providers. Both public and private practices are paid a combination of fixed payment (capitation, about $80 \%$ of total payment), feefor-service, and performance-related pay for achieving targets (e.g., patient satisfaction, registration in national registers, and compliance with recommendations from county council drug formulary committees). Public and private physicians, nurses, and other categories of primary care staff are predominantly salaried employees.

Outpatient and inpatient specialist care: Structural changes in specialized care during the past two decades have focused on a shift away from hospital inpatient care toward hospital outpatient care and day care, and on concentrating highly specialized care to university hospitals and/or regional centers for specific diseases, e.g. cancer. There are seven university hospitals, and about 70 hospitals at the county council level. Counties are grouped into six health care regions to facilitate cooperation and to maintain a high level of advanced medical care. Highly specialized care, requiring the most advanced technical equipment, is concentrated at university hospitals to achieve higher quality, become more efficient and to create better possibilities for development and research. Most hospitals are public, but county councils also contract with private hospitals. Global budgets or a mix of global budgets, diagnosis-related groups (DRGs), and performance-based methods are commonly used to determine payment to hospitals.

After-hours care: Acute care hospitals (seven university hospitals and two-thirds of all 70 county council hospitals) provide full emergency services. All county councils and regions provide information on how and where to seek care through their Web sites and a national phone line, 1177, with medical staff available to give advice about treatment 24 hours a day. A collaborative initiative between all county councils and regions to provide online information about pharmaceuticals, medical conditions, and pathways for seeking care is known as 1177. se.

Mental health care: Mental health care is an integrated part of the health care system and is subject to the same legislation and user fees as other health care services. People with minor mental health problems are usually attended to in primary care either by a GP or by a psychologist or therapist; patients with severe mental health problems are referred to specialized psychiatric care in hospitals.

Long-term care: Responsibility for the financing and organization of long-term care for older people and support for people with disabilities lies with the municipalities, but the county councils are responsible for these 
patients' routine health care. The Social Services Act of 1980, revised in 2001, specifies that older people have the right to receive public services and help at all stages of life. There are both public and private nursing homes and home care providers. The number of private nursing homes has increased gradually, but varies significantly among municipalities. Payment to private providers is usually contract-based, following a public tendering process. Eligibility for both public and private nursing home care is based on need and determined by each municipality. Since the 1980s, there has been an established national policy to promote home assistance and home care over institutionalized care. Also in national policy, older people are entitled to live in their homes for as long as possible.

\section{What are the key entities for health system governance?}

The National Board of Health and Welfare, a large government agency, supervises all health care personnel,disseminates information, develops norms and standards for medical care, and, through data collection and analysis, ensures that these norms and standards are met. It also maintains health data registries and official statistics. The Medical Responsibility Board (HSAN) decides on disciplinary measures in the event of complaints or possible malpractice. The Swedish Agency for Health and Care Services Analysis, established in 2011, analyzes and evaluates health policy as well as the availability of health care information to citizens and patients. The agency make the results from such analyses available through published reports.

The National Institute for Public Health provides the national government, government agencies, municipalities, and county councils with new knowledge based on scientific evidence, including health technology assessment (HTA). The main HTA body for pharmaceuticals is the Dental and Pharmaceutical Benefits Agency (TLV), which assesses the cost-effectiveness of prescription drugs. Since 2002, the TLV has been mandated to decide whether particular drugs should be included in the National Drug Benefit Scheme; prescription drugs are priced in part on the basis of their value. In 2008, the TLV's mandate was extended to include dental care.

County councils control the establishment of new private practices by regulating requirements for accreditation. Private providers must have agreements with the local county council in order to be publicly reimbursed.

\section{What is being done to ensure quality of care?}

Concern for patient safety has increased during the past decade, and patient safety indicators are compared regionally (see below). Eight priority target areas for preventing adverse events have been specified: health care-associated urinary tract infections; central line infections; surgical site infections; falls and fall injuries; pressure ulcers; malnutrition; medication errors in health care transitions; and drug-related problems (SALAR, 2011).

The National Board of Health and Social Welfare, together with the National Institute for Public Health and the TLV, prepares systematic reviews of evidence and guidance for priority-setting, which support disease management programs developed at the county council level; international guidelines and specialists are also central to the development of these local programs. There is a tendency to develop regional rather than local guidelines to inform priority-setting in order to avoid unnecessary variation in clinical practice. For example, a national cancer plan was established in 2009, and work has begun on the creation of six regional cancer centers (RCCs) intended to cover the whole population. 
The 90 or so national quality registries are increasingly important for monitoring and evaluating quality among providers and for assessing treatment options and clinical practice. Registries contain individualized data on diagnosis, treatment, and treatment outcomes. They are monitored annually by an executive committee, funded by the state and county councils, and managed by specialist organizations.

Since 2006, annual performance comparisons and rankings of the county councils' health care services using data from the national quality registers, the National Health Care Barometer Survey, and the National Patient Surveys have been made available to the public through a collaborative project undertaken by the National Board of Health and Welfare and SALAR. The 2012 publication included 169 indicators, organized into various categories, e.g., prevention, patient satisfaction and trust, access, surgical treatment, and drug treatment. Some 50 indicators are shown also for hospitals, but without rankings. Other projects aim to collect information about availability and waiting times for specific patient groups, e.g., cancer patients. Since 2009, statistics on patient experiences in primary care have been collected separately through a standardized biannual national patient survey and made available through the Internet in order to help guide people in their choice of primary care provider.

\section{What is being done to improve care coordination?}

The division of responsibilities between county councils (for medical treatment) and the municipalities (for nursing and rehabilitation) requires coordination. Efforts to improve collaboration and develop more integrated services include the development of national action plans supported by targeted state grants. Such grants are often awarded to county councils and/or providers according to their degree of fulfilment of goals related to the targeted area. Since 2005 , for example, there has been a new guarantee to improve access to care and ensure the equality of that access across the country. The guarantee is based on the 0-7-90-90 rule: instant contact (zero delay) with the health system for advice; seeing a GP within seven days; seeing a specialist within 90 days; and waiting no more than 90 days to receive treatment after being diagnosed. In order for county councils to access the grant targeted at accessibility, 70 percent of all patients should receive care according to the stipulated time frames.

\section{What is being done to reduce health disparities?}

International comparisons indicate that health disparities are relatively low in Sweden. Approaches to reducing disparities include preventive programs to support behavior changes and outpatient services to reach deprived groups in order to prevent diseases at an early stage. Most county councils allocate funds to primary care providers based on a formula that takes into account both the overall illness (based on diagnoses) and the overall socioeconomic conditions among their registered individuals.

\section{Who is responsible for population health?}

The Health and Medical Services Act specifies that the responsibility for ensuring that everyone living in Sweden has access to good health care lies with the county councils and municipalities. The county councils are responsible for the funding and provision of health care services. The municipalities are responsible for meeting the care and housing needs of older people and people with disabilities. The National Institute of Public Health is a state agency, responsible for performing cross-sectoral follow-up and evaluation of national publichealth policies. The national public health policy is based on 11 public health objective domains which cover the 
most important determinants of Swedish public health and guide all affected public authorities at national, regional and local levels. Apart from monitoring and coordinating the implementation of the national public health policy, the main tasks of the agency are to apply its expertise as a national body to the development and dissemination of methods and strategies in the field of public health, based on scientific evidence, and to exercise supervision in the areas of alcohol and tobacco.

\section{What is the status of electronic health records?}

Every hospital selects and procures its own preferred IT system. There are several ongoing efforts, at the county council level and at the national level, aimed at integrating the various systems and making them compatible in order to increase their security and effectiveness as a whole. Generally, both the quality of IT systems and the level of use are high in hospitals and in primary care; more than 90 percent of primary care providers used electronic patient records for diagnostic data in 2009 (Health Consumer Powerhouse, 2009). About 90 percent of all Swedish prescriptions are e-prescriptions, meaning that they are sent electronically to pharmacies (Dagens Medicin, 2012).

\section{How are costs controlled?}

County councils and municipalities are required by law to set and balance annual budgets for their activities. For prescription drugs, the county councils and the central government form agreements on subsidy levels paid to the county councils for a period of years. The TLV also engages in the value-based pricing of prescription drugs, determining reimbursement based on an assessment of health needs and cost-effectiveness.

At the local level, there is de facto cost control because most health care providers are owned and/or financed by the county councils and municipalities. Most private providers work under contract with county councils. The financing of health services through global budgets, capitation formulas, and contracts, as well as salary-based pay for staff, also contributes to cost control. Although several hospitals are paid on a DRG basis, payments are usually formulated to fall once a specified volume of activity has been reached, limiting hospitals' incentives to increase activity beyond a certain level. Primary care services are reimbursed mainly via capitation, with minimal reliance on fee-for-service arrangements. In several county councils, primary care providers are financially responsible for prescription costs, and therefore have an incentive to control pharmaceutical expenditure.

\section{What major innovations and reforms have been introduced?}

Recent reforms initiated by individual county councils have focused on strengthening primary care and developing coordinated care for older people. Choice of primary care provider combined with freedom of establishment for accredited private providers has been gradually introduced throughout the country during 2007-2010 and has been regulated by law since 2010 .

Recent reforms initiated at the national level have focused on county councils' and municipalities' responsibility for providing more direct benefits for patient groups and assuring regional equality of services. Some national reforms are as follows. 
- The role of the TLV was expanded in 2009 to include decisions regarding subsidies for dental services based on cost-effectiveness and needs assessment, similar to criteria used for drug reimbursement decisions.

- A new waiting time guarantee-the 0-7-90-90 rule (see above)-was introduced in 2005 and has been regulated by law since 2010 .

- A new patient safety act came into force in 2011, clarifying the responsibilities of health care providers in this area.

- Regional cancer centers (RCCs) were formed in 2011 following a national decision to develop cancer prevention plans as well as treatment and care plans for all stages of the disease. There are six RCCs-one in each health care region - all with the common purpose of coordinating and developing the processes of prevention and care in the area of cancer from a patient perspective.

- A proposition about a new act addressing patients' rights was delivered to the government by an appointed committee in 2013; a new act may come into force in 2015. One purpose of the act would be to strengthen the position of the patient by gathering all legislation about patients into one coherent patients act.

The author would like to acknowledge Anders Anell as a contributing author to earlier versions of this profile.

\section{References}

Anell, A., Glenngård, A.H., Merkur, S. (2012). "Sweden: Health System Review," Health Systems in Transition 14(5):1-161.

Dagens Medicin (2012). Dagens Apotek/Näringsliv/"Prisas för e-recept" 2012-10-10.

Health Consumer Powerhouse (2009). Euro Health Consumer Index 2009 Report (Danderyd: Health Consumer Powerhouse).

Statistics Sweden (2013). Systems of Health Accounts (SHA) 2001-2011.

SALAR (2011). National Initiative for Improved Patient Safety (Stockholm: Swedish Association of Local Authorities and Regions).

SALAR (2012). Statistik inom hälso- och sjukvård samt regional utveckling. Verksamhet och ekonomi i landsting och regioner (Stockholm: Swedish Association of Local Authorities and Regions).

SALAR (2013). Patientavgifter i hälso- och sjukvården 2013 (Stockholm: Swedish Association of Local Authorities and Regions).

Swedish Insurance Federation (2013). Web site: http://www.svenskforsakring.se, accessed May 21, 2013. 


\title{
The Swiss Health Care System, 2013
}

\author{
Paul Camenzind, Swiss Health Observatory
}

\section{What is the role of government?}

Duties and responsibilities in the Swiss health system are divided between three governmental levels: federal, cantonal, and communal. The system can be considered highly decentralized, as the cantons are given a critical role. The 26 cantons (including six demicantons) are responsible for licensing providers, hospital planning, and the subsidizing of institutions and organizations. Cantons are like states, in that they are sovereign in all matters that are not specifically designated as the responsibility of the Swiss Confederation by the federal constitution. Each canton and demicanton has its own constitution articulating a comprehensive body of legislation.

\section{Who is covered?}

Coverage is universal, with residents mandated under the 1996 Federal Health Insurance Act (FHIA) to purchase statutory health insurance (SHI) from competing insurers. There are virtually no uninsured residents. Every individual intending to reside in Switzerland is required, within three months of arrival, to take out an insurance policy, which is then applied retroactively to the arrival date. The federal council acknowledges the unsolved problem of missing SHI for undocumented immigrants and supports better insurance coverage for these "sans papiers."

SHI typically applies to the individual. It is not sponsored by employers, and individuals must purchase separate policies for dependents. Many residents also purchase complementary and supplementary voluntary health insurance (VHI) for coverage of services not covered under the basic basket, for free choice of hospital doctor, or for improved accommodation (e.g., an individual or twin room instead of a shared room) when hospitalized.

\section{What is covered?}

Services: The Federal Department of Home Affairs (FDHA, i.e., the Ministry of Health) decides whether or not to include a service in the SHI benefits basket by evaluating whether the service is effective, appropriate, and costeffective. It is supported in this task by the Federal Office of Public Health (FOPH) and by Swissmedic, the Swiss agency for the authorization and supervision of therapeutic products.

SHI covers most general practitioner (GP) and specialist services, as well as an extensive list of pharmaceuticals, medical devices, home health care (called Spitex), physiotherapy (if prescribed by a physician), and some preventive measures, including the costs of selected vaccinations, selected general health examinations, and screenings for early detection of disease among certain risk groups and for certain diseases (e.g., one mammogram a year if a woman has a family history of breast cancer).

Hospital services are covered by SHI, but highly subsidized by the cantons (further described below). Care for mental illnesses is covered if provided by certified physicians. The services of nonmedical professionals (e.g., psychotherapy by psychologists) are covered only if prescribed by a qualified medical doctor and provided to patients in the doctors' practice. SHI covers only "medically necessary" services in long-term care. Dental care is 
largely excluded from the SHI benefits basket, as are glasses and contact lenses for adults (unless such "secondary" problems are necessitated by "primary" oral surgical or ophthalmologic diseases). From mid-2012, however, optometry (including glasses and contact lenses) for children has been covered, along with some complementary medicine. Individual or personal budgets allowing patients to organize their own services are not known yet in the Swiss health care system.

Cost-sharing: Insurers are required to offer a minimum annual deductible of CHF300 (US $\$ 325$ ) for adults in SHI, though enrollees may opt for a higher deductible (up to CHF2,500 [US $\$ 2,715]$ ) and a lower premium. Enrollees pay 10 percent coinsurance above deductibles for all services (except for some services described below, and a $20 \%$ charge for brand-name drugs with a generic alternative unless specifically prescribed) and a CHF15 (US\$16) copayment per inpatient day in acute-care hospitals. Providers are not allowed to charge higher prices than SHI will reimburse. Maternity care and a few preventive services are fully covered and thus exempt from deductibles, coinsurance, and copayments. Minors do not have to pay deductibles or copayments for inpatient care.

Safety net: Out-of-pocket spending on covered services (i.e., 10 percent coinsurance) is capped at CHF700 (US\$760) for adults and at CHF350 (US\$380) for minors under 19 years of age in a given year. The Confederation, or federal government, and the cantons provide income-based subsidies to individuals or households to help cover SHI premiums; income thresholds vary by canton. Overall, 28.9 percent of residents (2011) benefit from individual premium subsidies. Municipalities or cantons cover the health insurance expenses of social-assistance beneficiaries and recipients of supplementary old age and disability benefits (EL-AHV/IV).

\section{How is the health system financed?}

Publicly financed health care: There are three streams of funding for publicly financed health care: first, mandatory SHI; second, direct financing by government for health care providers (tax-financed budgets spent by the Confederation, cantons, and municipalities; the largest portion of this spending is given as cantonal subsidies to hospitals providing inpatient acute care); and third, social insurance contributions from health-related coverage of accident insurance, old-age insurance, disability insurance, and military insurance.

Mandatory SHI, regulated by law and supervised by the FOPH, is purchased on an individual basis from a number of competing nonprofit insurers. Cantonal average annual premiums in 2013 for adults (for ages 26 and above, with a deductible of CHF300 (US\$329), and including coverage for accident) range from CHF3,591 (US\$3,899) (Appenzell Innerhoden) to CHF6,070 (US\$6,592) (Basel-Stadt). Costs are redistributed among insurers by a central fund, in accordance with a risk equalization scheme adjusted for canton, age, and gender. From 2012, risk equalization also takes into account hospital or nursing home stays of more than three days in the previous year.

Insurers offer premiums for defined geographical regions. The number of such "premium regions" is limited to three per canton. Within every premium region, the basis for variation in premiums is limited to age category (children up to age 18, young adults ages 19 to 25 , and adults over age 25), level of deductible, and alternative insurance plans (so-called managed care plans). In 2011, 53.2 percent of residents opted for basic coverage with 
a managed care insurer: a health maintenance organization, an independent practice association, or a fee-forservice (FFS) plan with gatekeeping provisions. Within a given region, the premium charge variation between insurers can be significant. However, this variation may be in large part because of risk selection (by insurers and policy holders) rather than efficiency differences. All premiums for the subsequent year are controlled and authorized by the FOPH, which puts a floor on the premiums they are allowed to offer to cover past, current, and estimated future costs for the insured persons in a given premium region. Otherwise, the insurer has to propose a new (higher) premium that satisfies the FOPH's criteria.

Cantons partially finance public acute-care hospitals, with the remainder financed by contributions from insurers. Private hospitals also receive public subsidies if the cantonal governments have need of their services to guarantee a sufficient supply of acute-care services within that canton. Outpatient care, nursing homes, homes for disabled and chronically ill persons, and public health programs are also directly subsidized (but much less extensively than acute-care hospitals) by the cantonal and communal governments.

All expenditures by government are financed by general taxation. In 2011, direct spending by government accounted for 18.9 percent of the total health expenditure (CHF64.6 billion [US $\$ 70.1$ billion]), while incomebased SHI subsidies accounted for an additional 6.3 percent. Including SHI premiums $(28.6 \%$ of total health expenditure, SHI subsidies subtracted), other social insurance schemes (6.5\%), and old age and disability benefits (4.5\%), publicly financed health care accounted for 64.9 percent of all health care spending.

Privately financed health care: Private expenditure accounted for 35.1 percent of total health expenditure in 2011. VHI is regulated by the Swiss Financial Market Supervisory Authority (FINMA); health insurers offering voluntary coverage can vary benefit baskets and premiums and refuse enrollment to applicants based on medical history. Service prices are usually negotiated directly between insurers and service providers. Unlike statutory health insurers, voluntary insurers are normally for-profit; often an insurer will have a nonprofit branch offering SHI and a for-profit branch offering VHI. It is illegal for voluntary insurers to base voluntary insurance enrollment decisions on health information obtained via basic health coverage, but this rule is not easily enforced. VHI accounted for 8.6 percent of total health expenditure in 2011. There is no available information on the number of persons covered; in general, VHI applies to the individual, not to groups.

In 2011, direct out-of-pocket payments (20.2\%) accounted for the larger part of all private expenditure on health. Cost-sharing in SHI and VHI accounted for 5.5 percent and 0.1 percent, respectively, of total health expenditure. Most out-of-pocket payments were spent on dentistry and long-term care. Almost 90 percent of all expenditure on dental treatment is paid for by private households.

\section{How is the delivery system organized and financed?}

Physicians: Residents are not required to register with a GP, and generally have free choice among selfemployed GPs, unless enrolled in certain managed care plans. In 2012, 39 percent of doctors in the outpatient sector were classified as GPs. Apart from scale of charge measures (see below) there are no specific financial incentives for GPs for taking care of chronically ill patients. And no reforming efforts are under way on the national level to engage GPs in "bundled payments" to coordinate care for such types of patients (e.g., diabet- 
ics). Outpatient care tends to be physician-centered, with nurses and other health professionals playing a relatively small role. In 2012, solo practice was the reality for around 60 percent of the physicians.

Residents have free access (without referral) to specialists unless enrolled in a gatekeeping managed care plan. Specialist practices tend to be concentrated in urban areas and in the proximity of acute-care hospitals. Specialists can hold appointments in public hospitals and private practice in parallel.

Apart from some managed care plans, in which physician groups are paid on a capitation basis, ambulatory physicians (including GPs) are paid according to a national FFS scale based on points (TARMED). TARMED offers some incentives for less resource-intensive forms of care, but is criticized by GPs as insufficient to render attractive services like coordinating and communicating with chronically ill patients, home visits, and afterhours care. The point values vary among cantons and service groups (physicians, hospitals) and are negotiated annually between the health insurers' associations and the cantonal medical associations or hospitals, or are decided by the cantonal government if the other parties cannot agree.

After-hours care: The cantons guarantee the reliability of care provision and are responsible for after-hours care. They delegate those services (paid by TARMED fees) to the cantonal doctors' associations, which organize appropriate care networks in collaboration with their affiliated doctors. The networks also can include public and private ambulance and rescue services, hospital emergency services, and, increasingly common in recent years, walk-in clinics. There is no institutionalized exchange of information between these services and GPs' offices (as people are not required to register with a GP). The amount of additional payment included in TARMED for after-hours care is heavily criticized by GPs.

Hospitals: About 70 percent of acute inpatient hospitals are public or publicly subsidized private hospitals. These public or publicly subsidized hospitals receive around half of their funding from insurers. In 2012, a national diagnosis-related groups (Swiss DRG) payment system was introduced for acute inpatient care, meaning reimbursement by rates per case. The corresponding base rates are negotiated between hospitals and health insurers and must be approved by the cantonal government. The remaining costs of public and subsidized hospitals are covered by the cantons and municipalities. Arrangements for bundled payments to include entire episodes of care (e.g., from diagnosis through rehabilitation) are not known yet.

Cantons are responsible for hospital planning. The policy of planning and funding hospitals at the cantonal rather than the central level is one of the main reasons why the Swiss system is fragmented along cantonal lines. However, since 2009, cantons have been legally bound to coordinate their planning with other cantons. The introduction of free movement of patients between cantons under the DRG system since 2012 also redresses cantonal fragmentation. The precise remuneration scheme depends on the insurance contracts; as a consequence, FFS remuneration is still possible for patients with VHI for inpatient services not covered under SHI. Hospital-based physicians are normally paid a salary, and public-hospital physicians can receive extra payments for seeing privately insured patients.

Mental health care: Psychiatric practices are generally private, and psychiatric clinics and hospital departments are a mix of public, private with state subsidies, and fully private. There is also a wide range of sociopsychiatric services and day-care institutions that are mainly state-run and -funded. The provision of psychiatric health 
care is not systematically integrated into primary care in Switzerland as in other countries. Outpatient psychiatric prices are calculated using the TARMED scale of charge system, while psychiatric inpatient care prices are usually calculated as a daily rate.

Long-term care: Since 2011, SHI pays a fixed contribution to cover direct care-related (i.e., medically necessary) inpatient long-term care costs; the patient pays at most 20 percent of uncovered care-related costs, and the remaining care-related costs are financed by the canton or municipality. Long-term institutional care (in nursing homes and institutions for disabled and chronically ill persons) cost a total of CHF11.3 billion (US\$12.3 billion) in 2011, representing 17.5 percent of total health expenditure. More than one-third of these costs (35.7\%) were paid for by private households (out-of-pocket and cost-sharing), one-quarter (24.6\%) by old age and disability benefits, 19.9 percent by SHI and other social insurances, and the rest by government subsidies (18.9\%). $29.7 \%$ of the 1,585 nursing homes in Switzerland (2011) are state-operated and -funded, $26.9 \%$ are privately operated but with public subsidies, and $43.4 \%$ are funded exclusively by private means.

For long-term outpatient care covered under Spitex, state subsidies and old age and disability benefits cover half (49.7\%) of the costs of Spitex's total expenditure of CHF1.7 billion (US\$1.8 billion) in 2011. SHI and the other social insurances cover the cost of home nursing care, which made up roughly one-third (29.3\%) of Spitex's total expenditure. The rest (21.0\%), devoted mainly to support and household services, is paid for by customers (outof-pocket), VHI, and other private funds.

\section{What are the key entities for health system governance?}

Since Swiss health care is largely decentralized, the key entities for health system governance exist mainly at the cantonal level. Their common political body, the Swiss Conference of the Cantonal Ministers of Public Health (GDK-CDS), plays an important coordinating role. The Federal Office of Public Health is the main national player, supervising the legal application of mandatory SHI, among other tasks. As described above, the Federal Department of Home Affairs defines the SHI benefits basket; it is supported in this task by the FOPH and various expert authorities, in particular by Swissmedic. The Swiss Health Observatory (Obsan) was created in 2001 to improve the transfer of health information to political authorities.

\section{What is being done to ensure quality of care?}

Professional self-regulation has been the traditional approach to quality improvement. Providers must be licensed in order to practice medicine, and are required to meet educational and regulatory standards. Since 2007, postgraduate training is compulsory. Many local quality initiatives have been undertaken, often at the provider level, including the development of clinical pathways and consensus guidelines.

At the end of 2009, the Swiss Federal Council, the highest governing and executive authority of the Confederation, approved the Quality Strategy of the Swiss Health System. From 2012 to 2014 the first national program is operational. It supports hospitals in improving their performance in three specific problem areas, i.e., hospital infections, drug safety, and surgical safety. 


\section{What is being done to improve care coordination?}

Care coordination is an issue, particularly in light of a projected lack of providers in the future and the need to improve efficiency to increase capacity. A task force led by the cantons and the Confederation (Dialog National Health Policy) discusses existing and new approaches to care. Strategies and networks tackling emerging areas of importance, like palliative care, dementia, or mental health have been built to find new ways to coordinate. They start on a conceptual level, aiming at the practical level to encourage different types of health professionals to work together.

\section{What is being done to reduce health disparities?}

There are several reasons why health disparities have not received as much political and professional interest at the national level as elsewhere. First, health inequalities are not considered to be significant in comparison to other Organization for Economic Cooperation and Development (OECD) countries; second, it is still difficult to obtain detailed statistical information about the epidemiological situation and health outcomes of the Swiss population as a whole, and for its different regional and socioeconomic subgroups in particular; and third, health inequalities are seen more as the responsibility of regional authorities (cantons or communes) than of the federal government, making them much less visible at the national level.

\section{Who is responsible for population health?}

The responsibilities for population health are divided between the three governmental levels. The Confederation is responsible for national prevention programs, infectious diseases, and the protection of the population against health risks of illegal drugs, chemicals, radiation, food safety, and pharmaceuticals, etc. Concerning national health prevention programs, the Confederation is in close partnership with "Health Promotion Switzerland" (HPS), the leading national player in health promotion. It is a public, semiautonomous foundation in force since 1996 and designed to implement article 19 of the Federal Health Insurance Act (which promotes the prevention of diseases).

The cantons, beside their very important role guaranteeing a sufficient supply of health care services, are responsible for implementing health promotion and health prevention measures in their geographic area. They are supported in this task by the municipalities that have important functions (among others) in the field of health prevention and promotion for school-age children.

Policy priorities and targets for improving population health are made explicit in the national strategy "Health2020" of the Swiss Federal Council (FDHA, 2013). One priority mentioned is the improvement of the prevention of and screening for nontransmissible diseases in order to reduce the number of new cases and their impact on people and the economy; with particular attention to promoting health in the workplace. Another priority concerns promoting mental health and improving the prevention and early detection of psychiatric disorders; with particular attention given to preventing people who develop psychiatric problems from being removed from the employment process. A third priority names improving the prevention, early detection and control of addiction disorders, including new forms such as addiction to the Internet. 


\section{What is the status of electronic health records?}

A national e-health service called eHealth Suisse (an administrative unit of the FOPH) was established in 2007. eHealth Suisse is coordinated and funded by the federal and cantonal governments and has three sets of responsibilities. First, starting in 2015, everyone in Switzerland should be able to give providers electronic access to information relevant to their treatment. Second, health-related websites and online services will be required to undergo quality certification and a national health website will be constructed. Third, the necessary legal changes will be made to realize these measures. The Executive Federal Council made a formal statement in May 2013 and sent it for further discussions to the national parliament.

A key element of eHealth Suisse is the SHI enrollee card, introduced in 2010, which encodes a personal identification number and allows all insured persons to record information about allergies, illnesses, and medication. GP eHealth is still at an early stage, and there are ongoing discussions about forthcoming incentives to be provided to physicians for adopting new technologies. Financial incentives and binding technical standards are seen to hold the most promise.

Hospitals are generally more advanced: some have merged their internal clinic systems in recent years and hold interdisciplinary patient files. However, the extent of this development varies greatly among hospitals and across cantons, in spite of efforts by eHealth Suisse to convince providers of the benefits of EHRs for medical practice. An interoperable national patient record is not a priority for eHealth Suisse, since the principles of decentralization, privacy, and data protection are regarded as very important in Swiss health care.

\section{How are costs controlled?}

Switzerland's health costs are among the highest in the world (only the United States, the Netherlands, France, Germany, and Canada spent a larger share of GDP in 2011). The introduction of regulated competition among nonprofit health insurers and among service providers in 1996 aimed to contain costs as well as to guarantee high-quality, comprehensive health care, and to establish greater solidarity among the insured. While scientific analyses and public perception have been particularly critical of competition's ability to cut or control health care costs, the other objectives are generally regarded as having been successfully achieved.

The failure of regulated competition to contain costs is largely ascribed to inadequate risk equalization, the dual funding of hospitals by cantons and insurers, and pressure on insurers to contract with all certified providers. In 2012, the risk equalization formula was improved, and should now bolster insurers' incentives to improve efficiency. In 2014 it will be changed to a fully prospective system, further strengthening those incentives. Greater use of managed care plans employing gatekeeping and capitation-based physician payment may also help to reduce expenditure in the future.

All new pharmaceuticals are evaluated before a coverage decision is made, and both effectiveness (by Swissmedic) and cost (by the FOPH) are considered. Efforts are also being made to reassess more frequently the price of older drugs. Generic drugs must be sold for at least 20 percent to 50 percent less than the original brand (depending on the national market volume); however, they made up only 9.8 percent of all drugs sold in the Swiss market in 2011. Patients pay a higher rate of coinsurance for brand-name drugs that have a generic 
equivalent (20\% instead of $10 \%$ ). Pharmacists are paid a flat amount for filling prescriptions, so have no financial incentive to dispense the more expensive drugs.

\section{What major innovations and reforms have been introduced?}

Since 2000 , two reform packages have been debated in parliament. The first was mainly concerned with reform of risk equalization between insurers, financing of long-term care, monitoring of insurers, SHI enrollee cards, selective contracting, premium reduction, and cost-sharing. The second involved reform of hospital funding and managed care. New financial arrangements for long-term care went into effect in 2011, and hospital payment was fully converted to the DRG system in 2012. The refined risk equalization formula has been in use since 2012 and will be changed to a fully prospective system in 2014. However, the parliament's proposed law to promote managed care was rejected in a popular referendum in June 2012.

In outpatient care, a "necessity clause" had been introduced in 2002 and regulated (and limited) the establishment of all new outpatient service providers through 2009, and for specialist physicians and pharmacists until 2011. After a short period without regulation, the necessity clause for specialists and pharmacists was reintroduced in mid-2013 for another three years.

The abundance of specialists is contrasted by a looming shortage of GPs. Therefore, the Federal Council launched an initiative, the Masterplan Hausarztmedizin und medizinische Grundversorgung, which focuses on concrete measures in the areas of training, further education, research, new care models, after-hours care, and a complete revision of TARMED containing a specific section of charges for GPs.

Finally, the Federal Council presented in January 2013 a comprehensive overview of its priorities in Swiss health care policy until the year 2020. "Health2020" describes the important topics to be treated, the respective objectives and measures. These important topics are to ensure quality of life, to improve equal opportunities and self-responsibility, to ensure and improve quality of care, and to create more transparency, better governance, and more coordination. Measures are planned to be put into action step by step until 2020 in collaboration with all the relevant partners in the Swiss health care system.

The author would like to acknowledge David Squires as a contributing author to earlier versions of this profile.

\section{References}

FDHA (2013). The Federal Council's health-policy priorities. Swiss Federal Department of Home Affairs. Berne. Online publication under: http://www.bag.admin.ch/gesundheit2020/index.html?lang=en.

Meyer, K. (ed.) (2008). Health in Switzerland-National Health Report 2008 (published in German and French) (Bern Verlag Paul Huber).

Minder, A., et al. (2000). Health Care Systems in Transition: Switzerland 1-76 (Copenhagen: WHO Regional Office for Europe on behalf of the European Observatory on Health Systems and Policies). 
OECD (2011). Reviews of Health Systems: Switzerland (Paris: Organization for Economic Cooperation and Development).

Siegrist, M., and Giger, M. A. (2006). “Swiss Survey on Teaching Evidence-Based Medicine,” Swiss Medical Weekly 136:776-78. 


\title{
The U.S. Health Care System, 2013
}

\author{
The Commonwealth Fund
}

\section{What is the role of government?}

The role of government is complex, and continues to evolve. Health insurance coverage is fragmented, with numerous private and public sources as well as wide gaps in coverage rates across the U.S. population. The Centers for Medicare and Medicaid Services (CMS) administers the Medicare program (a federal program for those age 65 and older, some of the disabled, and those with end-stage renal disease) and works in partnership with state governments to administer Medicaid and the Children's Health Insurance Program (joint federalstate programs for certain low-income populations). Private insurance is regulated at the state level, but generally is allowed wide discretion in designing benefit packages.

\section{Who is covered?}

In 2011, 56 percent of U.S. residents received primary care coverage from private voluntary health insurance (VHI): 51 percent received it through their employers, and 6 percent acquired coverage directly. Public programs covered 28 percent of residents: Medicare covered 15 percent, Medicaid 12 percent, and military health care programs i percent. Almost 50 million residents (16\% of the population) were uninsured in 2011 . Among those who were insured, 30 million were "underinsured" in 2012, vulnerable to high out-of-pocket expenses in relation to their income.

Public programs provide coverage to various and often overlapping populations. In 2009, about 9.4 million Americans were enrolled in both Medicare and Medicaid (the "dual eligibles"). The federal-state Children's Health Insurance Program (CHIP), which offers coverage to children in low-income families-in some states as an extension of Medicaid and in others as a separate program-covered 5.5 million children in 2012.

Undocumented immigrants are generally ineligible for public coverage, and nearly two-thirds are uninsured. Hospitals that accept Medicare funds (which are the vast majority) must provide care to stabilize any patient with an emergency medical condition, and several states allow undocumented immigrants to qualify for emergency Medicaid coverage beyond "stabilization" care. Some state and local governments provide additional coverage, such as coverage for undocumented children or pregnant women.

It is projected that the implementation of the Patient Protection and Affordable Care Act will reduce the number of uninsured by 25 million by 2022 .

\section{What is covered?}

Services: Benefit packages vary according to type of insurance, but typically include inpatient and outpatient hospital care and physician services. Many also include preventive services, mental health care, physical therapy, and prescription drug coverage. Private insurance plans often have restricted networks of providers, with limited or no coverage if patients receive out-of-network care. Private coverage for dental care and optometry is also available-sometimes through separate policies-as is long-term care insurance. Medicare covers hospital and outpatient care, and in 2006 was expanded to offer outpatient prescription drug coverage through a 
supplementary program. Medicare offers a choice between "traditional" Medicare, which is open-network and pays fee-for-service, and Medicare Advantage, where the federal government pays a private insurer for a network-based plan. Medicare does not cover long-term care services aside from special circumstances (see below), but Medicaid offers more extensive coverage of nursing home and home health care than other sources of insurance, although it varies from state to state (within federal eligibility and coverage requirements). Some state Medicaid programs have experimented with offering enrollees individual budgets rather than typical insurance plans, primarily for long-term or mental health care. As of September 2010, private health insurance is required to cover certain preventive services (with no cost-sharing if services are provided in-network), and in 2011 Medicare eliminated cost-sharing for a number of preventive services.

Cost-sharing: Cost-sharing provisions in private health insurance plans vary widely. High-deductible health plans can be paired with tax-advantaged "health savings accounts" (see below); these plans can allow maximum annual out-of-pocket costs of up to $\$ 6,050$ for an individual and $\$ 12,100$ for a family for care received in-network. As of 2012, 31 percent of the under-65 privately insured population had a deductible of $\$ 1,200$ or more. Medicare requires deductibles for hospital stays and ambulatory care, and copayments for physician visits and other services, while Medicaid requires minimal cost-sharing. Providers are typically not allowed to "balancebill" patients-that is, charge patients more than the copayment called for under their insurance plan.

Safety net: A variable and patchwork mix of organizations and programs deliver care for uninsured, lowincome, and vulnerable patients in the U.S., including public hospitals, local health departments, free clinics, Medicaid, and the Children's Health Insurance Program. Hospitals that provide care to a high percentage of low-income and uninsured patients receive federal Disproportionate Share Hospital payments to partially offset their uncompensated care. The federal government also funds community health centers, which provide a major source of primary care for underserved and uninsured populations. Private providers are a significant source of charity and uncompensated care.

\section{How is the health system financed?}

Publicly financed health care: In 2011, public spending accounted for 48 percent of total health care spending. Medicare is financed through a combination of payroll taxes, premiums, and federal general revenues. Medicaid is a tax-funded, joint federal-state health insurance program-administered by the states-that operates within broad federal guidelines. States receive matching funds from the federal government at rates that vary based on their per capita income-in 2013, federal matching ranged from 50.0 percent to 73.4 percent of states' Medicaid expenditures. The expansion of Medicaid in 2014 (see below) under the Affordable Care Act will be fully funded by the federal government for the first three years, after which the government's funding share will be phased down to 90 percent by 2020 .

Privately funded health care: In 2011, private health insurance accounted for 33.8 percent of total health care spending. Private insurers can be for-profit or nonprofit, and are regulated by state insurance commissioners and subject to varying state (and federal) regulations. Private health insurance can be purchased by individuals, but is usually funded by voluntary, tax-exempt premium contributions shared by employers and employees on an employer-specific basis, sometimes varying by type of employee. The tax exemption for employer-based health insurance amounted to about US $\$ 248$ billion in 2013. Some individuals are covered by both public and 
private health insurance-for example, many Medicare beneficiaries purchase private complementary "Medigap" policies to cover additional services and cost-sharing. Private insurers, in general, pay rates to providers that are higher than the rates paid under public programs, particularly Medicaid, leading to wide variations in payment rates among payment sources and in revenues among providers, depending on their payer mix and market power.

Out-of-pocket payments, through cost-sharing insurance arrangements and direct purchases of services by private households, accounted for 11.6 percent of total national health expenditures in 2011, and averaged US $\$ 987$ per capita.

\section{How are health care services organized and financed?}

Payment rates under the Medicare program are typically determined according to a fee schedule, with various regional adjustments (e.g., based on cost of living). How rates are determined under the Medicaid program varies by state. Private health insurers typically negotiate payment rates with providers.

Physicians: The majority of ambulatory-care physicians are in private practices, many of which they own themselves or in groups. Primary care doctors account for roughly one-third of all U.S. doctors. The majority of primary care doctors operate in small practices with fewer than five full-time-equivalent physicians. Practices, particularly large practices, often include nurses and other clinical staff, who are usually paid a salary by the practice. Patients generally have free choice of doctor, at least among in-network providers, and are usually not required to register with a primary care practice, depending on their insurance plan. Primary care doctors have no formal gatekeeping function, except within some managed care plans. Specialist doctors can work in both private practice and hospitals. Physicians are paid through a combination of methods, including negotiated fees (private insurance), capitation (private insurance), and administratively set fees (public insurance). Physicians can also often receive financial incentives based on various performance criteria. Insured patients are generally directly responsible for some portion of physician payment, and uninsured patients are nominally responsible for all or part of physicians' charges, although those charges frequently are reduced or waived (with the extent of charity care varying substantially among providers).

After-hours care: Provisions for after-hours care vary widely, with much of it provided by emergency rooms. Compared to other industrialized countries, after-hours care arrangements are minimal—only 34 percent of U.S. primary care doctors in 2012 reported having arrangements for their patients to see a doctor or nurse after hours without going to the emergency room. Some insurance companies make after-hour telephone advice lines available.

Hospitals: Hospitals can be nonprofit ( $\sim 70 \%$ of beds, nationally), for-profit ( $\sim 15 \%$ of beds), or public ( $\sim 15 \%$ of beds). Public hospitals can serve private patients. Hospitals are paid through a combination of methods, including per-service or per-diem charges, per-admission or prospective payments, and capitation. Some hospitalbased physicians are salaried hospital employees, but most are paid on some form of fee-for-service basis-physician payment is not included in Medicare's diagnosis-related group (DRG) payments. Hospitalists are becoming increasingly common, and are present in a majority of hospitals. 
Mental health care: Mental health care is provided by a mix of for-profit and nonprofit providers, and paid for through a variety of methods that vary by provider type and payer. As of 2010, most employer-based insurance has to provide the same degree of coverage for mental health care as for medical care. Integration of mental health and primary care is a goal of many experts and policymakers, but is not currently widespread.

Long-term care: Long-term care is provided by a mix of for-profit and nonprofit providers, and paid for through a variety of methods that vary by provider type and payer. Medicaid, but not Medicare, covers long-term care, and because Medicaid is a means-tested program, patients often must "spend down" their assets to qualify for

long-term care assistance. However, hospice care is included as a Medicare benefit, as are home health care and care provided by skilled nursing facilities, in certain circumstances.

\section{What are the key entities for system governance?}

The Department of Health and Human Services (HHS) is the federal government's principal agency involved with health care services. The Centers for Medicare and Medicaid Services (CMS) falls within HHS, as does the Centers for Disease Control and Prevention (CDC), which conducts research and programs to protect public health and safety; the National Institutes of Health $(\mathrm{NIH})$, which is responsible for biomedical and healthrelated research; the Health Resources and Services Administration (HRSA), which supports efforts to improve health care access for people who are uninsured, isolated or medically vulnerable; and the Agency for Healthcare Research and Quality (AHRQ), which sponsors, conducts, and disseminates research to improve health care quality and safety.

The Institute of Medicine (IOM), an independent, nonprofit organization that works outside of government, acts as an adviser to policymakers and the private sector on improving the nation's health. It undertakes many studies in response to specific mandates from Congress and requests from federal agencies or independent organizations. Stakeholder associations (e.g., the American Medical Association) comment on and lobby for policies affecting the health system.

\section{What is being done to ensure quality of care?}

In 2011, the U.S. Department of Health and Human Services released the National Quality Strategy; called for under the Affordable Care Act, it lays out national aims and priorities to guide local, state, and national quality improvement efforts. It is supported by an array of partnerships with public and private stakeholders, including the National Quality Forum-a nonprofit organization that builds consensus on national performance priorities and on standards for performance measurement and public reporting.

The Center for Medicare and Medicaid Innovation (CMMI) is charged with testing and spreading innovative payment and service delivery models that reduce spending while preserving or improving quality. Current initiatives include efforts to reduce hospital-acquired infections and preventable readmissions through the Partnership for Patients-a public-private partnership with stakeholders at the federal, state, and local levels.

The AHRQ funded by the federal government, conducts evidence-based research on practices, outcomes, effectiveness, clinical guidelines, safety, patient experience, health information technology (HIT), and health disparities. The Affordable Care Act created the Patient-Centered Outcomes Research Institute (PCORI), tasked with 
setting national clinical comparative-effectiveness research priorities and managing the funding and conducting of research. The range of research funded through PCORI is broad; it may include any component of the treatment, diagnosis, or prevention of illness or injury. The Institute is not permitted to present comparativeeffectiveness research findings as practice guidelines, coverage recommendations, or payment or policy recommendations, and federal insurance programs are not allowed to use PCORI findings as the sole basis for denying coverage.

CMS has moved toward increased public reporting with Hospital Compare-a service that reports on process of care, outcome of care, and patient experience measures at over 4,000 hospitals. In addition, states have developed additional public reporting systems and measures, including some that address ambulatory care. Medicare has developed a variety of pay-for-performance programs. As of October 2012, Medicare has tied hospital reimbursement rates to performance indicators that include process, outcome, and patient experience measures; payments to hospitals with high 30-day readmission rates are reduced. The majority of private insurance providers also have pay-for-performance programs.

The Joint Commission-an independent, nonprofit organization-accredits more than 20,000 health care organizations across the country, primarily hospitals, long-term care facilities, and laboratories, using criteria that include patient treatment, governance, culture, performance, and quality improvement. The National Committee for Quality Assurance is the primary accreditor of private health plans, and will be responsible for accrediting the plans participating in the newly created health insurance marketplaces (see below). The American Board of Medical Specialties and the American Board of Internal Medicine provide certification to physicians who meet specified standards of quality.

\section{What is being done to improve care coordination?}

Physician practices are mostly small (with fewer than five physicians) and single-specialty, although multi-specialty practices are not uncommon. Nurses and other nonphysician staff often provide, and help to manage, patients' care, although their scope of practice varies by state. The government and private insurance companies are funding many initiatives aimed at shifting from a specialist-focused health system to one that is primarily care-focused. The "patient-centered medical home" model—in which a patient receives targeted, accessible, continuous, coordinated, and family-centered care from a personal physician-has gained particular interest among U.S. experts and policymakers as a means to strengthen primary care. For example, under one current program, the Multi-payer Advanced Primary Care Initiative, CMS participates in multi-payer reform initiatives currently being conducted by states to make advanced primary care practices more broadly available. It is hoped that patient-centered medical homes will reduce unjustified utilization and expenditures; improve the safety, effectiveness, timeliness, and efficiency of health care; enable more decision-making by patients; and increase the availability and improve the delivery of care in underserved areas.

Another movement gathering considerable momentum in the U.S. among both public and private payers is the creation of "accountable care organizations" (ACOs). ACOs are networks of providers, including hospitals and physicians, that agree to take responsibility for providing a defined population with care that meets quality targets; in exchange, they can share in the savings that constitute the difference between forecasted and actual health care spending for their population. Two Medicare-driven ACO programs have been rolled out-the 
Medicare Shared-Savings Program and the Pioneer ACO Program. Other ACO-like models already exist among private insurers; for example, Blue Cross Blue Shield's “Alternative Quality Contract," a variant of the ACO concept, has been in place in Massachusetts since 2009.

Medicare, Medicaid, and various private purchasers, including employer groups, are also experimenting with new payment incentives that reward higher-quality and more efficient care. In addition to pay-for-performance, strategies being implemented include "bundled" payments, under which a single payment is made for services from a number of providers related to a single episode of care.

\section{What is being done to reduce disparities?}

There are wide disparities in the accessibility and quality of health care in the U.S. Since 2003, the AHRQ has been releasing an annual report - the - that documents disparities among racial, ethnic, income, and other demographic groups, and highlights priority areas requiring action. Federally Qualified Health Centers (FQHCs), which are eligible for certain types of public reimbursement, provide comprehensive primary and preventive care regardless of their patients' ability to pay. Initially created to provide health care to underserved and vulnerable populations, FQHCs largely provide safety-net services to the uninsured. Medicaid and CHIP provide public health insurance coverage for certain low-income populations. A multitude of public initiatives and policies at the local, state, and federal levels target disparities, as do a wide range of private initiatives.

\section{Who is responsible for population health?}

On the national level, the U.S. Public Health Service Commissioned Corps provides expertise within different agencies of the federal government on public health-related issues. In addition, the Centers for Disease Control and Prevention conducts research and programs to protect public health and safety. At the state and local levels, health agencies' responsibilities vary, but usually include preventive medicine, epidemiology, vaccinations, and environmental health.

On the provider side, ACOs are held responsible for providing high-quality care to their attributed population of patients, with incentives for keeping those patients healthy. While that responsibility does not necessarily correspond with the traditional definition of "public health" (i.e., the health of a population within a geographic area), it could nonetheless lead to a renewed focus on public health, particularly among ACOs with a dominant regional market share.

\section{What is the status of electronic health records?}

In 2012, 69 percent of primary care physicians used some form of electronic medical record system, as did 44 percent of hospitals. There is no universal patient identifier in the U.S. To stimulate the uptake of HIT, the 2009 American Recovery and Reinvestment Act made a significant investment through Medicare and the Office of the National Coordinator for Health Information Technology. Financial incentives for physicians and hospitals, totaling up to US $\$ 27$ billion over six years, were tied to the attainment of benchmarks for the "meaningful use" of HIT. Regional HIT extension centers were also created to provide technical assistance, guidance, and information on best practices to support providers' use of HIT. "Beacon communities" with already high rates of HIT adoption were given additional funding to demonstrate how HIT can be leveraged to improve quality, cost-efficiency, and population health. Support was also provided for clinical registries and health outcomes research 
networks. Currently, a priority of the Office of the National Coordinator is to improve interoperability of electronic records, with strategies that include developing policies and standards as well as setting goals and measures of success.

\section{How are costs controlled?}

Annual per capita health expenditure in the U.S. is the highest in the world-US\$8,508 in 2011. Total national health expenditures have historically increased faster than national income, although recent years have seen unusually slow growth rates. Total expenditures reached 17.7 percent of GDP in 2011 and are expected to reach 19.6 percent by 2021, if current trends continue. Payers have attempted to control cost growth through a combination of selective provider contracting, price negotiations and controls, utilization control practices, risk-sharing payment methods, and managed care. Tax advantages are granted for Health Savings Accounts, which pay out-of-pocket health expenses, if they are coupled with high-deductible (US $\$ 1,250+$ ) health insurance plans. Tax incentives plus double-digit increases in premiums have led to a shift in benefit design toward higher patient payments.

\section{What major system innovations and reforms have been introduced?}

In March 2010, President Obama signed into law the Patient Protection and Affordable Care Act, enacting a sweeping series of insurance and health system reforms. Major provisions of the legislation, many of which go into effect in 2014, include:

- expanding Medicaid to include everyone with incomes below 133 percent of the federal poverty level

- establishing state-based insurance marketplaces for individuals and small businesses

- providing insurance subsidies for low- and middle-income individuals and tax credits for small businesses

- instituting a series of insurance regulations that include guaranteed issue and community rating

- eliminating copayments for recommended preventive services and immunizations

- instituting a mandate for individuals to have health insurance or pay a fee

- establishing the PCORI to conduct comparative-effectiveness research

- establishing the Center for Medicaid and Medicare Innovation to develop and test payment models for improving quality and lowering costs

- establishing the Independent Payment Advisory Board, with a mandate to reduce the growth of Medicare expenditures through payment reforms

- creating a shared savings program in Medicare for ACOs that take responsibility for efficiently providing care to a defined population and meeting quality targets

- increasing Medicare and Medicaid payments for primary care

- expanding federal funding for Federally Qualified Health Centers that provide care for low-income and uninsured individuals 
The 2009 American Recovery and Reinvestment Act also made a number of significant investments in the health system, including a short-term boost in federal Medicaid funding and subsidies for the recently unemployed to remain insured. Investments were also made then in stimulating the use of HIT and in comparativeeffectiveness research.

\section{References}

OECD Health Data (2013).

Current Population Survey Annual Social and Economic Supplement (2012).

Davis, K., Guterman, S., Collins, S.R., Stremikis, K., Rustgi, S., and Nuzum, R. (2010). (New York: The Commonwealth Fund, Sept. 2010).

Health Reform Resource Center. The Commonwealth Fund.

The Henry J. Kaiser Family Foundation. www.statehealthfacts.org.

Keehan, S.P., Kuckler, G., Sisko, A.M., et al. "National Health Expenditure Projections: Modest Annual Growth Until Coverage Expands and Economic Growth Accelerates," , July 2012 (7):1600-1612.

National Healthcare Quality Report and National Healthcare Disparities Report (2012). Agency for Healthcare Research and Quality, http://www.ahrq.gov/research/findings/nhqrdr/index.html. 

1 East 75Th Street - New York, NY 10021

TEL: 212.606 .3800

1150 17Th Street NW - Suite 600

WASHINGTON, DC 20036

TEL: 202.292 .6700 